\title{
Heating ventilation and air conditioning systems condition assessment methodology
}

Anand Chandrashekaran

West Virginia University

Follow this and additional works at: https://researchrepository.wvu.edu/etd

\section{Recommended Citation}

Chandrashekaran, Anand, "Heating ventilation and air conditioning systems condition assessment methodology" (2005). Graduate Theses, Dissertations, and Problem Reports. 4138.

https://researchrepository.wvu.edu/etd/4138

This Thesis is protected by copyright and/or related rights. It has been brought to you by the The Research Repository @ WVU with permission from the rights-holder(s). You are free to use this Thesis in any way that is permitted by the copyright and related rights legislation that applies to your use. For other uses you must obtain permission from the rights-holder(s) directly, unless additional rights are indicated by a Creative Commons license in the record and/ or on the work itself. This Thesis has been accepted for inclusion in WVU Graduate Theses, Dissertations, and Problem Reports collection by an authorized administrator of The Research Repository @ WVU. For more information, please contact researchrepository@mail.wvu.edu. 


\title{
Heating Ventilation and Air Conditioning Systems Condition Assessment Methodology
}

\author{
Anand Chandrashekaran \\ Thesis submitted to the \\ College of Engineering and Mineral Resources at \\ West Virginia University \\ in partial fulfillment of the requirements \\ for the degree of
Master of Science
in \\ Industrial Engineering
}

Approved by

Bhaskaran Gopalakrishnan, Ph.D., Chair

Kenneth H. Means, Ph.D., Co-Chair

Robert C. Creese, Ph.D.

Department of Industrial Engineering

Morgantown, West Virginia

2005

Keywords: Facilities Condition Assessment Methodology, Priority Scheduling System, Deferred Maintenance Reduction Plan, Continuous Improvement in

Facilities Maintenance, HVAC Equipment Condition Based Maintenance, Proactive Work Order Generation Methodology

Copyright 2005 Anand Chandrashekaran 


\title{
Abstract \\ Heating Ventilation and Air Conditioning (HVAC) Systems Condition Assessment Methodology
}

\begin{abstract}
Anand Chandrashekaran
Facilities (equipment) renewal is assigned low priority due to insufficient budgets in universities, colleges, hospitals, and industries. Insufficient funds lead to postponement of major repairs and replacements of facilities. This lack of investments combined with deterioration of facilities increases the maintenance problem. When funds become available, replacement and repair maintenance projects are carried out, at the cost of the critical ones, due to lack of information on facilities conditions and deficiencies. Thereby developing a facilities condition assessment methodology with a prioritization technique will help in utilizing the available resources effectively. This assessment identifies the physical condition and maintenance deficiencies of HVAC equipment at its component level using failure checkpoints. A unique scoring and formula is used for prioritization, considering six potential risk parameters, overall condition index, and functional value of components. Hence, maintenance work orders are generated and executed based on this decision-making tool.
\end{abstract}




\section{Acknowledgements}

It is a pleasure to thank many people for their support in making my thesis possible.

First and foremost, I would like to gratefully acknowledge and thank my supervisor Gary Boyd for assigning me this task of developing a facilities condition assessment program for physical plant at WVU. During my 32 months of graduate research assistantship under his supervision, he always created a work place that was challenging and interesting. His project goals were to develop a physical conditional assessment program that should be simple, less time consuming, and user friendly with a scoring methodology. In spite of his busy schedule as an Assistant Director of mechanical operations, he spent a significant amount of time during work hours and also after work hours to discuss, brainstorm, and advice these goals to me. With his enthusiasm and great efforts in explaining things clearly and simply, he enabled me to think in all perspectives. He always shared his knowledge, experience, and literature material that he read. These helped me in understanding the magnitude of this problem in physical plant type industries. He also helped me realize the bigger picture of any problem with an example. His continuous motivation and confidence in me, and appreciation for my ideas and inputs inspired me to research on this area of study. His strategic manner of asking good questions especially on the thesis defense helped me answer interesting points that were part of this thesis work. I could not have finished this thesis without his encouragement and philosophical analogies that he used during all the time when I used to struggle moving forward.

A special thanks to my advisor Dr. Bhaskaran Gopalakrishnan, for providing me an opportunity to start working on a problem report under his guidance. He suggested different ways to approach a research problem and the need to be persistent to achieve my goal-thesis. He was always available to listen and give advice. He taught me to express my ideas of a problem report into this thesis by setting expectations that would lead me to the defense. By his series of questions and directions, he made me review the literature and explore the need for this thesis. He always insisted the significance of integrating this thesis work with the existing process of WVU's physical plant. He is most responsible for guiding me to the flow and structure for this thesis writing. On the same day of successfully completing the thesis proposal defense through his advising, he provided the first interviewing opportunity in the real world. His time management 
skills and clarity of suggestions have always inspired me. His good questions and insightful comments helped me answer the contributing points of this thesis to the literature.

Besides my advisor, I would like to thank my other two thesis committee Dr. Kenneth H. Means and Dr. Robert C. Creese. Dr. Kenneth Means was kind enough to accept my requests of an independent study during the summer 2003 in HVAC systems. This primarily helped me focus on HVAC systems for this thesis study combined with real time experience with physical plant. He advised me the importance of assessments and inspections in university type set ups. He and Mr. Gary Boyd helped me choose cooling tower as an example for testing and validation. He reviewed my work and advised the scope of operating characteristics of a cooling tower and direct digital control systems consideration in my thesis writing.

I would also like to thank Dr. Robert C. Creese for his hard questions and review of my thesis work that helped in developing benchmarking and conversion of the scores, and variation in assessment results due to multiple inspectors. He also suggested reviewing and applying his paper on prioritization scheduling technique. He always provoked my thought process by asking critical questions such as what are your research needs, where is it covered in your objective, how does it solve the problem, and what is the conclusion or findings of this thesis. He always insisted the importance of simple, consistent, and flawless writing. I thank Michelle Moore for a technical editing of my thesis.

My sincere thanks to Randy Hudak, Director of WVU Physical Plant for his support by attending my thesis defense. It stunned, delighted, and inspired me when he accepted my four hour prior invite to attend my thesis defense. One of his questions on the effectiveness of the tool helped me investigate and address the same. The support from Gary Boyd and Randy Hudak, made my defense very special and their presence helped me perform with confidence. All my three professors appreciated their support, interest, and participation that made it a very important work.

I thank Allen Heinz, Wade Bowser, Randy Long and Gary Boyd for performing assessments and helping me to complete my assessment variation study. I appreciate Gary Boyd for assigning them to help me from their routine work and also appreciate all the four for their assessment inputs and time. 
I find this opportunity as a great pleasure to also thank my inspirational friends and family members, without them completing this thesis would have been an impossible task.

My thanks to my loving room mates Kedhar, Nitin, and Wiselin for being there for me on all the time when I needed them to share my feelings. They extended their support to the fullest in helping me by all means. They were responsible for a peaceful, emotional, and homely environment which made us feel like brothers of a family away from home. Wiselin's helping attitude is always been an inspiration to me. I am always impressed by kedhar's positive attitude in life. I express my thanks to him for helping me in formatting this thesis report. I would like to thank my friend Venkat, for being there for me and he was the only reason that gave confidence to my dad in sending me here. His friendship and presence around me all the time made me feel not being away from home, as we always shared our problems and memories together. I would like to thank my friend Bharath for being a helping hand all the time whenever I had questions in Excel. His skills in Excel and attitude in teaching always inspired me. Thanks to my friend Srivatsan, who intellectually played a devil's advocate role in this thesis work and presentations. He questioned and challenged every idea that we would discuss which made me think more always. His interest and knowledge sharing attitude had always inspired me. I would like to thank my loving friend Nethaji, who has played a significant role in this thesis where he helped me generate the scoring numbers. His patience has always inspired me. I thank his efforts for being a devil's advocate in my thesis proposal presentation by reviewing it and asking challenging questions an entire night. I would also like to express my sincere thanks to Nethaji, Raja, and Vijay Raj for taking care of my parents in my absence which helped me focus on my thesis.

I am grateful to my friend Sunayana for being there as a big strength by providing emotional and moral support to me and taking care of me like a family member. She's been a sense of positive energy around me in motivating my dream goal-thesis come true. Her enthusiasm has been an inspiration to me. I also appreciate her efforts and time in proof reading my initial thesis writing. Without her love, confidence, and motivation it would have been impossible to complete my thesis.

Last but not the least, I express my thanks to my parents and beloved wife. I am forever indebted to my parents Chandrasekaran and Girija. They have been the greatest motivation and inspiration for me. Without my parents sacrifices financially and emotionally, it would have never been 
possible to perform my thesis and masters. Their love, encouragement, morals, principles, and confidence helped me succeed in life so far. My dads' understanding of any problem, logical and rationale decision making skills directed me in the right path always. His intellectual questions on my thesis amazed me on his overall knowledge. I strongly believe that my dreams became true through my moms' prayers and faith in god. I am happy and proud to be their son. I express thanks to my wife Archana for her sincere love, faith, trust, confidence, and patience that she expressed from overseas. Though we would miss each other, she was one of the primary reasons to support me in pursuing my masters program to lead a better life. I appreciate her efforts for proof reading my thesis from overseas and also my final version with me after our marriage.

Sincere thanks and appreciation to all these special people. Without their continued support, kindness, and help during both my smooth and tough days of life, it would have been impossible to accomplish this thesis work. 


\section{Table of Contents}

List of Figures __ xi

List of Tables__ xii

List of Tables in Appendix ___ xiii

Nomenclature_xiv

CHAPTER 1 - INTRODUCTION ___ 1

1.1 Problem Statement___ 1

1.2 An Overview of a Physical plant___ 1

1.3 General Types of Maintenance in Physical Plant __ 2

1.3.1 Planned Maintenance ___ 2

1.3.2 Unplanned Maintenance ___ 3

1.3.3 Deferred Maintenance (DM) __ 3

1.4 Department, Field, and Trade Classifications in WVU___ 3

1.4.1. Maintenance and Operations ___ 4

1.4.1.1. Electrical Engineering ___ 4

1.4.1.2. Structural Engineering ___ 4

1.4.1.3. Roads and Grounds and Labor

1.4.1.4. Mechanical Engineering ___ 4

1.4.2. Planning, Design, and Construction

1.4.3. Resource Management __ 5

1.5 Facts about Physical Plant___ 6

1.6 Root Cause of the Problem _ 7

1.7 Existing Techniques in Physical Plant___ 8

1.7.1 Run-to-Failure Management

1.7.2 Shortcomings of these Existing Techniques___ 10

1.8 Need for Research _ 14

1.8.1 Significant Backlogs of HVAC Equipment for Repair or Replacement ___ 14

1.8.2 Save Money and Time from Consultants and Engineers ___ 14

1.8.3 Prioritization of Maintenance Jobs Based on Condition, Safety, and Cost Need _ 15

1.8.4 Support Special Funding Proposal with Mathematical Comparison and Penalties _ 15

1.8.5 Improved Deferred Maintenance Plan __ 16 
1.8.6 First Two Steps of a PM Program

1.8.7 Lack of Corporate Memory (CM) in Maintenance Management 18

1.8.8 Reduce Risk (further) in Investment and Budget Planning 19

1.8.9 Inefficient PM and DM Program 19

1.9 Research Objectives _ 20

1.10 Conclusions _ 24

CHAPTER 2 - LITERATURE REVIEW __ 25

2.1 Background _ 25

2.2 No Decision Making Tool ___ 25

2.3 Preventive Maintenance (PM) and Benefits to Institutions __ 26

2.4 Structured Approaches to Evaluate HVAC Systems___ 28

2.4.1 Boilers 28

2.4.2 Air Handling Unit (AHU) __ 29

2.4.3 Cooling Tower 30

2.4.4 Air Compressors __ 31

2.4.5 Steam Distribution Systems ___ 31

2.4.6 Chillers _ 32

2.4.7 Motors 32

2.4.8 Heat Exchangers and Water Heaters __ 33

2.4.9 Pumps _ 33

2.4.10 Evaporative Coolers ___ 34

2.5 Evaluation of Industrial - Physical Plant Type of Systems ___ 34

2.6 Existing Methodologies for FCA __ 37

2.7 Shortcomings___ 41

2.8 Conclusions __ 42

CHAPTER 3 - RESEARCH APPROACH _ 44

3.1 Identification of HVAC Equipment

3.2 Identifying System Components ___ 51

3.2.1 User-Friendliness __ 51

3.2.2 Resource Constraints __ 52

3.2.3 Type of Manufacturers 
3.2.5 Equipment Deficiency __ 53

3.2.6 Functional Value of the Component

3.3 Identifying Component Checkpoints __ 55

3.4 Developing Corporate Memory in Assessment___ 58

3.5 Causes and Effect of Equipment/Component Failure ___ 59

3.6 Identification of Failure's Impact ___ 61

3.7 Identification of Risk Measurable Levels ___ 63

3.7.1 Defining Condition Level as a Measurable Scale __ 65

3.8 Identifying Priorities ___ 68

3.9 Improved Priority and Scoring Model___ 71

3.10 Improved Formula __ 75

3.11 Conclusions __ 81

\section{CHAPTER 4 - OVERALL IMPLEMENTATION PLAN FOR THE ASSESSMENT}

METHODOLOGY __ 82

4.1. Benchmarking the assessment scores __ 82

4.1.1 Score Conversion Method __ 85

4.2 Recommendations for Assessment Frequency ___ 86

4.3 Time-Based Sensitivity - Real Time and Time Based Interactions in Updating System

Reporting Aspects ___ 90

4.3.1 Modes of Work Requests and Classification of Work Orders ___ 91

4.3.2 Work Order Status Check__ 93

4.3.3 Generating Work Orders ___ 98

4.3.4 Implementing the Continuous Improvement Goals ___ 99

4.3.5 Integrating Assessment Model and Preventive Maintenance Program __ 103

4.3.6 Executing Work and Assigning Assessments __ 104

4.4. Testing FCA Methodology with Cooling Towers ___ 107

4.4.1 Assessment Input _ 108

4.4.2 Assessment Model _ 109

4.4.3 Assessment Output___ 119

4.4.4 Feedback__ 119

4.5 Operating Characteristic Checklists to the Cooling Tower Assessment ___ 121 
4.6 Variation in Assessment with Multiple Workers 122

4.7 Effectiveness of the Assessment Tool

4.8 Conclusions 127

CHAPTER 5: CONCLUSIONS 129

5.1 Summary 129

5.2 Results 129

5.3 Change Management 130

5.4 Advantages of FCA Methodology over Existing Practices 131

5.5 Applications and Future Work 132

REFERENCES 133 APPENDIX 137 


\section{List of Figures}

Figure 1.1. Cause and Effect Diagram for the Flood Example................................................ 13

Figure 1.2 HVAC Conditions Assessment System Flow Chart ............................................23

Figure 3.1. Identification of HVAC Equipment ................................................................. 46

Figure 3.2. Cooling Tower Process Flow Chart ................................................................. 49

Figure 3.3. Counter Flow Cooling Tower and Cross Flow Cooling Tower [47] ......................50

Figure 3.4. Component Checkpoints Identification Process Flow Chart ..................................56

Figure 3.5. Consequences of an Equipment Failure Flow Chart ............................................ 61

Figure 4.1. Overall Condition Assessment Score Benchmarking ........................................... 84

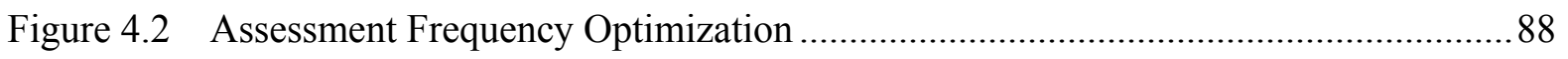

Figure 4.3. Work Order (W/O) Flow and Feedback Process............................................... 93

Figure 4.4. Work Order Status Recording Stages................................................................... 95

Figure 4.5. Continuous Improvement in Maintenance Management ..................................... 101

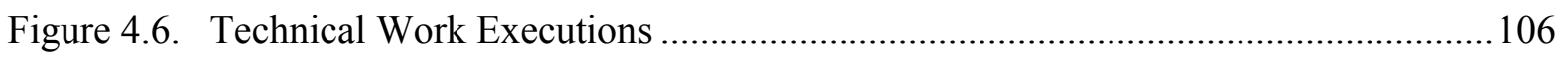

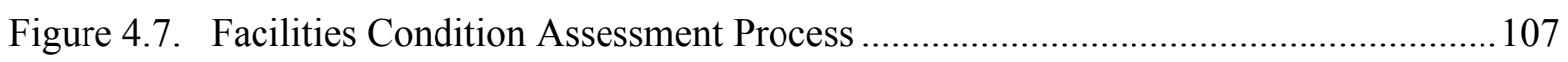

Figure 4.8. Example of a "Fair" Condition Structure in a New Cooling Tower ....................... 112

Figure 4.9. Example of a "Critical" Condition Structure in an Old Cooling Tower ................. 112

Figure 4.10. Example of a "Good” Condition Cooling Tower................................................. 115 


\section{List of Tables}

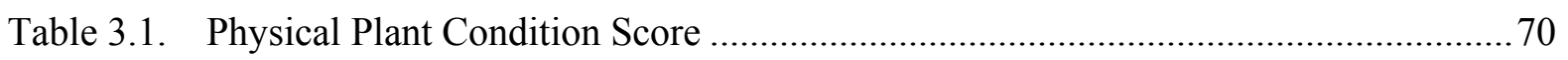

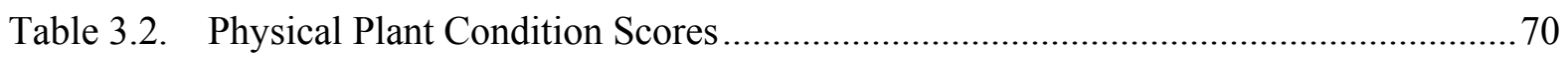

Table 3.3. Physical Plant Condition Scores........................................................................ 70

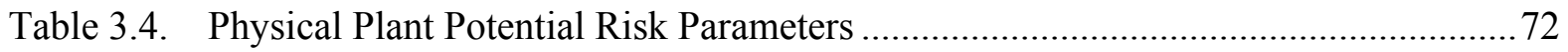

Table 3.5. University Potential Risk Parameters …............................................................... 72

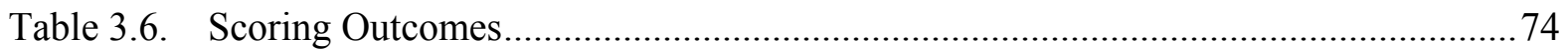

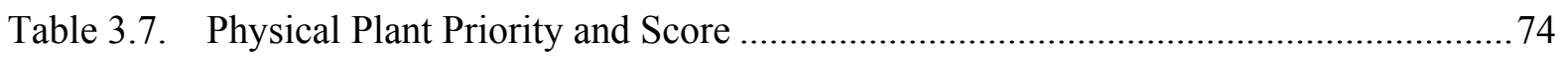

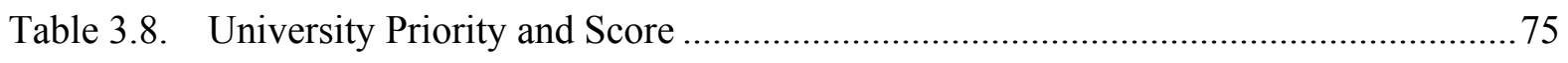

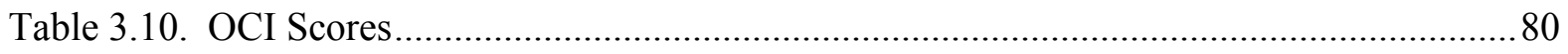

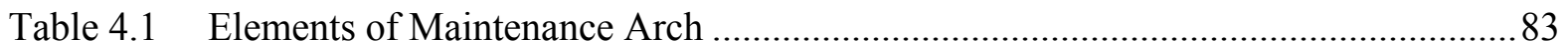

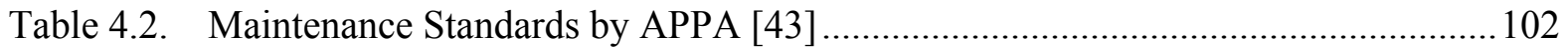

Table 4.3. Assessment Input for Corporate Memory........................................................... 109

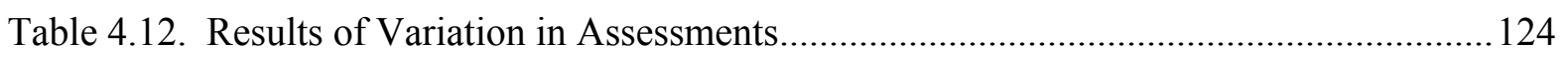

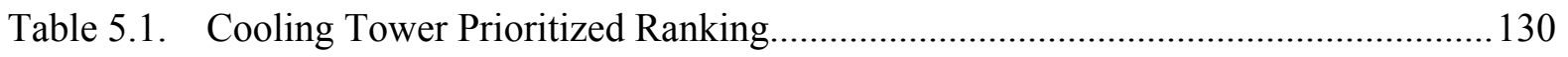




\section{List of Tables in Appendix}

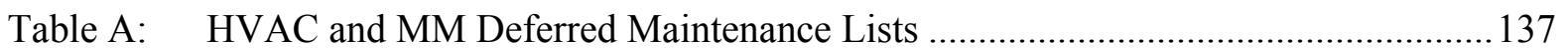

Table B: $\quad$ Plumbing Shop Deferred Maintenance Lists (October 2004)............................... 138

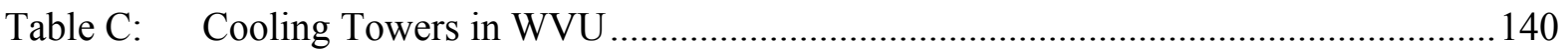

Table D: HVAC Systems Average Lifetime in Years ....................................................... 141

Table E: $\quad$ Weibull Data Lists for Beta and Eta Values ......................................................... 142

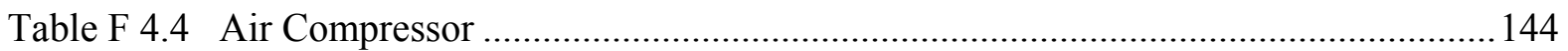

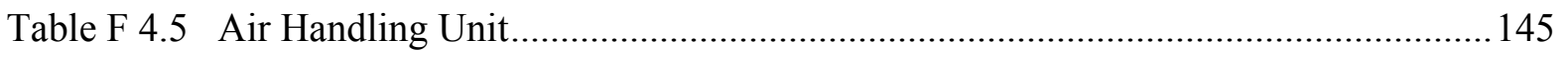

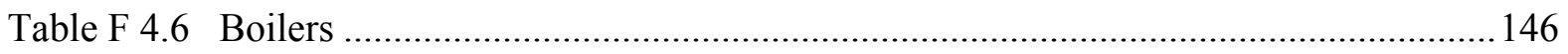

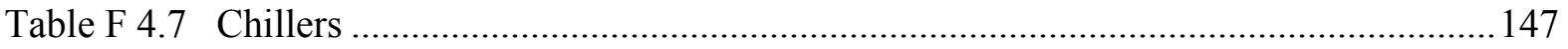

Table F 4.8 Heat Exchangers and Water Heaters .................................................................... 149

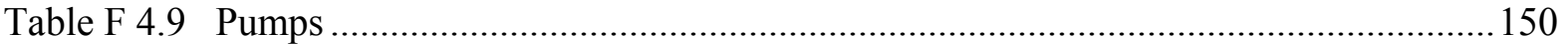

Table F 4.10 Steam Distribution Systems .............................................................................. 151

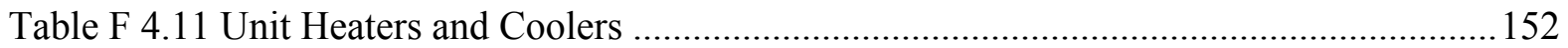




\section{Nomenclature}

\begin{tabular}{|c|c|}
\hline AHU & - Air Handling Unit \\
\hline $\mathrm{AM}$ & - Assessment Model \\
\hline APPA & - Association of Physical plant Administrators \\
\hline BER & - Building Evaluation Report \\
\hline CAC & - Creative Arts Center \\
\hline $\mathrm{CDV}$ & - Component Damage Value \\
\hline $\mathrm{CM}$ & - Corporate Memory \\
\hline DM & - Deferred Maintenance \\
\hline ESB & - Engineering Sciences Building \\
\hline FCA & - Facilities Condition Assessment \\
\hline FCI & - Facilities Condition Index \\
\hline FCU & - Fan Coil Unit \\
\hline FM & - Facility Management \\
\hline HVAC & - Heating Ventilation and Air Conditioning \\
\hline LS & - Life Safety \\
\hline MDT & - Maintenance Down/Hindrance Time \\
\hline MRT & - Maintenance Repair Time \\
\hline MTTF & - Mean Time to Failure \\
\hline NACUBO & - National Association of College and University Business officers \\
\hline NAVFAC & - Naval Facilities Engineering Command \\
\hline $\mathrm{OCI}$ & - Overall Condition index \\
\hline PDF & - Probability Density Function \\
\hline PDV & - Property Damage Value \\
\hline PM & - Preventive Maintenance \\
\hline POE & - Post occupancy Evaluation \\
\hline WJS & - Worker Job Safety \\
\hline WVU & - West Virginia University \\
\hline
\end{tabular}




\section{Chapter 1 - Introduction}

\subsection{Problem Statement}

To manage facilities in a pro-active manner, information regarding the deficiencies in existing facilities must be available. The administration remits funds ( $\$ 1.5$ million) to the physical plant at West Virginia University (WVU) for maintenance of the facilities every fiscal year. Maintenance of facilities includes new projects, routine maintenance, preventive maintenance (PM), and deferred maintenance projects. Project proposals from electrical, mechanical, and structural departments of the physical plant accumulate and await clearance at every board meeting. At the end of every year, a list of projects is considered, analyzed, and short listed for funding purposes with a view to commence the project during the succeeding year. Replacement and repair maintenance projects are carried out, at the cost of the critical replacements and repairs, due to the lack of centralized information on the assessment of deficiencies and conditions in the facilities. These projects are selected based on the trade managers' conflicting interests and contending priorities. Sometimes, these projects are also selected based on recent occurrence of failure or breakdown of equipment from the facility manager's memory rather than from an extensive condition assessment of the facility. Lack of priority in each investment decision presents a potential risk for the university. To set priorities for repair or replacement maintenance work, the existing conditions of the facility must be known through prior inspection. Hence, development of a facilities condition assessment (FCA) methodology with a decision making tool to prioritize projects based on its physical condition is imperative.

\subsection{An Overview of a Physical plant}

Maintenance of facilities is directly proportional to the students enrolled in a university, number of buildings, age of facilities, number of maintenance workers available, and logistics. However, the most important factor that drives a physical plant is budget allocation (funds) for each fiscal year. Physical plants are responsible for maintaining the campus buildings, mechanical equipment, electrical equipment, utility systems, and campus roads and grounds. Maintenance is provided through various departments to provide quality service for the growth and sustenance of the university. The purpose of maintenance is to provide maximum availability of facilities at the 
lowest cost, as well as highest quality and safety standards. Proper maintenance would reflect upon the quality of the university, though the actual quality of a university depends on the research work, faculty teaching strengths, courses offered, students' performance, number of companies hiring on campus interviews, and number of students obtaining jobs upon completion. Good condition of the facilities and maintenance standards would impress those visiting the campus for the first time. Facilities maintenance standards directly contribute to the students' enrollment and sustenance [45]. This would generate money flow into the university apart from faculty research projects. As the old saying goes "first impression is the best impression," this could be achieved only by ensuring higher quality standards in the maintenance of the facilities. The physical plant is solely responsible for facility maintenance. The maintenance operation must be properly organized and structured to perform maintenance tasks in an efficient manner. The general types of various maintenance activities that any facility would require are explained in the next section.

\subsection{General Types of Maintenance in Physical Plant}

Maintenance activities can be broadly classified as proactive and reactive maintenance. Proactive maintenance includes building inspection, preventive, predictive, component renewal, planned repairs, and deferred maintenance. Reactive maintenance includes emergencies, breakdowns, equipment failures, service calls, and corrective maintenance. The various types of maintenance are explained in the following sections.

\subsubsection{Planned Maintenance}

Any maintenance activity that has to be carried out through proper planning and with prior knowledge about the work is called planned maintenance. Planned maintenance can be preventive maintenance, predictive maintenance, and corrective maintenance.

- Preventive maintenance (PM): A planned maintenance and controlled program for periodic inspections, adjustments, and replacements of components.

- Predictive maintenance: A planned maintenance activity utilizing technology to predict failures by constant monitoring and analysis of the facility based on the condition.

- Corrective maintenance: A planned maintenance work to repair or replace obsolete, worn, broken, or inoperative components and pieces of equipment. 


\subsubsection{Unplanned Maintenance}

Any maintenance work performed after the failure of equipment or immediate action to avoid any catastrophic effect. Reactive maintenance and emergency work would fall in this category.

- Reactive maintenance: It is the most common approach in a physical plant. It could be minor or major repair or replacement, but it is done only after the occurrence of failure.

- Emergency maintenance: This is unscheduled work that required immediate action to restore facilities and to protect life and property.

\subsubsection{Deferred Maintenance (DM)}

DM is the backlogged jobs that require replacement or repair that can be done only when funds are allocated. This work needs a systematic process to plan and execute to extend or retain the facility.

\subsection{Department, Field, and Trade Classifications in WVU}

The maintenance activities and operations at WVU are also similar to the information provided in the previous sections. For this thesis research work, WVU's Physical Plant is studied to determine the research objectives and solution. WVU Physical Plant is divided into the following departments,

- Maintenance and operations

- Planning, design, and construction

- Resource management

Each department is further classified into different fields. Each field is further sub-classified into various trades. Each trade is broken down into different skill levels. Skill level is one of the major factors contributing toward the quality of maintenance. 


\subsubsection{Maintenance and Operations}

The maintenance and operations is classified into fields such as electrical engineering, mechanical engineering (thesis research focus), structural engineering, and roads, grounds, and labor.

\subsubsection{Electrical Engineering}

Electrical engineering maintains all electrical systems inside and outside the buildings all around the campus. These systems would vary from high voltage to low voltage equipment. Maintenance of electrical systems includes cable and wiring, panel boards, switches and breakers, lighting, switchgear, and transformers. This department also maintains fire control and limited electronic equipment.

\subsubsection{Structural Engineering}

Structural engineering maintains building in terms of infrastructure such as painting, plastering and masonry work, roof and lamping, lock and key, asbestos removal, sheet metal work, and sign shop.

\subsubsection{Roads and Grounds and Labor}

Roads and grounds and labor maintain the university roads, landscape, plants, trees, shrubs, flowers, lawn maintenance, snow cleaning, and other ground-related work. The labor crew is responsible for moving assets needed all over the campus, stage setup for events, custodial cleaning, waxing, and trash removal inside the campus buildings.

For this thesis point of view, focus would be only into mechanical engineering maintenance, its various trades, and only the equipment that is listed in the following section.

\subsubsection{Mechanical Engineering}

Mechanical engineering maintains the HVAC shop, plumbing shop, millwrights shop, and elevators. Elevator servicing is outsourced and only supervised by physical plant. They also 
maintain off-hours emergency and PM. Each shop/trade has its own function toward maintenance of facilities such as:

- The HVAC shop is responsible for maintaining, repairing, and replacing equipment, and not limited to cooling towers, air handling units, chillers, unitary heating and cooling equipment such as fan coil units, Weather Masters, and window air conditioners.

- The plumbing shop is responsible for maintaining, repairing and replacing equipment and systems, and not limited to boilers, steam distribution systems, and heat exchangers and water heaters.

- The millwrights shop is responsible for maintaining, repairing and replacing equipment, not limited to air compressors, motors, and pumps.

The shops perform jobs such as quick fix, minor and major repairs, minor and major alterations, PM, and other special projects on equipment and other facilities. The reason for mentioning only nine equipment systems and not all is because they directly generate and support the heating, ventilation, and air conditioning supply to buildings.

\subsubsection{Planning, Design, and Construction}

The planning, design, and construction department manages space planning, lease management, capital construction, contracts, project management, design standards and development, master planning, and interior design.

\subsubsection{Resource Management}

The resource management department manages work management and warehouse operations. Work management is responsible for time cards, work order initiating and closing, and payroll. Warehouse maintains and stocks the necessary materials for all the above-mentioned shops that are used on a regular basis.

The services rendered by these departments contribute to the success of this institution. Though it is a diverse group, they integrate to a common goal of assisting this institution in the execution of its core mission. 


\subsection{Facts about Physical Plant}

The departments, fields, and trades mentioned above strive hard to utilize the funds allocated to each of them in a 'best possible manner' for maintenance. To improve the best possible manner in an organized, structured, and efficient manner, a process or a methodology has to be created. If a process exists, it can be tested, validated, analyzed, and improved further. At present, there exists no proactive process for maintenance in a structured, organized, or methodical way. Instead, they work on reactive management, solving issues or attending to work orders and correcting deficiencies after they receive complaint calls or when they work in the field and notice any deficiency. This creates havoc and unplanned maintenance, but it does not imply that they do not practice any planned maintenance. They certainly do follow planned maintenance every fiscal year like PM on steam systems in the steam pits, PM on fan coil units, air handling units' filter change, lubrication and oil change on motors, pumps, fan gearboxes, and bearings. These activities are not sufficient to take care of all the facilities and do not have a strategic model. But, since they perform these planned maintenance operations, the complaint calls or failures on these pieces of equipment is relatively less. Without having a process or methodology to follow, this presently performed PM can also fail or have pitfalls and shortcomings. For example, in the Mineral Resources building at WVU, an air-handling unit was shut down for a week to replace the centrifugal fan assembly. A centrifugal fan is built with a wheel that is mounted on a horizontal shaft and rotates inside the housing. Air enters near the axis of the wheel and is discharged through the housing outlet. The main components are fan motor, blade and hub assembly, inlet cone, grill guard and housing assembly. Fasteners support the horizontal shaft to hold the housing. During a weekend, due to loose fasteners in the shaft, excessive vibration dropped the shaft and ruptured the entire fan and housing. Filter change, belt change, and lubrication are the only PM work performed in the air-handling unit. Since the operation did not schedule tightening of bolts and fasteners (inside the housing) as a task, this incident ended up costing an unexpected heavy price for removal of the ruptured housing, building a new housing, replacing a fan assembly, overtime labor, other work orders delayed and disturbed, express delivery of fan assembly from vendor to minimize lead time, and discomfort to building occupants for a week. 
Physical plant has a very strong working team with immense technical expertise and skills. They know the pulse of every facility and its performance. Physical plant is responsible for maintaining the downtown campus, Evansdale campus and a few other buildings outside these two campuses. Physical plant maintains 41 buildings on the downtown campus and 56 buildings on the Evansdale campus. To segregate the workload and minimize the travel time, campus is divided into four zones. Downtown campus has 22 buildings in zone one and 19 buildings in zone two. Evansdale campus has 19 buildings in zone three and 37 buildings in zone four. In each zone, maintenance workers are deployed to manage the facilities. Each zone worker would know the condition of each facility. Facilities (equipment) age varies from recently replaced to 40 years old. Technologically immense amount of change and upgrades have occurred to the facilities. A facility varies with construction type, manufacturers, and age. Hence, it becomes very difficult to keep track of these widely diverse facilities and their maintenance without a proper, consistent system. But, enrollment at WVU has been at record levels over the past two years, which indicates that WVU is appealing to a growing number of students and their families. It also reflects up on the hard work and dedication of the maintenance and operations units responding daily to the many and varied needs of faculty, students, and staff. The resource management department processed 17,000 work orders last year. Hence, the need and demand of maintaining these facilities is becoming even more challenging and critical.

\subsection{Root Cause of the Problem}

Escalating costs, funding cutbacks, growing tuition price sensitivity, and other issues are contributing to tight budgets and increasingly difficult choices for colleges and universities. WVU is no different. This affects the physical plant directly in maintaining the facilities, though the above-mentioned facts remain the same. The choices for management to address these problems may include program (course) elimination, cost reduction at all expenditures, downsizing employees, hiring freezes, etc. Hence, facility improvements are assigned a low priority. This under-investment, combined with the age of the universities facilities has created budget needs that cannot be met in a year or even within a five-year span. Hence, the only choice left to physical plant is to postpone major replacements and major repairs on a planned or unplanned basis to future budget years or until funds become available. This backlog of maintenance activities to a future budget cycle for capital is called "deferred maintenance." [32]. 


\subsection{Existing Techniques in Physical Plant}

Physical plant typically has two types of maintenance, either run to failure or PM. Maintenance is designed to increase the availability of the equipment/facilities by reducing the number of unexpected breakdowns or service interruptions. WVU Physical plant has a fan coil unit (FCU) maintenance team and an air handling unit (AHU) maintenance team. The FCU maintenance team troubleshoots electrical and pneumatic control systems, replaces motors, cleans and disinfects coils, drains pans, replaces control valves and filters, and replaces and calibrates thermostats. The AHU maintenance team replaces and adjusts belts, cleans and disinfects coils, lubes and sets dampers, and replaces filters. Physical plant also maintains records of complete scheduled lubrication maintenance and repair to 144 AHU's, 114 air compressors, 270 pumps, 1100 electric motors, 50 gear boxes, 330 roof fans, 21 emergency generators, 12 cooling towers, and 34 condenser fans. This is approximately 30 percent to 40 percent of the total equipment in the university. The number of breakdown and emergency work orders on these pieces of equipment is reduced, but the work orders (90 percent [44]) from these systems are not generated by PM inspections. Similar planned maintenance work is scheduled for every summer for steam line maintenance and boiler maintenance. These maintenance tasks are more related to scheduled maintenance activities than a PM program.

\subsubsection{Run-to-Failure Management}

The concept of run-to-failure management is 'not to fix a breakdown until it breaks.' Run-tofailure is a reactive management technique, which implies that equipment is not rebuilt nor are any major repairs made until the equipment fails to operate. This is not 100 percent true; Physical plant performs basic preventive tasks, that is, lubrication, machine adjustments, and other adjustments, even in a run-to-failure approach (for example, summer scheduled maintenance, FCU maintenance team, AHU maintenance team, etc). For example, in a centrifugal pump circulating hot water supply, the parts (gasket, seals, filter, and belts) can wear by 20 months, and when the pump is removed from operation and rebuilt during the $19^{\text {th }}$ month of its operation, then it is a PM activity. Under the same situation, if a plant lubricates and cleans the pump, but rebuilds the parts only after breakdown, then it is referred as 'run to failure' [36] (reactive maintenance) with scheduled lubrication and cleaning. 
At present, the plumbing shop has 13 maintenance employees, HVAC and the millwrights shop has 18 maintenance employees, and the floating shift (night shift and FCU and AHU PM) has 14 employees. In physical plant, percentage of reactive maintenance is more than planned maintenance, due to which, even after completing a particular task on a facility, another deficiency emerges. An insufficient staffing level is also one of the contributing factors; hence, a simple and achievable program or methodology (in terms of time and tools) is required to optimize the resources. To optimize the staffing level, one of the most important factors is the physical condition of the facilities. A strategic approach towards maintenance through assessment of a facility's condition and prioritizing jobs would result in effective utilization of resources (men, material, and money) in the right facility. By performing FCA, proactive maintenance hours should increase and reactive maintenance hours (emergency and breakdown maintenance) should decrease. Inspection or assessment of equipment becomes critical to improving the equipments is life as the years pass and new equipment becomes old and management's attention toward it decreases. During the initial couple of years of any new equipment, a manufacturer would prescribe the time schedules for lubrication, minor changes, etc. The real care and trouble in maintaining equipment begins once the warranty time period is completed.

At present in the physical plant, work descriptions are hand written (not elaboration as work description) and later recorded in a database. The problem is finding enough time to record valuable information on each individual work order. Since most of the work is done in a reactive mode, it becomes difficult to record events after they have taken place. For example, recording the number of times a particular motor has stopped running due to the tripping of a circuit breaker might be insignificant. But, if the tripping is due to motor overload caused by bearing wear, it is worth noting that particular failure and discovering such wear by prior inspection to prevent catastrophic failures. Hence, accurate recording becomes important since it enables availability of critical information. 


\subsubsection{Shortcomings of these Existing Techniques}

Physical plant's expenses are accounted for spare parts inventory, overtime costs, high equipment downtime and the negative impact of expedited shipments due to lack of anticipating maintenance requirements. Repair performed in the reactive or run-to-failure mode will average about three times more expenditure than the same repair made within a scheduled or preventive mode [36]. Improper training of workers, lack of knowledge in the consequence of a breakdown, and lack of structured inspection procedure or checklists for equipment are reasons for increasing reactive maintenance work. The PM program is limited to lubrication and minor adjustments. PM program performance cannot be measured as information on maintenance issues when corrective measures have not been documented. A PM program does not make sense in a component if it has a constant failure rate. For example in AHU, filters are changed every two months; it becomes scheduled maintenance rather than PM, as filter life is only two months. Inspection standard time is not established during routine maintenance. Hence, monitoring versus planned time cannot be compared. These maintenance practices have affected the equipment life, resulted in lack of records, lack of loss prevention, as well as the minimization of resource utilization. These practices have grown in repair and replacement jobs in significant numbers. Since the number of maintenance jobs has increased by 100 s, funds and manpower to rebuild these pieces of equipment in a fiscal year is not available. Existing maintenance techniques have significantly increased the DM backlogs, as shown in Table A and Table B of the appendix. These tables are the inconsistent DM lists for two different years.

For example, in Clark Hall during the winter of 1995, the outside air damper did not work and failed to close. Over the weekend, the outside air temperature made the water in the coils freeze. Water expanded as it froze and consequently broke the coil pipe. The emergency control switch that was supposed to shut off the supply water was bypassed (human error), leading to flooding in the building. To manage the disaster, extensive cleaning of the floor was required. The loss was in terms of overtime labor costs as well as coil replacement, not to mention the inconvenience caused due to flooding and the discomfort caused from the lack of heat to the building occupants. This situation could have been easily avoided by proper inspection of damper operation and control connection. An FCA would identify these failures in its methodology. 
Consider a situation where a 100 pound per square inch water pressure pipeline (two inches diameter) burst at $1 \mathrm{a} . \mathrm{m}$. Time is important because the severity of the incident can be lessened during the day. The water pipe leak is due to excessive corrosion (Pipe is unable to withstand water pressure.) This pipeline runs adjacent to a building five feet below the ground. The pipe break (inside a water meter pit) is on a right-angle turn entering the building from the city water line. The building has an unsealed (not plastered) opening in this pipe entry. The pipe enters the building through a basement floor equipment room of the building. Four hours later, seven feet of water is seen clogged in the equipment room. Water was unable to drain due to improper functioning of sump pump and outlet drain clogged with debris. Motors, air-handling units, supply and return pumps, a motor control center, and other equipment were immersed in floodwater that tripped down due to overload. The consequences of this are building shut down, property and equipment damage, possibility of workers getting electrocuted, as well as the added expense of overtime paid to maintenance workers. This damage can costs up to $\$ 200,000$. This entire situation could have been avoided if the physical plant had assessed and inspected the condition of each facility. The corroded pipe would have been identified for replacement, proper plastering could have avoided water entry into the mechanical equipment room, the sump pump would have pumped the floodwater, and proper cleaning would have prevented the clogged drain. Proper maintenance of facilities (equipment) by periodic inspection and assessment followed by corrective actions can avoid catastrophic failures, personnel safety hazards, and loss of money and time. Proactive maintenance adds benefits to the equipment as well as the physical plant management to identify and schedule tasks that would prevent premature failures, extend the useful life of critical plant assets, and minimize losses. A cause and effect diagram, shown in Figure 1.1, for this flood example indicates the need for a facilities assessment methodology.

All these consequences are eventually associated with direct and indirect costs. These costs are not investments, instead losses incurred are due to failure or not having a structured PM program and DM reduction plan. Hence, these programs would indicate the declining trend of a university's physical plant performance because of deterioration and decline of assets.

Best maintenance indicators [44] are a benchmark for maintenance management. Research goals must eventually obtain results to meet these metrics.

- 100 percent of maintenance workers' time is covered by a work order,

- 90 percent of work orders are generated by PM inspections, 
- 30 percent of all work is PM,

- 90 percent of planned or scheduled work compliance,

- 100 percent reliability is reached 100 percent of the time,

- Spare parts stock outs are rare,

- Overtime is less than 2 percent of total maintenance time,

- Maintenance budget is within $+/-2$ percent,

- Proactive maintenance is the mission [44].

To meet these goals in the long run, a work order process and continuous improvement technique with a flowchart is explained in chapter 4.3 . 


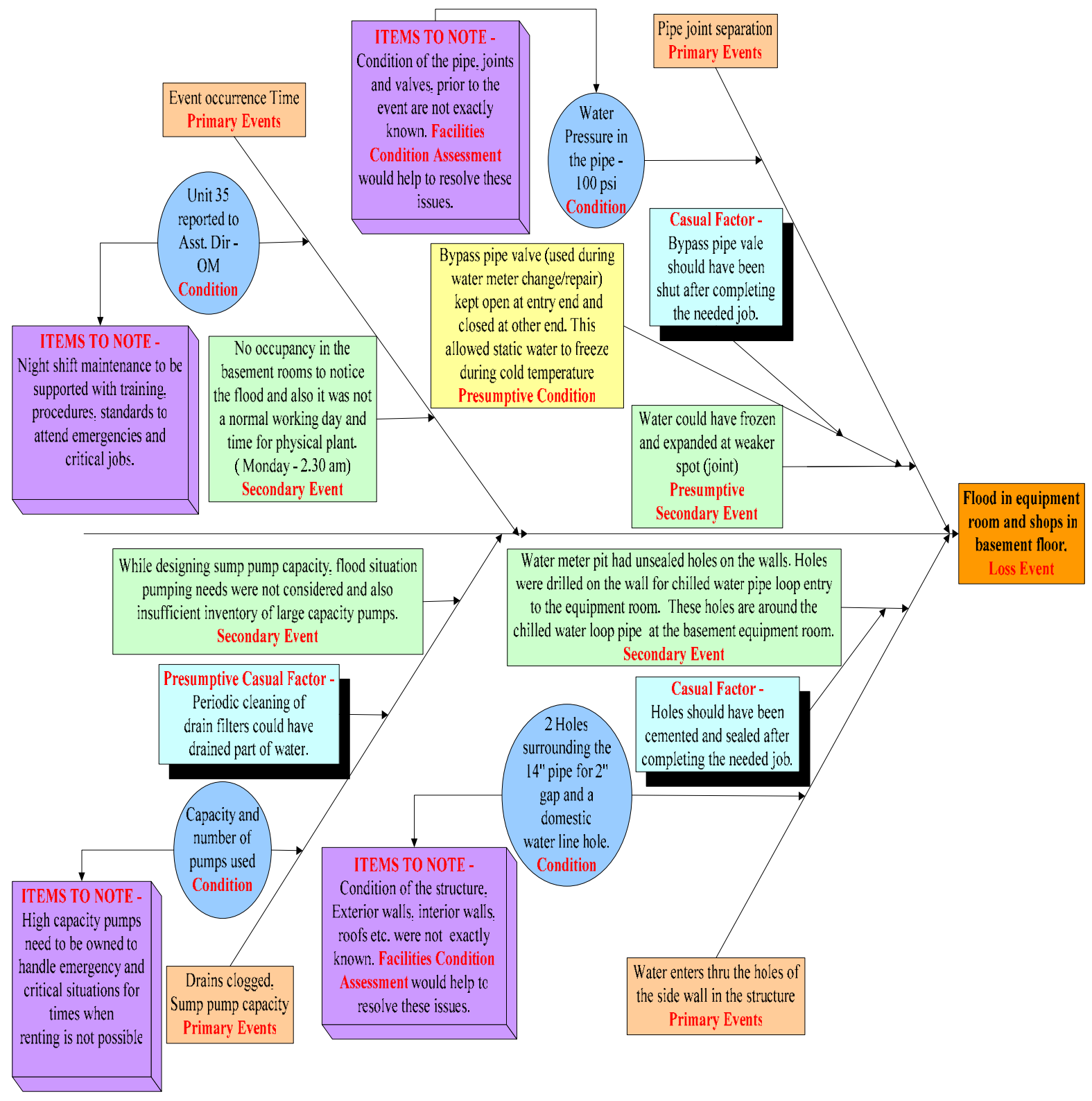

Figure 1.1. Cause and Effect Diagram for the Flood Example 


\subsection{Need for Research}

\subsubsection{Significant Backlogs of HVAC Equipment for Repair or Replacement}

As mentioned earlier, the university remits $\$ 1.5$ million for investment in facilities and/or equipment. At present, the number of work orders received by the mechanical engineering department in the physical plant averages approximately 105 per week. This includes plumbing, HVAC and the millwrights shop. The work order types can be quick fix, minor repair and alteration, routine maintenance, PM, or major repair and alteration. Though physical plant workers attend to and rectify these problems, they are unable to solve the root cause of the problem. The reasons could be such as, the amount of PM work done is less than 10 percent of the total work orders, most (75 percent) of the work time is spent for reactive maintenance, and the average age of physical plant maintained buildings is approximately 40 years, and the condition of the equipment or the exact need to rectify the deficiency is not known, or equipments is not inspected or assessed. All these reasons plus deterioration in equipment condition resulted in repair or replacement work orders accumulating as backlogs.

\subsubsection{Save Money and Time from Consultants and Engineers}

To start solving this problem of backlogged repair and replacement facilities, the present condition of the equipment is to be evaluated. For the large volume (over 12,000 pieces of equipment) and different construction types, multiple consultants and engineers have to be hired to inspect and assess the equipment. The time they need to complete an assessment and report on the condition of the equipment is not less than three days. The inspection time published in [31] for 1,000 square footage of a mechanical facility is 1.6 hours, and the report generation time on these inspections is equal to the field inspection time [34]. For example, to assess 20 cooling towers in our university, at least five manufacturers have to be hired. The information (inconsistency) in these 20 reports from five different manufacturers might become obsolete very soon. These evaluations cost at least $\$ 2,000$ each for physical plant to identify the repair and replacement need. 


\subsubsection{Prioritization of Maintenance Jobs Based on Condition, Safety, and Cost Need}

Evidence has not been found in the literature to prioritize repair or replacement of components or equipment considering safety, damage value, and downtime. Limited resources of physical plant, such as money, men, and time, should be used for the most critical projects. For example, water treatment in the engineering sciences building (ESB) cooling tower is to be performed first when compared with the law school, as the condition of the water is poor (biological growth and health hazard for Legionnaires disease) in ESB compared to Law School or any other tower. Health safety, and/or job safety must be given highest priority. For example, the fan deck of the creative arts center cooling tower is torn apart due to deterioration. Maintenance access to repair or inspect the fan assembly, gearbox, motor, water distribution, and spray headers becomes unsafe (may not withstand bodyweight of a worker; they can fall from a height of 15 feet). The current methods do not evidently assess safety and risk of the potential work environment. The current methods prioritize the jobs based on the facilities condition index, which is the ratio between costs of deficiency and current replacement value. A cost estimation method does not indicate the physical condition of a facility.

\subsubsection{Support Special Funding Proposal with Mathematical Comparison and Penalties}

Presently, trade managers' convincing explanations, worker input, photographs, and expenditures on the patchwork on the equipment are the sources for seeking funding proposals. For example, in the Mountainlair, the chillers, cooling tower, and pumps are to be replaced. This replacement need arose in the year 1996. It has not been replaced and the project might require more than 40 percent to 50 percent of the annual funding. Sufficient facts (physical condition of equipment in component level) and consequences in the event of failure were not supported (no program) to transfer the equipment from being a DM project to a special funds project. The risk potential factors, such as safety, property damage, downtime, etc. are to be assigned penalties (scores) and pointed out to the management with a comparative study to seek special funds. No evidence is found in the literature to address these issues in an FCA. 


\subsubsection{Improved Deferred Maintenance Plan}

During each fiscal year's for funding requests, physical plant attempts to reduce backlogs of projects in order to improve conditions within facilities. To justify the financial benefits (return on investment and loss prevention) and deficits (lack of funds) while seeking funding, scientific evidence has to be supported. The techniques in literature are cost-based. There are 31 other buildings apart from the Mountainlair (refer to Appendix Table A and Table B) waiting for funds for replacements and major repairs. These pieces of equipment perform, but do not deliver output as desired. All these buildings receive many service calls and complaints, such as insufficient heating and cooling, no airflow, lack of hot and cold water supply, drops in pressure as well as leaks in the system that are unsafe for workers to attend to, machine faults, weak structure, excessive energy consumption, etc. This equipment is more than 35 years old. DM projects can be reduced only when the physical plant has a process whereby the facility's components and subcomponents are evaluated as to their condition. The information obtained during the assessment is used to estimate costs for repair, renovation, or replacement. This would help to plan for spending. The consequences and risks associated with the maintenance deferral should be documented as a measure of caution.

DM projects can be minimized by the following plan:

- Conduct a facility condition inspection.

- Identify and tabulate the deficiencies in the facility.

- Prioritize the deficiencies based on consequences and risk impact.

- Support required decision-making and identify the amount of work to be done.

- Find the total costs of labor, material, and other areas of expense.

- Correct the deficiencies based on priority and funds available.

- Complete and document the work order for a better corporate knowledge. 


\subsubsection{First Two Steps of a PM Program}

Any planned maintenance activity that is designed to improve equipment life and avoid any unplanned maintenance activity is PM. The primary goal of any PM program is to prevent any failure or breakdown of equipment before it actually occurs. To maximize return on investment of the physical plant's assets, a facility manager must have authentic information on the distinctive elements and the prevailing condition of the assets. This can be done by visual inspections and physical condition assessment of equipment. FCA methodology is one technique to perform a PM program in a strategic and organized manner. To compare two or more facilities on a similar measuring scale, facilities must be evaluated using the same formal standards and approach. As equipment ages and deteriorates, the importance of a PM program becomes imperative. The first step of a PM program is to identify the equipment that requires PM, and the second step is to identify the present condition of the equipment. FCA methodology is a part of the PM program that includes working through a structured methodology, inspection of checkpoints, scheduling assessment, and offering decision making on maintenance action without compromising on job safety, downtime, and component damage. PM programs should also identify failures prior to breakdown and avoid the costs and losses likely to be incurred otherwise. Identifying failures would generate continuous work order flow to the shops and eventually reduce the reactive maintenance percentage. In the physical plant type of facility, reactive maintenance is predominant over proactive maintenance. They lack measures and statistics to quantify the percentage of reactive and proactive maintenance, as they do not perform significant amount of proactive maintenance. Since FCA methodology enables a proactive maintenance approach, it can generate more proactive work orders for shops. By practicing this methodology, quantifiable numbers of work orders would be generated and would eventually reduce the reactive (corrective, emergency, and breakdown) service calls. 


\subsubsection{Lack of Corporate Memory (CM) in Maintenance Management}

The coherent integration of dispersed knowledge and information in a corporation is called "corporate memory." CM is achieved by improving the ability of an organization to remember the lessons learned across multiple fiscal periods, such as turnover in key personnel and changes in leadership, and sharing that information at work using the available technology. There is an increasing industrial interest in the capitalization of theoretical and practical knowledge of groups of people, equipment, and facilities in an organization that are dispersed geographically. A good working corporate memory will recapture the time, material, and action lost by not retaining the important knowledge (knowledge is power) and information. In universities, the buildings are usually dispersed geographically and are numerous (similar to WVU). The different facilities in all these buildings have to be maintained in proper working condition irrespective of the geographic dispersion. On a daily basis, physical plant receives service or complaint calls that need to be checked and corrected according to the deficiency. Apart from these calls, maintenance workers are in the field on regular inspection. They identify deficiencies and generate work orders to the corresponding shops.

All these deficiencies are corrected based on men, money, and time availability. Aging of facilities is also one of the major reasons for deficiencies apart from unattended maintenance. All these deficiencies and their corrections or repair or replacement action are not recorded in a structured and strategic manner. FCA is one of the techniques to improve corporate memory in maintenance management. FCA is a methodology to inspect a facility based on its physical condition. It is a systematic way to assess a facility in identifying specific maintenance, repair, or replacement requirements. A facility condition assessment program provides a comprehensive evaluation package that can be used to make critical management decisions based on the facilities' prevailing condition.

Once the assessment is completed and deficiencies are identified, corrective measures are to be taken. These corrective measures are to be recorded for future reference towards similar decision making and knowledge sharing. At present, maintenance work is done after receiving complaint calls or through routine maintenance and not through a complete assessment of the facility in a timely fashion. On completion of any maintenance work, the information is not recorded in a structured manner by the appropriate facility profile or history to record the lessons learned. 
Hence, reinventing the wheel is becoming a common approach to solve similar problems. The situation could be the same when a maintenance worker is transferred or promoted or retired, and the knowledge base in the shop is not in place to retain critical departmental information where it was created and needed. Hence, equipment details such as model number, serial number, capacity, type, manufacturer, location, etc., becomes critical to track and retrieve for future reference. To solve the problem in having a structured "corporate memory" towards maintenance management, FCA methodology will be a powerful tool. No significant evidence can be found in literature that includes corporate memory in FCA.

\subsubsection{Reduce Risk (further) in Investment and Budget Planning}

Possibility of occurring loss is a risk. Loss can be in terms of injury, equipment damage, overtime payment to workers, investment in one facility leading to expenditure in another, etc. Each dollar spent should be an investment and not expenditure. For example, if it is worth replacing a component or a piece of equipment instead of repair, replacement reduces risk in investment. Mountainlair and CAC cooling towers were built in 1967 and 1968 respectively. Both are equally in critical condition. When funds are available for only one, one tower has to be prioritized over another based on extensive evaluation in considering the overall condition index (OCI). For example, on an exam week, graduation, or game day, investing in that particular facility is worth more than taking a risk. The deficiencies identified from these assessments help in materials and man-power planning. Not enough evidence considering OCI is found in literature.

\subsubsection{Inefficient PM and DM Program}

The consequences of inefficient, preventive and DM can lead to catastrophic failures, fatalities, and losses. A few direct impacts follow:

- Impact on university quality and image.

- Dissatisfaction of students, faculty, and staff can lead to withdrawal and turnover.

- Facilities maintenance costs (material cost, overtime labor) would increase exponentially.

- Change in worker attitude (not sensitive to situation as management lacks policies and procedure for maintenance).

- Energy losses and excessive utility bills. 
- Risk involved in worker job safety (WJS), occupant safety, and environmental safety becomes detrimental.

- Increase in downtime and hindrance time.

- Property damage and equipment damage.

All these consequences are eventually associated with direct and indirect costs. These costs are not investments but are losses incurred due to failure and/or not having a structured PM program and DM reduction plan. Hence, these programs would indicate a declining trend on a university's performance because of deterioration and downfall of the university's assets.

Research in this area will help the facilities managers in physical plant type of industries to inspect their facilities and assess their physical condition in a structured methodology. An automated tool would prioritize the inspection results to use them effectively to reduce DM backlogs and start an efficient PM program.

\subsection{Research Objectives}

The need for research, shortcomings of the existing techniques in physical plant, and the lack of evidence in literature for condition-assessment time and cost savings, helped to determine the research objectives. At present, several months repair or replacement requirements are collected from the shop workers' from their corresponding zones. Ten important pieces of equipment are ranked between one and ten according to workers' priority. Based on each equipment priority assigned by workers, the priority number of all workers for that particular piece of equipment is added for a total score and ranked. The number prior to the building name in Table A and Table $\mathrm{B}$ of the appendix represents the priority, and the number on the right side is the score. This workers' input from their knowledge and years of experience helps to initiate action from management. But, this input has to be supported by some scientific measure through an assessment process. The exact condition of the equipment, repair or replacement decisions,

priority of the equipment, and cost estimation has to be performed. Worker input is very important in decision-making, but it should be part of the system and not the only system. 
Hence, development of an FCA methodology is one of the better-suited solutions for physical plant facilities. The aim of this research is to develop a tool that can support the facilities manager in having an in-house program that will save time and costs in assessment:

- To identify equipment that needs condition assessment.

- To evaluate equipment at component level and reduce the inspection time in [4].

- To guide the workers through the inspection process with checkpoints in components.

- To identify the functional value of each component to the equipment.

- To identify the impact (safety, downtime, and equipment damage) on physical plant and the university in the event of component failure or poor condition. This technique would eliminate a cost estimator and facilities condition index.

- To analyze the repair or replacement decision-making process.

- To determine factors and levels to measure and score the equipment.

- To determine a formula to prioritize repair jobs for the equipment and their components. .

- To be used by workers without extensive training, without hiring consultants, with minimum assessment time, and zero costs for assessments, at any physical plant and any size.

- To capture all the above equipment details for corporate memory in maintenance management.

An FCA methodology must be a visual inspection of all the facilities responsible for heating ventilation and air conditioning. More than inspection, it must be an assessment technique, a source for identifying the physical condition of the facility, its functional value, and maintenance deficiencies. From the literature review, it is evident that facilities assessment was related more to cost estimation. The assessment cannot be performed without a cost estimator. But, this research has eliminated the use of a facilities condition index, which is a very tedious process in finding the cost of deficiencies and current replacement values. In this research, the assessment is performed considering the risk potential factors such as worker and environmental safety, component and property damage value, and time taken to repair or replace components/equipment.

The FCA must also be a decision making tool that prioritizes the maintenance activities or actions to be taken in a sequential manner. It identifies the most crucial facility and its components that need to be given first priority. It must also have data recording capability that 
can be analyzed and converted to useful information. Prioritization and recording capability is not evidently found in the FCA techniques explained in the literature.

For this thesis, mechanical equipment is considered for the design and assessment of the tool as they are directly involved in generation of heating, ventilation, and air conditioning. The equipment includes air handling equipment, air compressors, boilers, chillers, cooling towers, heat exchangers and water heaters, pumps, steam distribution systems, and unitary heating and cooling. Analysis, testing, and validation are performed as a test case on the cooling towers. FCA's design and methodology are explained in the later chapters of this thesis.

Considering all the above-mentioned consequences and facts about physical plant, development of a strategic process becomes a crucial start. A process must include structure, methodology, analyzing, and recording capability. A process should also be feasible to perform within the given conditions and resources. A model process flow chart is shown in Figure 1.2 for developing an automated tool. 


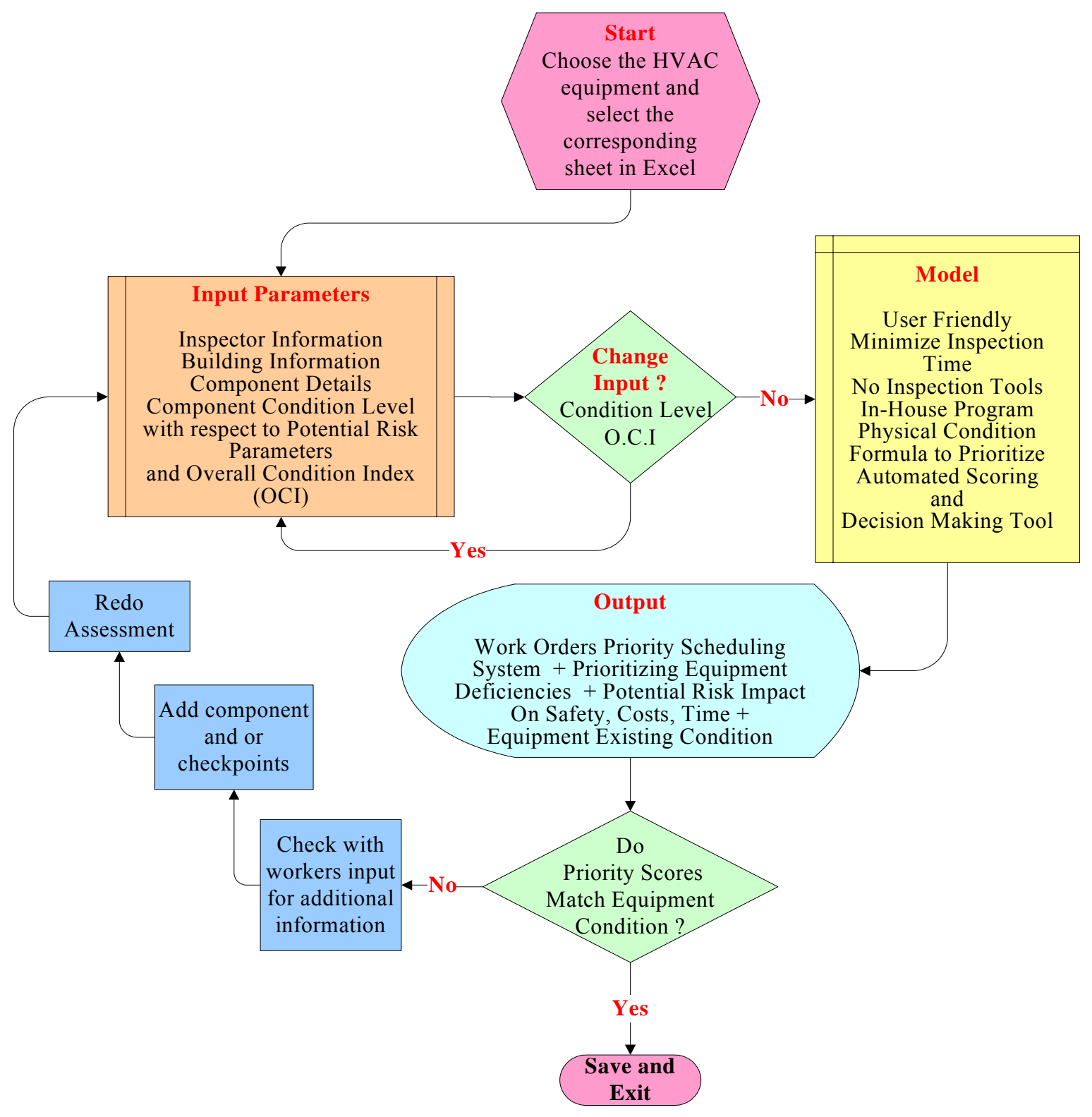

Figure 1.2 HVAC Conditions Assessment System Flow Chart 


\subsection{Conclusions}

Physical plant has the responsibility for university's assets (facilities) in good working condition and for achieving the desired performance from each facility. The mechanical and operations department directly controls the maintenance activities of the physical plant. To reduce the number of work orders called in by the students, faculty members, and staff, facilities are to be maintained in their best functional value. Deterioration, age, and shortage of resources are contributing to the failure of facilities apart from the usage wear and tear.

The need becomes imperative, as a structured methodology to evaluate HVAC systems is not seen in the literature. Only a PM program and a DM reduction plan can improve the university's assets. FCA methodology is a technique that includes a structured and systematic manner of inspection. Hence, it becomes imperative to adopt an FCA methodology to avoid catastrophic failure and loss to facilities. An FCA helps in achieving quality in facilities management and the university's growth and sustenance. 


\section{Chapter 2 - Literature Review}

\subsection{Background}

All universities face challenges with facility renewal and replacement backlogs. Many universities operate with insufficient facilities, unusable classrooms and laboratories, inadequate libraries, etc. Universities face similar problems with old equipment serving buildings with heavy maintenance costs. In some places, equipment is over utilized and at a few places, new equipment is underutilized. Building renovations do not always include replacement of older equipment or facilities. DM backlogs show hundreds of millions of dollars needed. The problem is not only financial but also the inability to meet the growing proportion of students, faculty, and staff members with facilities requirements. To handle these facilities requirements, new construction and renovations take place. The increase in the number of assets increases the maintenance requirements to meet day-to-day operations. But, the primary concern includes shortage of funds to maintain more equipment and limited training and education to operate more complex equipment, which leads to less frequent and reduced quality of preventive and predictive maintenance.

\subsection{No Decision Making Tool}

Many papers have been published about the causes and effects of DM backlogs. Comparatively, there is no structured methodology published for assessment of facilities or equipment on the component level and the different failure mode checkpoints. There exists no automated decisionmaking tool that can prioritize the corrective measures considering safety, costs, and time to repair or replace. These would serve as tools to reduce DM backlogs. The design of an FCA program creates opportunities to perform data analysis with the information collected. This information acts as a corporate memory and helps management's decision-making process. Adopting an FCA program, as a PM technique, would identify the deficiencies in the facility and prioritize the resources allocation appropriately. This in-house program would save thousands of dollars to physical plant. Otherwise equipment or facilities assessment would generally be performed through either manufacturers or consultants. In this paper, the assessments, 
prioritization, and data analysis of each facility is more relevant considering the facilities management resources.

\subsection{Preventive Maintenance (PM) and Benefits to Institutions}

"To meet the duties of a school board's specified statute, PM should be a key element in the board's mission statement" in [1]. By law, school districts have two main responsibilities regarding PM. They include, developing a PM program and implementing the same. A PM program is initiated through acceptance of the needs of the school and the development of a planned program to address the individual and different requirements of each specific system or its equipment. The first step in this PM process is to identify the facilities that require PM. Lists of systems are listed in appendix A in [1]. The second step is to determine the present condition of the facility and, depending on the present condition, PM action is initiated. This step includes gathering information about the equipment or facility (such as size, type, model, etc.) and condition assessment to determine the immediate and future need of PM for the system. To continue the process, the levels of maintenance and a work plan are needed. Depending on the resources availability, tasks are to be prioritized. Inadequate PM not only increases the rate of deterioration but also increases the risks for not qualifying for state aid for school capital projects in [1].

"Improved HVAC PM resulting directly from technician training has a significant energy savings potential, ranging from 6 percent to 19 percent of a typical community college's total energy bill” is mentioned in [2]. Nine campuses ranging from " 83,000 to 357,000 " square feet were considered for energy savings calculation from PM program. It was estimated that " $\$ 0.09 /$ square foot/year to $\$ 0.26 /$ square foot/year" annual cost savings is possible. The principal areas of concern in HVAC equipment were scale, corrosion, fouling of heat transfer surfaces, misalignment, improper lubrication, controls out of calibration, equipment operating unnecessarily, excessive parasitic losses, leaks and failure to utilize free energy sources. A list of equipment, the criteria for assessment (table 1), and also the energy saving calculation is in [2].

Duke University [3] uses a PM program and mentions that proactive maintenance helps to prevent equipment or system failures, extend life of mechanical machinery, and exceed customer 
expectations. This also reduced maintenance costs, labor overtime costs, and increased run time by identifying problems prior to failure. This shift to condition-based proactive maintenance improved the appearance of facilities. Reactive maintenance is the most expensive alternative, used on low-cost and easy-to-replace components, and the component or system must be noncritical to operations. The keys to starting a PM program are equipment and facilities inventory, maintenance standards, work generation, setting priorities, planning and estimating material coordination, determination of labor needs, organizing and staffing PM teams, integrating flow charts for the PM process, and establishing performance and effective indexes are discussed in facilities management - a manual for plant administrators.

"If a PM program is effective, each dollar invested in PM will result in significantly more than a one dollar reduction in remedial maintenance costs" in [4]. PM is an investment and not a cost. Maintenance workers' input is becoming vital for a successful PM program. The advantage of knowledge and years of experience in maintaining equipment is valuable information for management. This also makes a worker feel part of the PM program and improves his involvement and commitment to the institution. The PM program increases availability and improves the reliability of a facility. Proper information about equipment and the facility helps management in directing the maintenance efforts to the most critical job. Productivity is increased as a result of PM due to reduction in the number of breakdowns, service interruptions and emergencies. Quality of service (indicated from the number of complaints about a facility) and safety (ensured without accidents) are also important benefits from PM in [4].

Failure of equipment is often due to wear and tear on parts that should be replaced on a periodic basis, such as filters, belts, seals, bearings, valves, gaskets, etc. By attending to these problems on a periodic basis, component deterioration can be minimized. These material and labor costs for replacing are to be compared with unexpected and catastrophic failures that will occur. "An ounce of prevention is worth a pound of cure" [5].

To maintain a healthy workplace requires assessment of health risks from hazards. The term "sick building syndrome" (SBS) is becoming a reason for ailments that cannot be found medically. Symptoms, such as headaches, eye, skin, nasal complaints, lethargy, and irritability, are most common. Naturally ventilated buildings have less SBS complaints than HVAC systemsupported buildings in [8]. A prepared and planned maintenance in air handling units, cooling 
towers, and refrigeration units can minimize health problems. In air handling units alone, 28 different species of fungal spores have been found in [6]. PM on ducts, filters, and grills can avoid this problem. One of the most common SBS diseases, Legionnaire's from cooling towers, can be avoided by planned water treatment. A simple cleaning operation leads to reduced runtime, less noise, and pollution in [6].

If an air conditioning unit in a university residence hall breaks down or needs repair that is not planned, the residence hall may be closed for a period of time. This would incur costs for the university to arrange for alternative housing for students. The situation can be critical if the same incident happens during an exam week. There is a potential risk involved if the budget is not allocated to the right priority. It is important for facilities management to make the correct decision through scientific study before investing in facilities. Hence, PM (assessment) helps in budget planning in [7].

The benefits of a PM program based on historical data in the USA [8] are in the following areas: downtime, manpower, costs, and useful life. PM eliminates the unscheduled downtime caused by equipment failures. Reductions of 40 percent to 60 percent are achieved within the first two years and up to 90 percent reductions have been achieved and sustained within five years. PM increases the manpower utilization (75 percent to 85 percent) by identifying the precise task, tools, material, and support needed to rectify a problem. PM reduces the maintenance expenditures in labor and material cost by between 35 percent and 60 percent in the long run. PM extends the useful life of plant assets by 30 to 60 percent, by detecting incipient problems and performing minor repairs and adjustments before damaging the equipment or a serious problem arises.

\subsection{Structured Approaches to Evaluate HVAC Systems}

\subsubsection{Boilers}

Boiler failures and remedial actions lead to large capital expenditures. The most common causes of catastrophic boiler failure includes fuel explosion (due to fuel oil atomizing and tip clogging), low water incident (due to improper function of low water level cutout controls), poor water 
treatment (leads to scale formation inside tubes and results in localized overheating and tube failure), contaminated feed water (due to makeup and condensate returns, leads to oxygen corrosion, leaks and severe boiler fouling), improper blow-down techniques (results in drum level instability, foaming, nuisance water-level alarms, moisture carryover in steam and super heater fouling), improper warm-up (leads to refractory cracking and damage with steam leaks), impact damage of tubes (due to poor soot blower alignment and soot blowing with wet steam causing erosion), severe over firing (overheat damage to refractory, tube, breeching, baffles, reducing overall strength), improper storage (lack of hot and dry storage and improper sealing) and pulling a vacuum (due to improper steam drum vents) in [9]. A safety control in boilers is a primary function of the system. In the event of an unsafe condition, the fuel to the burner is to be interrupted. The functions of the flame safeguard system are provided by pressure and temperature controllers, limit controls, interlock controls, firing rate controls, fuel valves, and flame detectors, etc. in [10]. Proper condition and functioning of these systems ensures safety. "Boiler life extension requires accurate condition assessment" in [11] lists the typical life expectancies for several key components subject to fatigue, corrosion, creep, and overheating. Most of the component replacement problems are related to corrosion and creep. These can be easily detected by visual inspections on a periodic basis. In [12], critical systems and components are prioritized based on the impact they have in safety, reliability, and performance. A list of components, such as drums, headers, tubing, piping, de-aerator, burners, fans, structural supports, etc., that contribute to all these 3 areas is discussed. In all of these papers, component checkpoints (to identify the failure mode of that component) could not be seen.

\subsubsection{Air Handling Unit (AHU)}

The maintenance of AHU is categorized into two internal loops, air and refrigerant. Filters take care of maintaining indoor air quality, and they protect components like the evaporator coil and fan from accumulating dust. Filter changing intervals can be determined depending on the pressure drop and dirt accumulation based on visual inspection. Evaporator coil dirt reduces system airflow and directly degrades the coil's heat transfer efficiency. This significantly cuts the cooling capacity. Checking coil cleanliness by measuring supply fan amperage and filter/ coil pressure drop and comparing with fresh filters or new coil can determine the need for cleaning. Supply fan have bearings that needs to be lubricated. Excessive noise, vibration, or heat emanating from the bearing can be a warning sign. Over-greasing is as much of an under- 
greasing. The drain plug is to be checked for excess drain. The direction of rotation of the supply fan is also a possible problem. Fan belt slip, worn belts, and belt alignments are common belt problems. "It makes sense to preempt breakage with scheduled replacement because replacing a belt set for a 10 -ton unit would cost $\$ 5$ to $\$ 10$, while a service calls to replace a broken belt costs \$65." Fan motor burnout is also an important concern. An outside air dampers' improper operation is a common AHU problem. Damper service would include cleaning, lubricating, and testing damper movement. Cabinet integrity is a very important factor for holding the expensive chilled air by maintaining access panels without leaks. Refrigerant charge in the direct expansion cooling system is to be checked for undercharge or overcharge. An expansion valve system's malfunction can be due to the sensing bulb or internal spring screw. The compressor should be tested for electrical wires, motor winding, and size of wires. A condenser coil dirt can reduce the efficiency. Condenser fan and motor should be checked for seals, lubrication, noise, heat, and vibration. Maintaining and inspecting these units at regular intervals would reduce energy costs and avoid expensive repairs in [13].

\subsubsection{Cooling Tower}

Routine cooling tower service, including visual inspections, mechanical maintenance, and a physical cleaning program designed to maintain year round system cleanliness, will provide a return on investment. "A regular maintenance program for cooling towers can reduce operating costs and improve system efficiency" in [14]. Effective water treatment programs can avoid legionellosis. Corrosion of metal parts and erosion of system components, including tubes and seals, will increase equipment life. Without a proper structure guided tool, visual inspection is often overlooked. Water leaks, air leaks, pre-strainer clogging, bleed-off tank, and operating pressure should be checked. Mechanical components are to be checked for unusual noise or vibration from pumps, motors, and fans. Tower fan and drive system assembly should be checked for loose mounting, hardware condition of fasteners, grease, and oil leaks. Check gearbox oil level or belt tension. Tower structure, tower basin, safety rails, and ladders are checked for corrosion and other deterioration. Water distribution and quality, sump water level and nozzle clogging should also be checked. All electrical connections are to be checked for insulation, voltage, and amperage. In this paper, the components are categorized and also the checkpoints are mentioned in a detailed manner. This would definitely provide good direction for to maintaining and assessing a cooling tower. The paper also emphasizes regular visual inspection, 
proper mechanical maintenance, and tower cleanliness that would lead to equipment reliability, economical operation, and safety.

\subsubsection{Air Compressors}

The three most expensive items in operating a compressed air system are inadequate and inefficient controls that waste energy, production loss due to improper maintenance of the system, and air leaks in [15]. This paper describes condition monitoring that provides vital information for PM of dirty inlet air filters, fouled inter-stage coolers, and excessive wear of components. By monitoring key parameters such as inlet and inter-stage pressures and compressed air temperatures, PM can be performed rather than emergency maintenance. In this paper, some troubleshooting tips are also suggested such as air filter maintenance, motor overload, low water pressure, and oil filter maintenance, as well as the probable causes and remedies to correct these problems. The main focus of this paper is on compressor controls, such as start/stop, load/unload, modulation, dual/auto dual, variable displacement and variable speed. It also explains the purpose of these controls toward monitoring the air system and providing maintenance alerts. The benefits of monitoring an air compressor and troubleshooting and the physical condition of the component directly relates to the performance of the system in [16]. For example, the high pressure drop in an oil filter and high air temperature can occur at the same time due to a clogged oil filter that can restrict the air flow causing the high temperature condition. The hidden costs and inefficiency caused due to dirty inlet filters, and monitoring and correcting all compressor functions significantly reduce energy and maintenance costs in [17].

\subsubsection{Steam Distribution Systems}

In order to ensure that the steam distribution systems' components like pressure-reducing valves, temperature control valves, steam traps, etc., operate trouble free, it is essential to perform maintenance throughout the entire year and not just by annual shutdown. Steam utilization [18], considering steam trap fault, water logging, condensate management, flash steam recovery, etc., is discussed. Visual testing of steam traps, temperature control valves, pressure reducing valves, steam meters with symptoms, etc., is presented. Controls and regulators are used to maintain ideal temperature, pressure, and flow control. Steam traps are for efficient drainage of condensate for maximum heat transfer by trapping the steam. Flow meters measure the liquid quantity. Drain 
traps and liquid traps increase the system efficiency. Filters increase the productivity by proper filtering of fluids. Steam generated in the boiler must be carried through pipelines and distributed to the utility points. To perform this process in an effective manner, the steam header, steam line reducer, steam separator, steam strainer, steam drip stations, safety relief valve, actuators, air regulator, etc., and their importance in control and regulation of steam are discussed. This published manual helps to understand the steam distribution process and its various components towards energy savings and maintenance.

\subsubsection{Chillers}

The different types of chillers are absorption chiller, screw chiller, rotary chiller, reciprocating chiller, and centrifugal chiller. Machine tightness, capacity control valve, cooling tower by-pass valve, ball check valve, return valves, valve diaphragms, pumps, solution spray headers, etc., are listed in [19] as part of a PM schedule. Lithium bromide solidification, air leakage, machine shutdown on safety control, etc. are stated as a trouble shooting guide in [19]. More than the physical components, maintenance is more focused toward the performance characteristic factors or operating factors, such as cooler water temperature, condensate water temperature, generator temperature, capacity control valve position, purge tank level, evaporator water temperature, etc.

\subsubsection{Motors}

To prolong the motor life and predict a motor failure, a sequential maintenance procedure is needed, the motor being the most important part of an HVAC system. Studies have shown that mechanical failures are the main causes of premature electrical failures in [20]. To reduce maintenance costs, the problems need to be detected at an early stage so as to allow better maintenance planning and lessen the chance of unexpected failures. Preventive and predictive maintenance programs for a motor are important, because if and when they fail, the unexpected downtime may be extensive. Weyerhaeuser Corporation has developed a motor maintenance program to determine the reason for motor failure and steps to avoid the same failure in future. This program is explained as a flowchart in [20]. Motor failure is to be analyzed by checking windings, bearings, starter, and wiring and steps should be taken to rectify the problem. During the damage analysis, the damage can be major with winding, bearings, end bells, shaft, rotor, stator, and balance or minor with bearings and balance. Once this is identified, a decision- 
making need arises whether to purchase a new motor or rebuild the existing one. "If it is a critical application and running more than 8000 hours per year" a new motor should be purchased. PM on motors to avoid catastrophic failure includes voltage imbalance, motor ventilation, alignment, lubrication, and full-load considerations. Predictive maintenance such as motor temperature, vibration, insulation considerations, insulation resistance test, surge test, DC high potential test, polarization index test, and infrared thermograph should be performed to reduce maintenance costs by early detection. The causes and remedies for all these maintenance points are also explained in [20]. This paper explains motor maintenance problems and remedies in a detailed and structured manner, but no comparison or ranking the priority in rectifying the problem or replacing the motor is discussed.

\subsubsection{Heat Exchangers and Water Heaters}

Coils are the most important component in a heat exchanger and water heater. To increase the efficiency of equipment, typical changes include fins per inch increase, increase the face area of the coil, enhanced fins to increase airflow, and greater vortex of air passing through the coil, and these are discussed in [21]. All these changes increase the risk of corrosion, dirt, and dust accumulation, reducing the efficiency. Scheduled cleaning removes corrosion, accumulated same dirt, soils, insect residue, etc. Alkaline, acidic, and surfactants, cleaners remove deposits on the surface of the coils. A filter over the face of the coil can prevent deposits. Filters clogging and air blocking are to be checked. Corrosive resistant coatings can also prevent damage to the coil.

\subsubsection{Pumps}

The consequences of inadequate alignment are premature deterioration of couplings, bearings, and seals. They also create dynamic stresses on bearings and couplings, distort the shafts, and wears clearances in close running seals. These are discussed in [22]. Misalignment usually creates some abnormal noise and vibration. To evaluate or recognize any misalignment, vibration analysis is generally used. The identification can be done by performing checks such as repair history of failures of couplings, bearings and seals, binding, fluid leaks, loose bolts, cracks, abnormal noise, and excessive temperature. 


\subsubsection{Evaporative Coolers}

Periodic inspection of potential scaling, biological fouling, dry spots, fan lubrication, motor bearings, belt tension, bleed-off, filters, cabinet cleanliness, water distribution system, recirculation pump, etc., along with recommended annual/periodic maintenance would result in good operation in [23]. Air quality, water quality, chemical treatment, and humidification are discussed in this paper. "A clean water system is the most important aspect for maintaining an evaporative cooling system." This paper discusses more about the design of evaporative coolers, though it is a guide for operation and maintenance.

\subsection{Evaluation of Industrial - Physical Plant Type of Systems}

P.F. Sherman Company Inc. has reported the physical condition of the cooling towers in Mountainlair and CAC at West Virginia University. The report [24] explains the condition of the Marley cooling tower at the CAC by listing 13 components, such as casing, fan deck, hot water basin, structural lumber, fill, drift eliminators, air inlet louvers, cold water basin, gearboxes, drive shaft, fan cylinder, oil drain line, and structural tie rods. For example, in the hot water basin, the comment is "Poor condition. Plywood is weak causing leaks under seals mid-span of supports". A similar report is also submitted for the Mountainlair Marley cooling tower with the same 13 points, but the hot water basin is referred as distribution the basin, and the comment is "Plywood floors appear to be intact. Hot water basin seals are bad for the entire length of the basin. Flow control valves are not operational." These reports are made after evaluating the cooling tower. During the evaluation process, the representative of this firm made a visual inspection and identified the physical condition. The physical condition was noted as to how it was seen during the field visit and the reports are generated with opinion as in the example shown above. These reports do not have any substantiated evidence such as scoring or a quantitative measure to support the document.

RMF Engineering [25] is focused on developing, expanding, and rehabilitating central utility plants for colleges, universities, and institutional campuses. The approach used by RMF is to analyze major systems and sub-systems at macro and micro levels. This approach includes the review of all usages, occupancies, operating schedules, and alternate technologies to meet the 
demand. The next step is a system analysis, considering initial and maintenance costs, and adaptability of the system. Services include survey, planning, design, and commissioning of chillers, cooling towers, pumping systems, piping, and valve replacements. Some of the key technical issues to be addressed include the physical condition, efficiency, and operational reliability of the existing chillers, pumps, cooling towers, and piping. System analysis is performed and reasons to repair or replace the current equipment, based on its physical condition, are reported. Campus-wide utilities infrastructure and chilled water improvements were performed in various schools like Dartmouth College, The College of William and Mary, University of California San Francisco, Gallaudet University, University of Maryland Baltimore, Emory University, Harvard University, North Carolina State University, University of Virginia, and West Virginia University.

Risk assessment flowcharts, hazard identification, and risk assessment checklists were generated to evaluate the risk level and the risks that need more analysis. Using this same technique, risks were ranked and priority-based decisions were made for Chevron Nigeria Offshore facilities in [26]. The risk assessment procedure consists of identifying the risks that could lead to significant loss, calculation of risks, alternate protection and prevention strategies, and estimation of variation in the probability. The risk identification is for potential hazards such as hazardous substances, work environment, radiation hazards, electrical hazards, mechanical hazards, and work activities. These risks were classified into high (10 to 14 points with probability factor 0.57), medium ( 5 to 9 points with probability factor 0.33 ) and low (0 to 4 points with probability factor 0.1) exposure levels. Dividing average weighting values of each level with the sum of three average weighting values derives the probability factor. Probability multiplied by the points generates ranking and the highest number is attended immediately. The assessment was performed for processes such as facility layout, compressors, storage tanks, instrumentation, pumps, fired heaters, pressure vessels, emergency response, exchangers, and human factors, considering various factors on each. For example, compressors were assessed with 16 factors. Personnel safety, property conservation, and environmental impact are considered and analyzed for process safety equipment, fire and gas exposure, and site-specific safety factors. The checklists of factors in each type process are of yes or no type with three risk levels. The "yes or no" data collected are not used in the model and do not affect the risk level. The highest ranking is picked by the maximum number of risks in that level multiplied with the probability factor. In 
this case, 10 high risks and 17 medium risks are approximately equal when multiplied with 0.57 and 0.33 , respectively. Hence, the weights assigned to risks level is not prioritizing risk ranking.

A facility management (FM) audit is a process to compare the organization's resources, such as staffing, services, physical facilities, and financial performance to internal and external benchmarks in [27]. The FM audit process is of two types, one is a four-month project using outside consultants for data collection, benchmark, and analyzing and the other is a six-month project using internal staff. In this later case, a consultant would guide the staff through the process. An FM audit is explained in Figure 1 in [27] with a time line for each step in the process. An FM audit also lists rules of thumb, such as customer opinion benchmark, consistent information, etc. The audit examines facility performance in information resources, such as customer satisfaction, facility facts, financial facts, organization and resources, change data, and benchmarks/research. For example, in customer satisfaction, quality of facilities is assessed for appearance, health, housekeeping, construction, space planning, and comfort (HVAC, lightings, acoustics, etc.). The opinion on the quality of these facilities leads to benchmarking costs. Facility facts would become the baseline data to compare with the customer opinion. Figure 4 in [27] shows the facility condition, HVAC, mechanical, fire protection, etc., per building. These are ranked into three categories, such as meets or exceed requirements, meet minimum requirements and do not meet requirements. In the financial facts, the cost of providing these facilities is analyzed and the remaining information resources are also considered. On analyzing the six information resources, the project priorities are found by listing project improvement, as shown in Table II in [27]. Considering criteria scale, average score, project complexity, process improvement, communications, and critical projects, the priority is set. Depending on the condition, they are assigned the corresponding level. The priority attained was not found to be explained in the literature.

Over time facilities continue to degrade in quality and performance, but the results are not immediately apparent. A post-occupancy evaluation (POE) is a process by which the potential degradation of quality is identified [28]. The POE process is directed toward technical, behavioral, and functional evaluation, of a facility's performance. In the technical evaluation elements such as safety, health, security, and performance of a facility are considered. In the behavioral evaluation, elements such as social interaction, privacy, transmission capacity, and territoriality are considered. In the functional evaluation, elements such as workflow, 
productivity, operational efficiency, and the organization are considered. The POE process has three levels, such as indicative (major failures and successes), investigating (reliability assurance by detail evaluation), and diagnostic (in-depth physical measurements, observations, survey). To conduct a POE, planning, conducting, analyzing, and applying are the four steps. Once these steps are performed, priorities are developed based on life-cycle cost/benefits as opposed to an initial cost basis. The objective of this paper was to create a process and later develop a cost model based on this strategy. Financial, maintenance, and operational models with a shared database is to be integrated to further work on this model.

Major disciplines such as structures, reactor engineering / operations, risk management, and materials were divided into 35 (eight systems) subsystems for assessment. The subsystems include the cooling water system, supplementary safety system, emergency cooling system, moderator recovery system, river water system, water removal and storage system, service raw water system, and service clarified water system. These subsystems were ranked with six attributes, namely, safety classification, degradation material, difficulty of replacement, failure mode, radiation dose to workers, and consequences of failure. Each attribute was assigned a set of consequences with corresponding weighting scores. Table 7 in [29] shows a matrix with disciplines and attributes assigned rankings in the range from 1 to 10. Each attribute is summed considering all the disciplines. The weighting factor is found by dividing each attribute sum to the total score of all attributes. During assessments, the weighting factor is multiplied with each attributes classification numeric value. For example, during assessing the cooling water system for degradation problems, there are have 3 levels such as severe, moderate, and low with 4, 2, and 1 respectively. Evaluation of structural integrity is based on the priority ranking score. The priority is classified into two levels; priority 1 is for the subsystem's normalized score which is above or equal to 50 , and the priority 2 is a subsystem score that is less than 50 .

\subsection{Existing Methodologies for FCA}

Naval Facilities Engineering Command (NAVFAC) [30] published manuals on inspection of shore facilities for public works and public utilities departments. The purpose of this program was to create a process that would reveal the physical condition of shore establishments. The objective was to create a continuous inspection program comprised of operator maintenance, PM, 
and control maintenance. The control maintenance inspection procedure consists of a facility inspection checklist, facility condition summary report, and a facility condition deficiency report for every facility. The facility inspection checklist classifies facilities as satisfactory or unsatisfactory. The facility condition summary provides labor hours and cost by trade and material to restore the facility. The facility condition deficiency report lists description, cost of correction, and urgency of the facility.

The PM inspection procedure consists of a record card and an inventory and tracking record. The record card is for a checklist of descriptions of deficiencies, actual time, date, and inspector initials. It is primarily concerned with items that, if disabled, would endanger life and/or property and/or require long lead time to restore. The operator maintenance procedure is a procedure that requires assignment and attendance of an operator. The PM inspection procedure is to be performed for this maintenance.

Procedural guidance and inspection guides needed to perform control inspection were published in NAVFAC [31]. This manual includes inspection guides for structural, electrical, mechanical, and roofing. For this thesis point of view, considering only mechanical equipment, this method consisted of inspection instruction and repair/replacement criteria. The inspection instruction includes but is not limited to air-conditioning, air handlers, boilers, heating, piping, steam utility systems and water utility systems. The repair or replacement criterion is also defined for these pieces of mechanical equipment. This manual is to be integrated with NAVFAC [31] to obtain a condition assessment program for control inspection. NAVFAC Volume III is the instructor's manual for a control inspector training course. In these manuals, the Department of the Navy also established facility inspection time standards for different types of facilities.

The National Association of College and University Business Officers (NACUBO) [32] published a book Managing the Facilities Portfolio on facility renewal and DM. The primary focuses was to establish a detailed and structured inspection process, estimate short and longrange renewal needs, create decision support models, and a facilities report portfolio. The inspection process times are referred from NAVFAC [31]. Priorities to repair are defined based on time. The deficiencies and correctional action are set priorities based on the needs of that year. The priority varies from 0 to 5 , indicating immediate to five years. The facilities condition and the deficiency are reported as a listing with labor hours and material hours calculated from 
NAVFAC [30] using NAVFAC [31] standards. The overall facilities condition is expressed in terms of a "Facility Condition Index (FCI)", the ratio of cost of deficiencies and current replacement value. The three ranges of FCI, less than 0.5 , between 0.5 and 0.1 , and greater than 0.10 are related to three conditions rating, Good, Fair, and Poor respectively. This benchmark of priorities is the method for restoring facilities.

An FCA has two levels of surveys; level 1 and level 2 assessments are performed at "3D/I" [32]. A level one assessment is a mathematical model to determine the facilities condition, based on the life cycle of the component. From this the capital renewal cost is obtained. Level two is the inspection of existing facilities and the reporting of the current deficiencies. A comprehensive facility evaluation of both current deficiencies and future renewal costs are obtained by adding level one and level two values. Each deficiency is categorized into four priorities 1, 2, 3, and 4. Priority 1 being that directly affects the educational mission, priority 2 being that which indirectly affects the educational mission, priority 3 being that which is beyond the expected useful life, and priority 4 being that which requires finishing and improvements. Each deficiency is classified into one of the following categories; life safety code compliance, building code compliance, accessibility code compliance, capital renewal, DM, energy efficiency improvement, and hazardous material. Each deficiency is assigned one of the adverse effects such as campus closure, safety hazard, program disruption, code violation, greater future damage, and inconvenience. The facilities are compared using the same idea as that of facilities condition index in [32]. All these tasks are performed on software called 'Condition Management Estimation Technology.' The only difference of this method from [32] is the classification in the deficiencies into priorities, categories, and adverse effects.

There are many FCA vendors following the same idea of FCI [32], with minor changes to their priorities and classification of deficiencies. Companies possess software that integrates and analyzes this information. A structured methodology to assess facilities is not available and not reported. These are the most expensive ways to conduct an assessment.

Description of the building component, an analysis of building conditions, and an overall rating of a building's condition are the three purposes of a facilities audit. In this facilities audit methodology, physical evaluation is categorized into primary structure, secondary structure, service systems, safety standards, and energy use efficiency. Maximum point values are assigned 
to each category and the maximum point for each facility comprised of all these categories would have 100 points. A facilities physical evaluation is performed by classifying each system into satisfactory, remodeling $\mathrm{A}$, remodeling $\mathrm{B}$, remodeling $\mathrm{C}$, and unsatisfactory. For example, service systems include electrical components, cooling, heating, plumbing, and conveying. These classifications are the benchmark for this method defined by the replacement costs. These classifications are assigned condition multipliers as $1,(0.8+$ or -0.1$),(0.5+$ or -0.1$),(0.2+$ or 0.1 ), and 0.0 for satisfactory, remodeling $\mathrm{A}$, remodeling $\mathrm{B}$, remodeling $\mathrm{C}$, and unsatisfactory, respectively. A point rating system is developed for each of the physical categories, for example, service systems is comprised of five sub-systems including cooling, heating, plumbing, electrical, and conveying. These are assigned maximum point value of $10,10,5,8$, and 1 respectively. If a heating system is evaluated, they are assigned condition multipliers based on easy on difficult, correcting the cost of the component, and multiplied with the maximum point value to attain a numerical rating. Similarly, when all categories are completed, they are added and compared with the maximum points (100). When different facilities are evaluated, they are ranked based on the point rating, and facilities with lesser scores for 100 are considered for immediate action in [34].

Identifying the failures and determining the consequences of these failures with their frequency of occurrence a facility risk review (FRR). For example, the consequences of a failure are grouped into production loss (with respect to time), equipment damage (with respect to millions of dollars), public safety, and employee safety (with respect to health effects or injury). Each consequence has four categories and is assigned separately in Table 1 of [35]. In Table 2, the frequency categories are listed as extremely unlikely to occur; not expected to occur during the lifetime of the facility; but expected to occur no more than once during the lifetime of the facility; expected to occur several times during the lifetime of the facility, and expected to occur more than once in a year. A risk matrix is formed for each consequence of failure, for example, equipment damage on $\mathrm{x}$ - axis and frequency category on $\mathrm{y}$-axis. The numbers are filled in the matrix correspondingly, and the increasing severity and frequency of risks move in the direction away from the origin on both axis. Low risk, intermediate risk, and unacceptable risks are decided based on the category levels. A list of information (14) is required to perform the FRR process of Table 3 in [35]. For example, process PM schedule, cost estimation for each component replacement, etc., is needed to perform an FRR. This is a valuable tool to reduce risks for complex plants, but it does not provide a detailed analysis of risk assessment. The U.S. 
Department of Health and Human Services has published System Safety and Risk Management manual, in which the risk assessment matrix model is explained with probability and severity of risks for use in hazard analysis, similar to this paper.

\subsection{Shortcomings}

The existing methods explained above for an FCA involves the cost estimation to replace and cost of deficiency for each facility to complete the process. Calculating costs for every facility is one of the most important tasks in these processes. Facility inspectors would not know the condition of the facility or the facilities requirements until they estimate the costs of repair or replacement. The shortcomings of these published materials are that they do not discuss a common methodology to assess and analyze any facility in a structured manner with guidance. The methods do not consider a holistic approach toward a facility in terms of safety, costs to repair or replace equipment, and maintenance time to restore each facility. There is no evidence of the risk exposure levels based on existing physical condition of the facility. Scheduling priorities for corrective measures were not built into the program design. Few papers focused in creating a process for assessment and few focused on prioritizing a facility on its condition.

From these papers, it is observed that there is no emphasis on facilities being classified to the component level. The assessment lacks guidance towards failure mode for any component. Lack of failure modes or checkpoints definitions does not provide a facility inspector a uniform platform to measure similar facilities. The rating system does not in itself set priorities. All these methods do not include any storing or recording system. No evidence is seen in these papers of the impact of a facility's failure or the impact on physical plant or university properties. To create a PM program, the methodology should be an automated and continuous process. Lack of a computer application (the programs built by consultants are very expensive for physical plant) on all these methods creates chaotic paper information. Tracking equipment or facilities inspection and condition reports are not easy. All these concepts are directly dependent on writing report of the inspection. Incomplete, inaccurate reports result in confusion, extra paper work, avoidable costs, and may endanger life and property. Inspectors should be instructed in inspection report preparation. Each deficiency should be reported in detail to explain the gravity of the condition. Assessment is dependent more a visual observing power, and the program design does not guide 
the inspector. The report should contain enough detail to enable a work order without revisiting the job site. Each deficiency report should define the problem, location of problem, and the corrective measure to be taken.

FCI is a benchmark method for buildings and infrastructure in schools and universities. The building evaluation report (BER) is for government. For other institutions and industries, there are no such standardized processes. Comments about FCI [32], such as a master plan, is needed before you perform FCA; estimates done by consulting engineers are not accurate; FCA is initiated from below and pushed up through to management; budgets are based on present costs, 10 percent of the engineering cost should be added to each piece of equipment replaced; data needs to be adjusted for more realistic numbers, etc. They also state that FCI is applicable for "not-for-profit" institutions and institutions that are there for the "long haul," published in Howard [36].

Methodology, inspection, evaluation, prioritization, risk exposures, and corrective action are not a single process. Organization mission, a major factor in prioritizing of workflow, is not considered. Hence, all these methods do not help in providing a real world tool to conduct assessments and making decisions.

\subsection{Conclusions}

Since proper utilization of funding, maximization of equipment availability, reduction of DM backlogs, continuous PM program, and prioritizing the work orders are key areas of concentration, an automated decision-making tool is needed to address these problem.

Optimum system performance depends on each individual component working at its design capability, and therefore a tool that defines any system into its component and sub-component level is needed. A tool that defines checkpoints and failure modes of any component by visual inspection is needed. A tool used for identifying safety standards, component repair or replacement value, and maintenance time in restoring the deficiencies is needed. A tool that can predict the probability of "repair, or replace, or do-nothing" is needed. A tool that can generate continuous work order flow to the different trades is needed. A tool that records updates and 
serves as a memory for maintenance management, considering the inspector, building, and equipment details, becomes a basic but critical requirement. Generation of FCA methodology satisfies all the above needs correcting the demerits of past research work. 


\section{Chapter 3 - Research Approach}

Methodology: To solve the present and future problems in knowing the exact condition of any facility, to make appropriate decisions in investing resources, and to make appropriate corrective measures towards repair and replace, FCA methodology is one of the best techniques. The program design should also meet all the objectives discussed in Chapter one. The two main reasons that led to the development of this research were lack of a single model in literature that could identify equipment condition and prioritize the repair and replacement need for a system and the lack of a DM reduction plan.

\subsection{Identification of HVAC Equipment}

FCA can be performed for any facility including Mechanical, Electrical, and Structural, etc. The focus of this research is in mechanical engineering and the equipment identified for further research and assessment study is heating ventilation and air conditioning systems. HVAC systems usually provide year-round control of several air conditions, namely, temperature, humidity, cleanliness, and air motion. The primary function of HVAC systems is either (1) generation or maintenance of healthy and comfortable interior conditions for occupants in a conditioned space or (2) supplying a set of environmental conditions (high temperature and high humidity, low temperature and high humidity, etc.) for a process or product.

In the United States, many people spend nearly 90 percent of their time indoors. In the year 2000 alone, over \$20 billion of air-conditioning equipment was sold in the U.S. If HVAC systems are not sized or maintained improperly, the desired environmental conditions will not be met. This will also lead to excess energy bills, high initial and maintenance costs, and in return, customer dissatisfaction and complaints. Due to improper maintenance and design features, energy consumption would be more. According to the U.S Department of Energy (DOE), buildings in the U.S. consume roughly $\$ 220$ billion worth of energy every year. Buildings account for 36 percent of all energy used in the U.S. energy use in a commercial building is as follows: heating (22.9 percent), refrigeration (16.4 percent), air moving (16.2 percent), lights (37.6 percent), hot water (.2 percent), and others (6.9 percent) [5]. Hence, HVAC systems have to be maintained 
well and the root cause for any technical problem should be analyzed statistically. This would save energy costs and maintenance costs along with preserving building occupants' satisfaction.

Facts explained above regarding the importance of HVAC systems in the world, lack of condition-evaluation models as explained in the literature review chapter, and the existing techniques followed in physical plant explained in Chapter one, created the need to identify and study different HVAC systems and equipment. The list of DM projects in Table A and Table B of the Appendix indicates the repair and replacement need for the equipment. Hence, the study of HVAC equipment is important to understanding the problem.

Hot water and/or steam can be generated from boilers. When the potential to generate steam using boilers (high capacity) is not available, steam can be purchased (at WVU steam is supplied by Morgantown Energy Associates) and distributed to the different facilities. Steam systems distribute and reduce pressures using reducing stations, and steam is converted to hot water using heat exchangers. Heating equipment can be classified into systems such as boilers, steam distribution systems, heat exchangers, and water heaters, as shown in Figure 3.1.

A chiller, as shown in Figure 3.1, uses a refrigerant to absorb the heat and reduce the temperature of normal water. This chilled water is allowed to pass through a series of coils, and air is blown over the coils. The chilled water in the coils absorbs heat from the air and cools the air. This air is distributed to the building space. The series of coils are part of the air-handling unit, as shown in Figure 3.1. They have a series of coils for both heating and cooling. Hot water is passed into the coils from the boilers or heat exchangers during winter and chilled water from chillers is used during summer. Cold air and/or hot air are passed through the duct system to the desired space. The cool supply air picks up heat in the conditioned space. The warmed air makes its way into the return air inlets, then into the return air duct, and back to the AHU. Return air and outside air is mixed in the mixed chamber in the AHU, to save energy. This cycle repeats in the AHU. The water, after picking up heat from the mixed air, leaves the cooling coil and goes through the chilled water return pipe to the evaporator in the chiller. The evaporator is a heat exchanger that allows heat from the return water of the chiller to flow by conduction into the refrigerant tubes. Heat is removed in the evaporator by the refrigeration process. The liquid refrigerant in the tubes is converted to vapor after removing heat from the water and conveying the heat to the compressor and then to the condenser. The refrigerant vapor is condensed to liquid in the 
condenser either by water-cooled or air-cooled methods. The air-cooled method uses outside air to condense the refrigerant. In the water cooled condenser, the heat from the condenser is conveyed to the cooling tower by the condenser water. A cooling tower, as shown in Figure 3.1, is a heat rejection system that extracts heat from the water and transfers it to the atmosphere. This difference in temperature saves energy in chillers and improves the efficiency of the process. To transfer any fluid from one system to another, pumps are needed. Depending on the application, types of pumps differ. These pumps are driven by motors, so, pumps and motors are an important part of an HVAC system as shown in Figure 3.1.

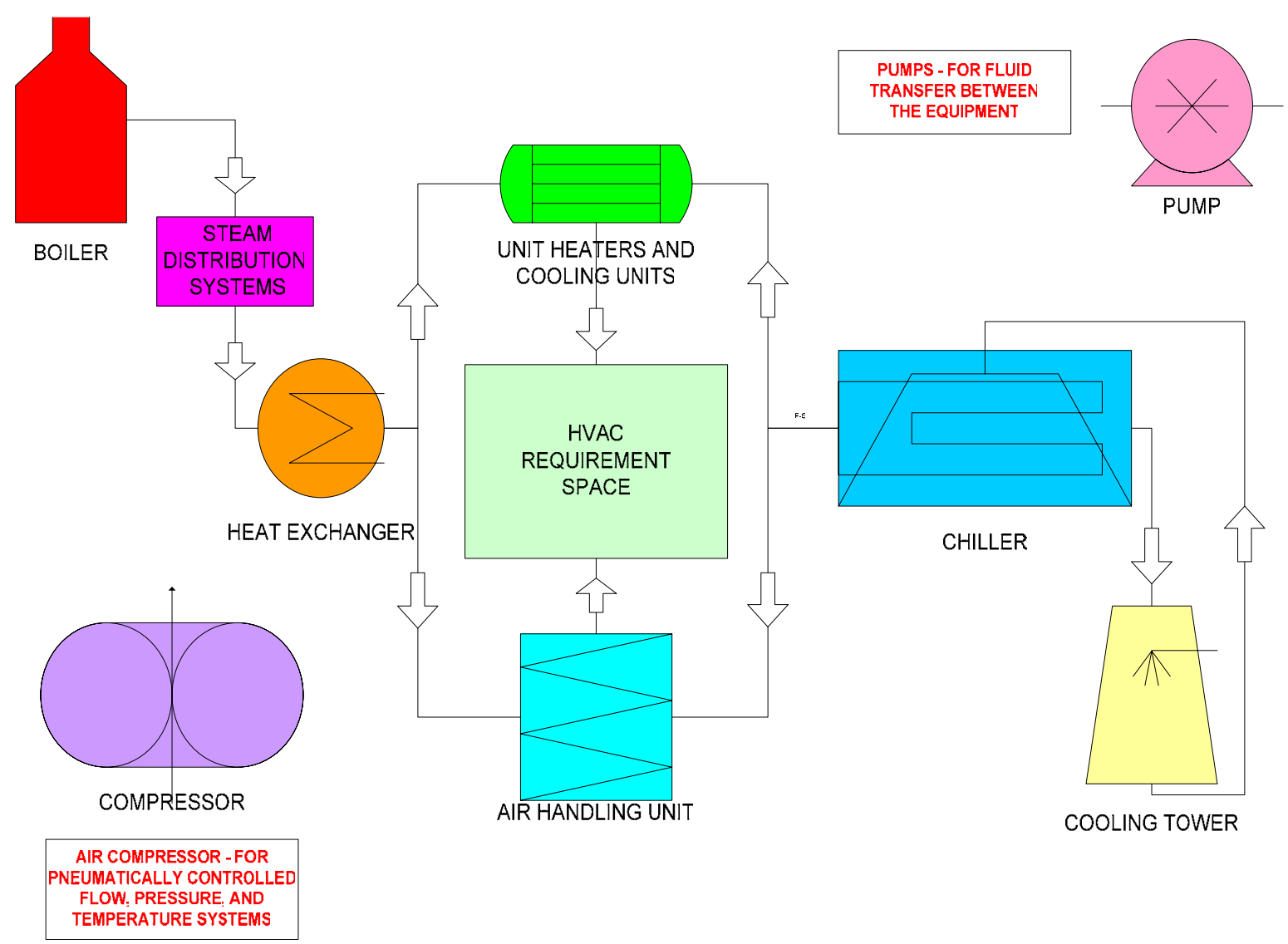

Figure 3.1. Identification of HVAC Equipment

The heating and cooling generation systems explained above can also distribute hot water and chilled water through a series of coils and blow air from the space into these coils to heat or cool the space. These types of systems are called unitary heating and cooling systems, as shown in Figure 3.1. They include fan coil units and unit condensers. The window air conditioners and electric coils fall in to this category, though the construction is different. These systems can be 
controlled from the space itself. Unitary heating and cooling systems can be a distribution as well as generation system.

To control and regulate the room temperature, thermostats are used. These thermostats are controlled by pneumatics or electronics. The air pressure in the pneumatic system is generated and maintained by air compressors. These thermostats in the room send a signal to the AHUs, boiler, steam systems, and chillers to increase or decrease the temperature of water and air. Pneumatics also control and regulate the pump, cooling towers, and steam distribution systems. Therefore the air compressor is one of the most important pieces of equipment in the HVAC system.

These days many building operations are controlled by direct digital control (DDC) systems. DDC systems are part of the building automation and energy management systems. DDC is a set of controllers, communication devices, and operational software. Controlling HVAC systems using DDC includes three main functions, such as measuring data, processing data into information, and causing a control action. The hardware units that perform the above three functions are sensors, controllers, and the controlled devices. A sensor measures the data, a controller processes the data into information, and a controlled device causes an action. A computer receives the input signals, computes the desired need, and sends the output signal to the maintenance worker. In this system, the computer is directly part of the control loop. In systems where the computer is outside the control loop, automated controls are operated by the conventional electronic or pneumatic control system. The thermostat and sensors send the signal to the valves and dampers. Computer monitors track and reset settings. The physical units that perform the work, such as valves, dampers, etc., and also the measuring units, such as sensors and thermostats, would be included in the assessment. Since all the nine pieces of equipment mentioned in the previous pages would have their own control system units based on design, manufacturers, model, etc., they should be included as components with checkpoints in the equipment unit. DDC systems would be considered and included, when necessary, but would not be a comprehensive assessment sheet. Hence, during the discussions with physical plant management, it was decided to include the control system as part of the equipment assessment. 
Apart from heating, cooling, and ventilating systems, support systems, such as pumps, air compressors, cooling towers, heat exchangers, etc., become part of HVAC systems. HVAC systems are divided into nine major systems, such as AHUs, air compressors, boilers, chillers, cooling towers, heat exchangers and water heaters, pumps, steam distribution systems, unitary heating and cooling systems, as shown in Figure 3.1, based on its purpose and usage, considering all buildings in attaining the desired temperature, humidity, pressure, ventilation, airflow, hot water, chilled water, steam, hot air, cold air, etc.

The irony of HVAC systems operation is that, when the system is performing to its desired level in providing comfort to the space, the maintenance workers' efforts go unnoticed and unappreciated. However, if comfort levels decline, the response expected is immediate. As the name implies, HVAC systems have to provide heating, ventilation and air conditioning to the building occupants, depending upon the season and, at times, both heating and cooling on the same day. The size of the HVAC system is completely determined by the building load, ventilation requirements, and type of use (e.g. lab, classroom, etc.). Building load depends on size of the buildings, number of occupants in the building, and various losses (leaks) in the building. The load will fluctuate depending on the occupant fluctuation. In a school, one class room can have 50 students in a particular hour and the next class may have seven students. The system has to supply according to the demand in the space. The construction year of the buildings varies from the 1900 s to 2000 . There were many buildings that were extended, and the HVAC systems for these extended portions were added to the existing systems. The HVAC system technology and complexity will also vary accordingly. For example, as a test case, a cooling tower study and assessment was performed in this research.

Cooling Tower: A cooling tower is a mass heat exchanger in which the hot water transfers the heat to the air (atmospheric temperature). A simple process flow of a cooling tower is shown in Figure 3.2. 


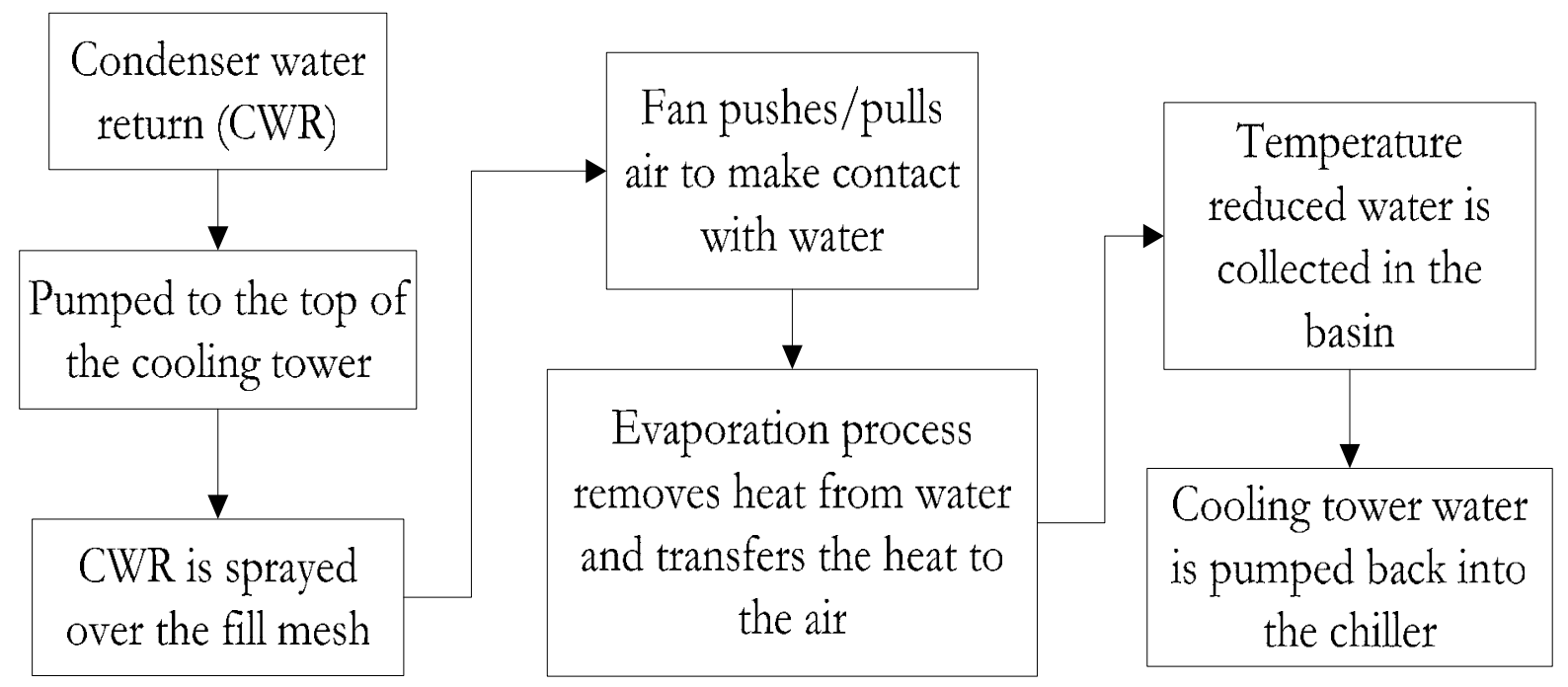

Figure 3.2. Cooling Tower Process Flow Chart

Types of Cooling Towers

- A natural draft cooling tower is a large concrete chimney that uses natural convective air moving up the chimney to cool the water that is sprayed from the top of the tower.

- Mechanical draft cooling towers utilize fans to force the air over the water. The water is sprayed down over fill surfaces that help to increase the contact time between the water and air and maximizes the heat transfer. The two different types of mechanical draft cooling towers with respect to design are counter flow and cross flow as shown in Figure 3.3 .

- Open loop: The hot water from the building is pumped to the top of the tower and water flows down through a series of baffles or plates and air removes the heat.

- Closed loop: Cold water is circulated in a closed pipe or coil and hot water runs over the pipes or coils for evaporative cooling. 

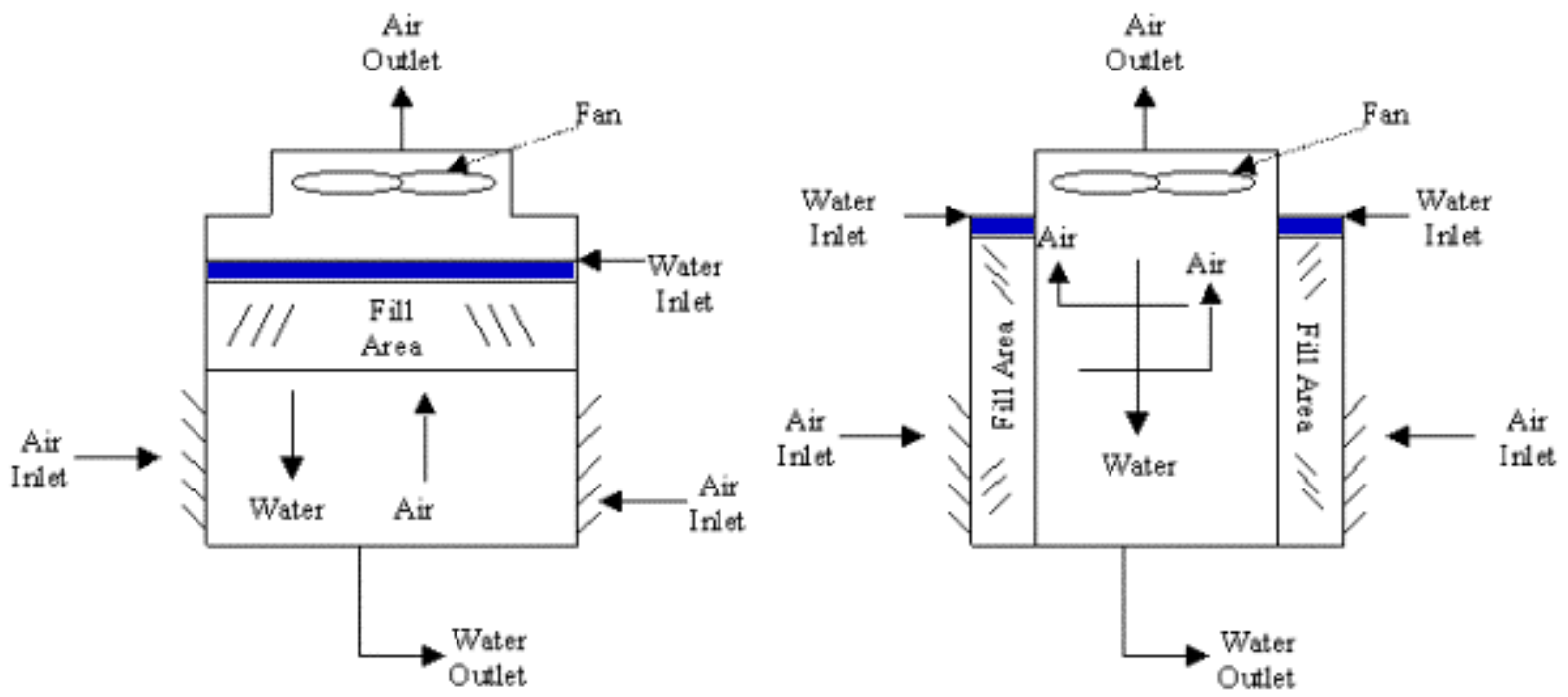

Figure 3.3. Counter Flow Cooling Tower and Cross Flow Cooling Tower [47]

Depending on the type and location of the fans in a cooling tower, they are called "forced draft" and "induced draft" cooling towers. The evaporation process rejects the heat from water when air and water are in contact in the tower.

- Forced draft: Fans located at the bottom of the cooling tower push air up through the tower.

- Induced draft: Fans located at the top of the cooling tower pull air up through the tower.

The principle appears to be very simple, but the heat transfer process is complex. To improve the heat transfer, contact time between water and air must be increased. The flow of air is achieved by using fans. Though the flow of water is by gravity, the water is sprayed using a nozzle for wide-spread droplets. Loss of water (drift) takes place during this spraying process. The other type of water loss is in the evaporation process, that is, water discharges into the atmosphere as hot, moist water vapor. A cooling tower saves money by producing colder water for the refrigeration process by saving the energy consumption of a chiller in converting the hot water directly returning from the building to the chilled water. One degree Fahrenheit colder water returning to the compressors and condensers in a chiller saves 3.25 percent of electrical energy. A little more than three degree Fahrenheit colder water from the tower can save 10 percent of electrical energy. A 2000-ton chiller circulating 6000 gallons per minute could use $\$ 350,000$ in 
electrical power in a year. A 10 percent savings would result in $\$ 35,000$ could be obtained by passing the hot water from the building to the cooling tower in [37].

Regular maintenance on cooling towers can reduce operating costs and improve their efficiency. To develop a maintenance methodology, the program should be designed in such a manner that any related equipment should fit into the model with minimal modifications. Since the research area and focus of HVAC system is identified, the next step is to identify and study equipment at its component level. Optimum system performance is dependent upon each individual component working at its designed capability. There are no unimportant components in an efficiently operated system, so identifying HVAC equipment at the component level becomes imperative research.

\subsection{Identifying System Components}

To identify an HVAC system at its component and sub-component level for assessment, the important parameters to be considered are,

- User friendliness

- Resource constraints

- Type of manufacturers

- Construction types

- Equipment deficiencies

- Functional value of the component

\subsubsection{User-Friendliness}

The field inspection is designed for quick reading consideration of only the physical condition of the system (not operating characteristics) and is a self-guiding process. The components identified are listed in a sequential manner with respect to their priorities, explained in later sections. The terminologies used in identifying these components are standard and familiar to the inspectors. The inspection sheet is designed to be handy, with one or two pages. The inspection should be as simple as possible without any additional information, history, or training requirements. The tool is flexible enough for easy future addition, editing, and changes. The 
more the components are broken down, the more extensive and accurate is the evaluation of physical condition.

\subsubsection{Resource Constraints}

Resources, such as men, money, and time, are an integral part of any process. Inspection is a process where planning is required to choose the inspection personnel, inspection time schedule, and inspection costs. No special inspection personnel can be assigned to perform the inspection. The routine maintenance worker and his knowledge level should be considered. The main reason for any program failure in any physical plant-type organizations is the lack of simplicity and failure to consider the prevailing resources. The inspection time is one of the most important components and it should be minimized. (Test results for this tool indicate an average of 30 minutes. The inspection time in [30] is 1.6 hours for a 1,000 square foot mechanical facility). The inspection costs should be nil. No consultants or engineers should be involved in the inspection and assessment process. The inspection schedule should be flexible to fit in a routine maintenance time, if needed. During assessment any inspection instrumentation tool must be eliminated to avoid implementation costs, time, and training of the personnel.

\subsubsection{Type of Manufacturers}

In a university environment, the age of equipment differs according to the expansion and growth of the university. The amount of HVAC equipment in the university numbers several thousand. For example, the number of units of FCU in buildings, such as downtown library, Allen Hall, agricultural sciences building, Creative Arts Center, and the engineering sciences building are 149, 294, 207, 124, and 298 respectively (total is 1,072). It is common to have several manufacturers for reasons such as bidding price, quality, design type, size, etc. One of the best ways to know the different manufacturers is by collecting manufacturer manuals from the physical plant and research to find other suppliers and verify the same with the management. This study was done and the leading manufacturers were identified in each HVAC equipment classification, and the equipment product manuals were referred to. Table $\mathrm{C}$ shows the list of cooling tower manufacturers apart from a few recommended manufacturers by Physical plant. There are 22 cooling towers in WVU with at least 6 manufacturers, as listed in Table $\mathrm{C}$ of Appendix. 


\subsubsection{Construction Types}

HVAC equipment varies in their construction based on design, materials, size, capacity, safety regulations, location, etc. These types have to be researched and studied to understand the common and exclusive components. This study was made for all the nine HVAC equipment components to get an overall picture. Construction type plays a vital role in the component classification, as it has to satisfy two needs: one is the extensiveness of the tool design and the other is the usability of the tool. For example, consider the types of cooling tower:

Type of draft - natural and mechanical draft, Location of fan - forced draft and induced draft, Type of airflow - cross flow and counter flow, Type of construction - field erected and factory assembled, Type of shape - rectilinear and round, and Type of heat transfer - open loop and closed loop.

\subsubsection{Equipment Deficiency}

HVAC equipment deficiency relates to the number of failures and type of failure of a component and/or equipment. The equipment failure history can be obtained by two sources, one is the work order received in the past and the other is the worker's input. The work order was collected for these nine HVAC systems for the last two years and the respective zone maintenance worker's input was collected. This data collection would help in understanding the repair and replacement trends in these pieces of equipment. Any repeated failure can be identified. The cause and effect of each failure is analyzed as an input. All of this verification work is performed as a part of the design process (not during inspection in the field). Since the tool has the potential to add changes, it is convenient to add any critical component or any component that may be added in future for predictive maintenance or improving energy efficiency.

For the cooling tower example, during the first design sheet, only 22 components were added, but after repeated review from workers and research from manuals, they were improvised to 24,25 , and, presently, 27 components. From the research, it is found that the mechanical components had the maximum failure rate when not maintained periodically, and mechanical failures are the 
main cause of premature electrical failures [20]. The work order failures were concentrated toward motor, fan, belt, gearbox, water leaks, etc.

\subsubsection{Functional Value of the Component}

The components were not classified based on the functional value during the initial design stage. The components were listed as they were studied. But a sequential representation was mandatory for reducing the inspection time and making it user friendly. Hence, the classification of equipment was researched. The equipment was classified as interior, exterior, mechanical, electrical, controls components, etc. These classifications consumed extensive design time to group them together and satisfy all the above constraints. They were also not producing any desired assessment output, like priority. As all of these classifications are an integral part of a component, they cannot be ranked or given weights for priorities. During the next stage of design, only the components that were directly involved in operating equipment were considered and termed as "critical components." When these components fail to operate, the desired output of the equipment will not be achieved. Still, it did not make sense to classify a few components as critical and others as non-critical. Each component's significance towards the equipment was studied and the functional value of the component was included as a factor ' $z$ ' to the model. These factors are classified as safety or operational components, primary components, secondary components and accessories and/or fittings. The basic idea behind this classification is the builtin ranking according to their meaning, and this is one way of defining each component's role in the equipment. The components can be grouped according to their functional value. Based on time availability and purpose of the assessment at a particular instance, the inspection can be stopped at the first level or second level (Also depending on the availability of resources while working on correction measures, after identifying the deficiencies certain levels can be attended depending on the priority).

For example in a cooling tower, motor, belt, gearbox, fan, water distribution, and electrical wiring are considered to be operational components. Bearings, structure, strainers, fin tube, basin, casing, drift eliminator, and fill (mesh) are considered to be primary support components. Controls, stop, check and drain valves; bolts; brackets and fittings on columns; water treatment;

fan enclosures; fan decks; louvers; and piping are considered to be secondary support 
components. Temperature gauges, pressure gauges, ladders, and access doors are considered to be accessories and fittings.

- Operational components: Critical components where, in case of failure(s), these components will not produce the desired output of the system.

- Primary support components: Components that support the operational components and second set of critical components. Failure of these components will affect the operational components. These components failure affect energy loss and efficiency loss.

- Secondary support components: These are additional components that are added to the system for better efficiency, safety, and value addition to the performance of the system. The equipment will not stop running without these components.

- Accessories and fittings: These are the components that ensures safety, and are part of the monitoring process, and the components that do not fall in the above three categories. These components are not an integral part of the equipment. Failure of these components will never affect the equipment is performance or operation.

By classifying each component as to its functional value for the equipment, the significance of each component is known. Ranking these components in this order sets a priority towards, maintenance and the thought process for further research in the model.

\subsection{Identifying Component Checkpoints}

During the process of identifying the components of HVAC equipment, the work orders were referred and studied to find the number and type of failures. This demonstrated the importance of identifying the components with the checkpoints. The checkpoints help in understanding the component's mode of failure. Based on this idea, checkpoints identification was further developed considering the resource constraints, that is, the inspection time and the tools required for measuring a component's condition. The physical plant management was consulted and the model scope was discussed again. It was found that the tool should enable the existing workers to use them with minimal training, and no tools should be used during this inspection. This would maintain the process's simplicity and would eliminate cost. Hence, it was determined that only the physical condition of the component is to be considered and also the inspection is to be performed only through visual inspection. These two factors were considered very important to 
control cost, training, and time of the inspection. Figure 3.4 shows the component checkpoints identification process.

The facility inspector also needs a guiding and uniform procedure to follow while assessing the system and its components. The checkpoints on these components would indicate 'what and how to inspect'. These inspection checkpoints determine the modes of failure.

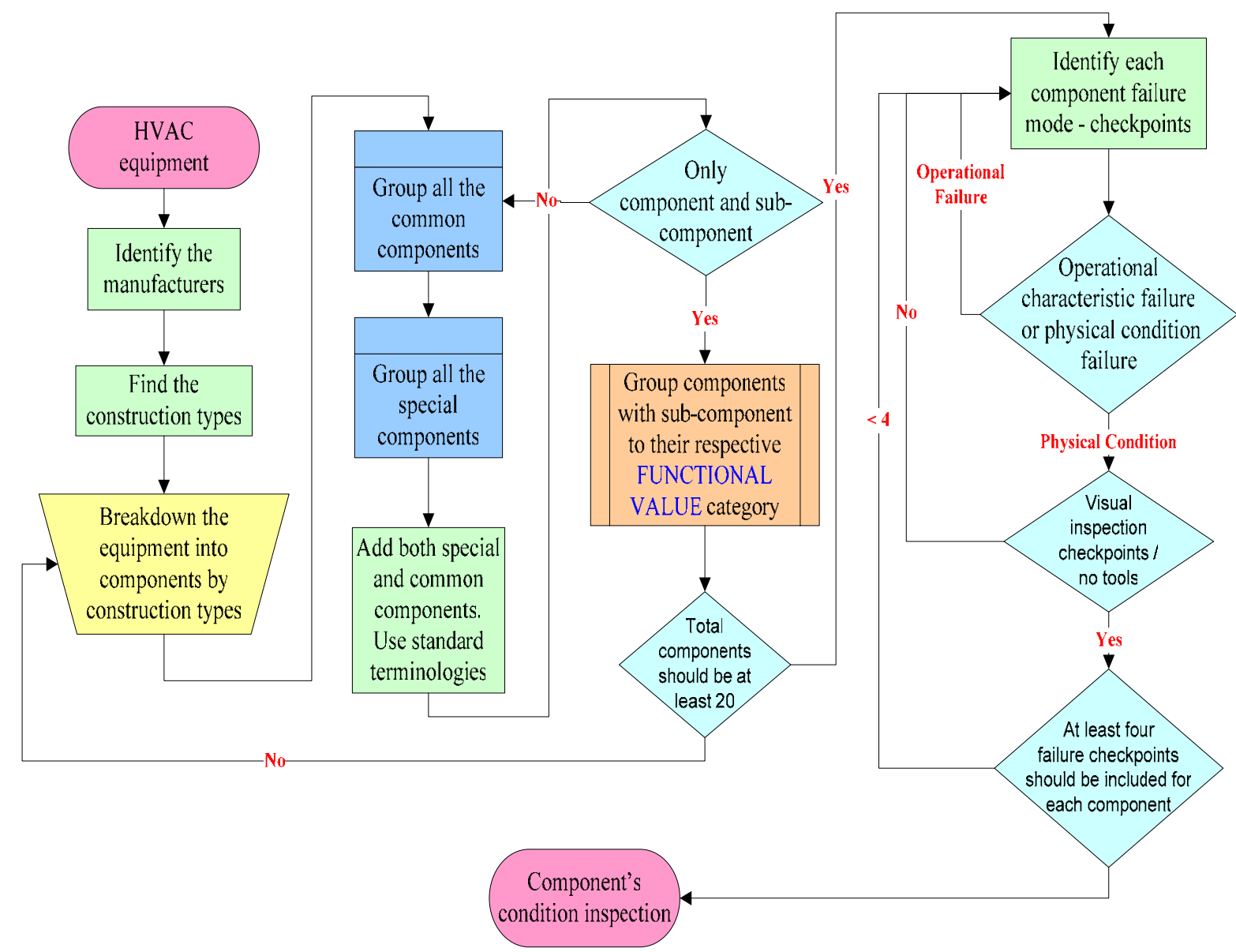

Figure 3.4. Component Checkpoints Identification Process Flow Chart

Identifying modes of failure helps the facility inspectors to foresee the possibility of failures and predict the occurrence depending upon the existing condition of that component. To maximize the availability of any system, the maintenance quality has to improve. To determine the maintenance quality or level, the physical condition of the component has to be known. The physical condition influences the performance and operational condition of the system. Hence, identifying the checkpoints depends on the following: 
- Type of component,

- Inspection time,

- Inspection training,

- Inspection tools,

- Types and number of failures,

- Worker's input, and

- Scope of the tool (physical condition or operating characteristics).

Cooling Tower Example: Research and study helped in identifying the common, yet important, problems of corrosion, erosion, lubrication, greasing, vibration, excessive heat, leaks, etc., in a system. All major problems start with these common known factors. But, by not attending to these checkpoints at the early stages, components deteriorate and reduce the useful life of equipment. Worker input was also a contributing factor in identifying these checkpoints. Workers become familiar with their equipment under all operating conditions and they can identify all minor problems before they turn into major problems. Without checkpoints, the inspection process is overlooked due to lack of guidance. Troubleshooting tips from the equipment manufacturer's manual helped in identifying the different modes of failure in a component, to an extent. Component type (functional value) is one important factor; "electrical wiring" is an operational component. The checkpoints are insulation, loose connections, charring, and corrosion. Insulation in electrical wiring is a safety element, as it is visible and a physical condition of the component. Strainers in a cooling tower are for filtering the foreign particles in water. The checkpoints include mesh condition, clogging, corrosion, leaks, cleanliness, and filtering. These checkpoints identify the physical condition of the component and since they are primary support components, mesh condition and clogging would affect the operational components, motor and pump. The three constraints such as no tools to be used, no training should be required, and the minimum inspection time (less than 30 minutes) are satisfied for these types of checkpoints. But, they become informative and revealing about the physical condition of the component. These factors also affect the scope of the tool. The physical conditions are the influencing parameter for the operating characteristics and for the performance of the equipment. These checkpoints are the root cause or failure mode of identification for the equipment's performance. The scope of the tool is to prioritize the component and equipment based on its physical condition and corrects these deficiencies according to the priority. 
Fin tube - scales, corrosion, leaks, open or close operation of the valve, and flow: A fin tube is a series of coils used in a closed loop cooling tower. Cold water is circulated in a closed pipe or coil, and hot water runs over the pipes or coils for evaporative cooling, and fans are used for blowing air. This is a primary support component. Physical condition failure modes, such as leaks, flow of glycol, scale-formation, and corrosion, directly affect the heat transfer rate and reduce the change in temperature. This affects the operating characteristic and performance of the system, which is temperature. This also leads to energy loss. Hence, the physical condition of the component is responsible for the performance of the system. Identifying the actual condition level of the component is the purpose of this tool.

Water treatment - frequency, sediments, fouling, biological, and airborne impurity: When the air is induced or forced through a cooling tower over water, it collects water droplets. Air leaving the tower carries aerosols into the environment, and these aerosols may sometimes be contaminated with Legionella bacteria. If people breathe this bacterium, they might develop Legionnaire's

disease. Proper water treatment with appropriate biocides minimizes this risk. Drift eliminators can also minimize the water droplets escaping from the tower. The frequency of the water treatment can be identified from the condition of the water and the presence of sediments, algae growth, fouling, biological impurity, etc. All these are physical parameters that can be visible. These checkpoints become very critical in terms of health hazards and law violations, though they do not contribute to the direct operation of the tower.

Hence, the checkpoints should identify the failure mode based on the component's function. To maximize the availability of any system, maintenance quality has to improve. These checkpoints directly improve the quality of maintenance by identifying and improving the quality of the inspection.

\subsection{Developing Corporate Memory in Assessment}

Inspection and assessment is a continuous process. Corporate memory should recapture the time, material, and action lost by not retaining important knowledge and information. As mentioned earlier, the number of buildings at WVU is more than 100 and the amount of equipment in the 
university numbers in thousands. The total number of workers in the mechanical department of the physical plant is approximately 50. The inspection design should be such that every worker can use it easily. Hence, it is very important to capture the name, the date, and when they inspected the equipment. The inspection time also becomes important, to be recorded corresponding to the worker who formed it. With this information, the efficiency and accuracy of each worker, with respect to time, can be evaluated. The inspection should also indicate the location of the equipment. Building number, building name, room number, and square feet would help in identifying the equipment easily. This will also help in analyzing the performance trend of the equipment in each building. The other important information includes equipment details, such as equipment name, equipment number, model number, serial number, type, capacity, manufacturer, and installation year. This information will help in identifying the spare parts for repair or replacement, age and useful life calculations, operating characteristics, and other analyses, such as construction type versus failure, age versus score, inspection time versus the equipment total score, etc. Comparison charts can also be made by using this information. It also helps in retrieving the information based on any of these identification fields. On completion of 100 such assessments, the volume of information is very large. Data can be retrieved using these fields and analyzed and/or compared with other facilities.

- Inspector information - name of the inspector, date of inspection, time to assess.

- Building information - building name, building number, room number, and gross square footage.

- Equipment information - equipment name, model number, serial number, type, capacity, and year installed.

\subsection{Causes and Effect of Equipment/Component Failure}

The major challenge for a maintenance engineer is to implement a maintenance strategy that maximizes availability and efficiency of the equipment, controls the rate of equipment deterioration, ensures safe, environmentally and friendly operation, and minimizes the total cost of operation. This can only be achieved by adopting a structured approach to the study of equipment failure and the design of an optimum strategy for inspection and maintenance. Extensive research has been done on risk and failure analysis. Risk analysis is a technique for identifying, quantifying, and evaluating the loss from an event. Risk analysis is also a process of 
identifying the unexpected failure of the equipment. This type of approach is obtained from the study of failure modes and their consequences [38]. The flood example, given in Chapter one, gives an overview of a university-type maintenance setup, nature of failures, and the maintenance operation, considering the geographical location and the volume of equipment. A cause and effect diagram depicting this flood example indicates one of the methods of identifying the failure reasons and consequences. In this example, out of the four predicted causes for the failure, two of those were indicating the need for FCA. This is one of the reasons to identify the consequences of an equipment failure or component failure in this research. In Figure 3.5, possible causes for a component failure are identified. The next step in this process flow is identifying the equipment or component failure impact or consequences. Hence, study of equipment failure and its consequences becomes vital for an assessment. The component and failure modes (checkpoints) are identified and listed according to the functional value. The step to convert the inspection to an assessment is done by identifying the consequences of these components' failures on these failure modes (checkpoints). The key research influences are:

- Cause and effect diagram for the flood example in Figure 1.1.

- Component/equipment condition inspection process in Figure 3.4.

- Consequences of an equipment failure flow chart in Figure 3.5.

Similarly, the idea is applied in identifying the consequences or impact in the event of component or equipment failure. When a facility or component performs to its designed capabilities and meets the desired requirements, the maintenance resources (men, money, time, etc.) invested in that facility are less, in fact nil. When a facility is unattended, deterioration and changes in its physical condition can lead to equipment failure. To bring back the equipment to its normal working condition, resources such as men, money, and time must be invested. Resources investment on equipment in proactive maintenance will result in return-to-investment, but if the same investment is on reactive maintenance, it is an expenditure that could have been avoided. This expenditure mostly results in loss of time and money, and at times, safety issues. The importance of monitoring a facility becomes crucial only when the facility functions improperly. Any facility can become unsafe to the owner and user if it is not maintained as per the manufacturers and environmental standards. 


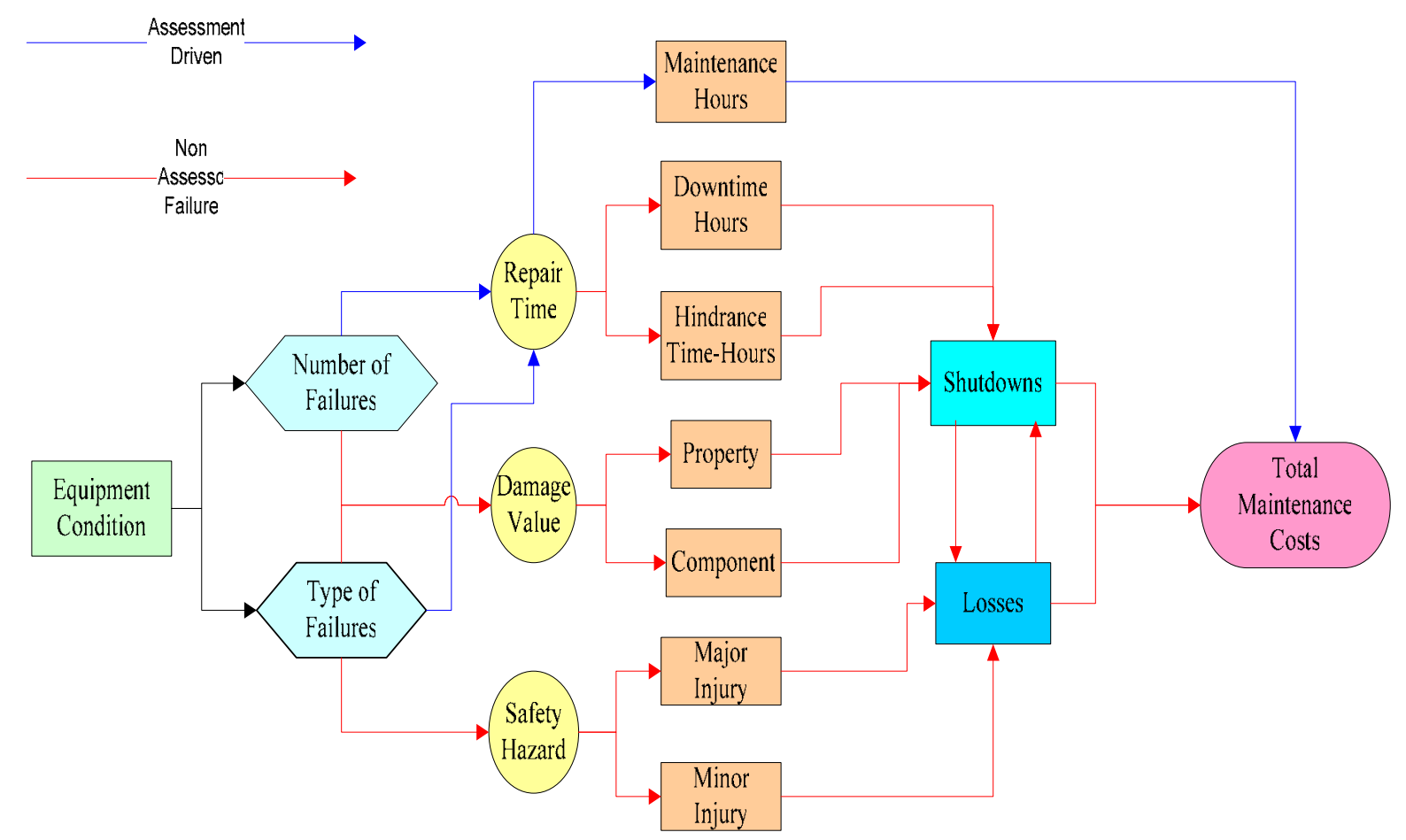

Figure 3.5. Consequences of an Equipment Failure Flow Chart

\subsection{Identification of Failure's Impact}

The first step in the identification process is to know "who uses the equipment and who owns the equipment." The university owns the equipment and uses the equipment. But, to identify the impact, the immediate users and owners who are exposed to the risk are "physical plant being the owner" and "students, faculty, staff, and others being the users." For convenience, the user group is classified as building occupants - university and, facilities maintenance and ownership physical plant. The second step is to consider this user and owner, and investigate the resources that can be affected due to a component or equipment failure. To identify the resources, the work order flow in physical plant is to be studied to know their operation. In brief, the complaint call is received in the radio room where they generate work orders. Subsequently, the work order is sent to the respective shops based on the trade (HVAC, plumbing, millwrights, etc.), where workers are assigned, followed by field inspection of the work order problem, with material and tools needs identified and repair or replacement maintenance hours entered in the work order. This paper work is returned to the shop, and the job is completed. Hence, during a failure of the component resources (direct costs), such as maintenance time, material for component repair or 
replacement, and the other costs, will be indirect costs to the job. Depending on the type of failure and number of failures, the job safety of the worker becomes critical. In the flood example, electricity was not switched off in the building immediately after the flood, and there were presumptive conditions indicating the possibility of electrocution. But, the reason for not switching the power off in the building immediately was that the building is a chemistry research laboratory and switching off the power might damage experiments. Another important reason is that there were fume hoods in the laboratory for exhaust purposes. These fume hoods are operated by fans over the roof and power supply disconnection would create a fume hood chemical hazard for occupants in the building. This failure is a risk on the job for the worker. Identifying this potential risk is a vital safety component in the assessment. In a reactive maintenance operation, the magnitude of risk is severe. The component repair and replacement maintenance time presents a potential risk for down time. Similarly, the material for repair and replacement of the component creates a potential risk for equipment or component damage. Hence, the potential risk impact parameters for Physical plant in the event of equipment or component failure are:

- Worker job safety (WJS),

- Component damage value (CDV), and

- Downtime for maintenance (MDT).

In the event of a component failure, the consequences to the university as a user can be as simple as inconvenience or as complex as severe damage. When equipment or a component fails, such as direct use of a thermostat or indirect use of boilers, the thermostat failure can lead to the common too hot or too cold discomfort level and a boiler failure can interrupt the flow of hot water in the rest rooms or laboratory. Physical plant would receive a service request to restore both these facilities. If facilities inspections were not being done, maintenance workers would not know the physical condition of these two facilities or the reasons for failures. Improper functioning of a thermostat can be due to a temperature sensor's loose contact connection. Repairing this is a simple repair task, which might involve little material and time. The WJS risk exposure level is also low. On the other hand, hot water generation can be stopped if the burners in the boiler are blocked in the orifice, corroded, or are not clean. This can shut off the fire, but the gas could still be leaking. This is a potential high-risk human safety and system safety issue. A physical plant worker in this job is exposed to danger and also the university occupants in the 
environment are exposed to severe risks. For example, consider the cooling tower water cleanliness and water treatment problems. If the water circulating in the tower is not maintained by proper chemical treatments, it can lead to scale, corrosion, biological fouling, algae formation, etc. This can eventually be carried in the air as airborne disease called legionellosis. This certainly can be prevented by periodic water treatment using drift eliminators, locating the tower in a safe place, etc. In the other example of the thermostat, occupants lose time when physical plant maintenance work is formed. In the boiler example, there is a potential risk of property damage, safety hazard, and hindrance time involved. The facility usage in the university varies, such as in the (life sciences building) herbarium, the green house and the laboratory for aquatic growth, the plant science green house, plant and soil testing labs (agricultural sciences building), the chemistry research laboratory (chemistry annex), general auditoriums, classrooms, equipment rooms, etc. HVAC is supplied to all these spaces. Therefore it is important to protect plants, animals, and any living thing apart from human beings. Safety and risk exposure levels must be accounted for in all the elements of the design. The potential risk impact parameters for the university in the event of equipment or component failure are:

- Life safety (LS) (human, animals, plants, environment, etc.),

- Property damage value (PDV), and

- Hindrance time during maintenance (MHT).

Safety hazards, damage value, and maintenance time should be identified, corrected, and eliminated through proper inspection of the facilities. Risk level changes in accordance with the physical condition of the equipment and its maintenance levels. Hence, inspection of facilities at the component level with possible modes of failures (checkpoints) and assessment across the risk potential parameters becomes imperative for facilities management. It is evident from these examples that the condition of a component or equipment is always with respect to potential risk impact that can occur in the event of failure, so, inspection related to risk exposure condition assessment helps in better decision making for investments.

\subsection{Identification of Risk Measurable Levels}

Assessments on these potential risk impacts are to be measured by their magnitude. During the initial stages of this research, once the condition assessment was designed with components and 
checkpoints, the next step was to identify the condition of these pieces of equipment. It was considered that the condition could be measured in four levels as good, fair, poor, and critical. But, it did not make much sense when the inspection was carried out because all these four terms were truly subjective and can vary depending on each piece of equipment and the individual who performs the inspection. For example, a component can rate as Good according to inspector X, and inspector $\mathrm{Y}$ can rate the same component as Fair. There is also another possibility that inspector $\mathrm{X}$ can rate component $\mathrm{A}$ as good in one piece of equipment, and the same inspector $\mathrm{X}$ can rate component $\mathrm{A}$ in another piece of equipment as fair. This could occur since the condition is being measured without a scale. Hence, the need for a measurable scale and the parameter (risk impact) to which it is measured would need to be researched. The risk impact is explained in the previous section. The research work on identifying the risk exposure measurable levels is explained in this section.

Risk assessment can be measured as quantitative or qualitative. The nature of output of a quantitative risk assessment will be a number, such as cost impact per unit time. The number could be used to prioritize assessed items when compared. Quantitative risk assessment requires extensive data for assessment of consequences. Qualitative risk assessment is less rigorous and is a subjective approach and it has no metrics. A significant amount of research has been performed on risk assessments. Papers either follow the quantitative approach or qualitative approach based on the research, output requirements, and availability of data. In this research, apart from data availability and output requirement, there are other constraints, such as inspector training, skill level, inspection time, and simple and user-friendly model that are to be considered during the design. For a program to be successful and to be adapted to everyday work activity, the model has to be user-friendly and custom-made. In this research, this was the goal that was maintained and given priority. This is the similar environment in all physical plants and industrial setups.

The best of both theories is adopted in this research. Qualitative risk assessment is simple, easy to understand, and assess. The drawback in using this approach is that it does not indicate any numbers for comparison. But the inspectors or assessment personnel find this comfortable, simple, easy and user friendly. Quantitative risk assessment is the numerical method of assessment, but it cannot be used by workers without required qualifications and it cannot be used with out available resources. To meet the required output such as numerical comparison of equipment and prioritizing the repair and replacement maintenance tasks, quantitative assessment 
is at the backend by converting this qualitative assessment into numbers. The next step was to decide on condition levels (could be three, four, five, or six). To optimize between time and accuracy in assessment, it was decided to maintain four levels after a discussion with physical plant management. The four level classifications are good, fair, poor, and critical for all the six risk potential parameters. These condition levels are to be measured on a scale by defining and assigning boundaries to make it scientific rather than subjective.

\subsubsection{Defining Condition Level as a Measurable Scale}

Considering "worker job safety" in the "Physical plant" category, most of the job safety risks can lead to minor injuries and a few may cause major injuries. Death has not occurred in the past, but these risks should be included. The injury trends indicate only minor injuries. Since it is a risk assessment, the assessment should be predicting if the existing condition of the equipment or component could cause a major injury or fatality. Hence, considering the severity level from safe to worse, the four classifications include good when it is safe to work, fair when it can expose to minor injury, poor when it can expose to major injury, and critical when it can expose to fatality. Definitions of these terms are:

Safe work place indicates that the equipment or component would not lead to minor or major injuries or fatality. Safe work place also indicates that completing a job should not result in taking a sick leave due to job stress or inconvenience.

Minor injuries can include minor health effects such as those requiring first aid, bruises, sprains, strains, low back pains, chemical poisoning, minor head injuries, minor eye infections, foreign bodies, scratches and skin wounds, and or anything that might require a doctor's consultation but not hospitalization other than resting, etc. These can be reportable or non-reportable injuries.

Major injury can include, electric shocks; loss of consciousness due to lack of oxygen; exposure to harmful substances or biological agents; fracture to finger, thumb or toes, etc.; loss of sight (temporary); hot metal burn; struck by moving or falling object; and anything that might require hospitalization.

Fatality indicates immediate or eventual loss of life. 
The "university" category includes life safety issues for people, plants, animals, and the environment. The human being classification can be considered the same as worker job safety. The plants and animal injury trend definition for minor and major injuries are beyond the scope of this research, hence, they can be subjectively called as good, fair, poor, and critical. The environmental protection can be classified as absolutely no harm to the ecological system, minor damage to the ecological system, significant damage to the ecological system and catastrophic damage to the ecological system as good, fair, poor, and critical, respectively.

In physical plant, the maintenance work orders are categorized into "quick fix," "minor repair," "major repair," "projects," "PM," "routine maintenance," and "service/set up," etc. In this research, "quick fix", "minor repair", "major repair", "projects" would be considered, since these are the continuous work orders received or carried out and more relevant to this study. Performing a process flow analysis by flow charting work orders in physical plant, average time and average spending related to these terms were found. quick fixes are those that can be performed within 1 to 1.5 hours and expenditures are not more than $\$ 1000$. Minor repair can be simple tasks that can be completed within a day or that can extend up to 3 days, and the expenditure is generally between $\$ 1000$ and $\$ 25,000$. Major repairs require certain components to be replaced with other repair work in equipment, and projects are complete replacement or most of the components being replaced in equipment. Major repair and projects are those that might need definitely more than three days of maintenance time and might exceed the expenditure of $\$ 25,000$. These expenditures were considered as the reference for defining a measurable scale for the assessment for component damage value and maintenance time considered for the assessment of down time for repair and/or replacement maintenance work. Since the expenditures are the maximum and minimum numbers, the expenditures are distributed approximately in a percentage range of the component damage value. Similarly, the average time is distributed in a range for down time of repair and/or replacement maintenance. They are also related to the qualitative condition levels as follows.

Considering component damage value as a percentage of repair or replacement maintenance costs in physical plant due to the existing condition, the assessment of the condition levels are; good, when it can cost less than 10 percent of the component costs in maintenance, fair, when it can cost $10-30$ percent of the component costs in maintenance, poor, when it can cost $30-50$ 
percent of the component costs in maintenance, and critical, when it can costs more than 50 percent of the component costs in maintenance.

Considering property or product or inventory damage value as a percentage of repair or replacement or maintenance costs in university due to existing condition, the assessment of the condition levels, good, when there is no damage or costs nothing, fair, when it costs less than 10 percent for restoring the damage, poor when it costs 10 - 30 percent for restoring the damage, and critical, when it costs more than 30 percent for restoring the damage. Since the assessment is predicting the potential risk impact for the occupant's property in the event of equipment or component failure, the percentage ranges have been reduced approximately. By this, priority can be increased.

Considering maintenance repair and/or replacement time in physical plant due to the existing condition, the assessment of the condition levels are good, when it can take only less than two hours to perform maintenance activity, normally a quick fix work order, fair, when it can take more than two hours and less than one day to correct the deficiency, normally a minor repair work order, poor, when it can take one day to three days to restore the component failure or condition, normally a major repair and critical, when it can take more than three days to repair or replace the component, normally a project.

Considering down/hindrance time for repair and/or replacement maintenance work in university due to the existing condition, the assessment of the condition levels are good, when it can take only less than two hours to perform maintenance activity, normally a quick fix work order, fair, when it can take more than two hours and less than one day to correct the deficiency, poor, when it can take one day to three days to restore the component failure or condition and critical, when it can take more than three days to repair or replace the component. The reason for the time is same as for physical plant as the hindrance time is due to the down time to perform the maintenance activity. Consequences of risk categories (1, 2, 3, and 4) are explained as production loss, facility damage, public safety, and employee safety with frequency of occurrence in five categories in [35].

The design could be simply maintained in such a way that when the worker performs the inspection and assesses the component, he can use the drop-down menu in the corresponding 
matrix (in Excel) and enter the input data. For the cooling tower example, a worker observes in the assessment process that the condition of the component motor is critical in worker job safety due to the un-insulated wiring and loose wiring in the motor. To enter this data, the worker has to just click on the drop down menu and select the condition critical from the list displayed. The same method is to be continued for the other assessments. Hence, each component is inspected on its checkpoints and assessed based on these six risk impact parameters with their corresponding condition levels to know the severity of potential risk.

\subsection{Identifying Priorities}

The output of this research should indicate the existing condition of the equipment. It should also indicate the components' existing condition. The components' condition should be indicated in all the six risk potential parameters. The condition level of the component could be "good", "fair", "poor", or "critical" in each matrix (component and risk potential parameter) cell of the Excel. This depends on the component condition with respect to the corresponding risk potential parameter. Hence, one component would consist of six individual condition levels, common or different, depending on the existing condition. Similarly, each component would have the respective data input. This data should be converted to meaningful information to represent the condition in numerical format or a qualitative to quantitative assessment result. Indication of this number would help in prioritizing the condition depending on the correctional measure required. In simple terms, priority is nothing but a critical component that requires immediate attention followed by a poor component followed by fair and then good. As explained earlier, since the resources are not sufficient, deficiencies can be corrected only in that order to reduce further losses. Ideally, the work orders received by physical plant on a daily basis should be attended to on a priority basis depending on the condition criticality as they are unable to attend to and complete all calls on the same day. Since this assessment process is generating continuous work orders (apart from the first two steps of a PM and DM reduction program) to the respective shops, depending on the condition of the component, the work orders should be prioritized.

Similar problems, but not identical (not as complex as this appears) are being solved in the literature. The reason that this problem is complicated is explained in the next few pages. During the design stage for scoring methodology in the model, it was understood that the four condition 
level scales are not linear but ordinal. For example, condition level critical does not mean it is four times worse than a component in condition level good, since we have four levels. Hence, the scoring methodology was designed by experimenting different ways as follows:

In the first proposed scoring (S) method M I, the condition levels were assigned one, two, three, and four for "good", "fair", "poor", and "critical" respectively and the potential risk impact parameters "Worker Job Safety (X1)", "Component Damage Value (X2)", and "Downtime for Maintenance (X3)" were assigned three, two, and one respectively. Though there are three "critical" conditions such as fatality, greater than 50 percent, and greater than three days representing $\mathrm{X} 1, \mathrm{X} 2$ and $\mathrm{X} 3$ respectively, these three criticality levels should be ranked as the consequences are not the same. The assumptions made were that the X1 (safety first) parameter should be assigned the maximum weight (penalty) than $\mathrm{X} 2$ and $\mathrm{X} 3$, and $\mathrm{X} 2$ is more important than X3. A similar score pattern is assigned for university. Physical plant management accepted that their mission and service priorities were the same. These assigned numbers are multiplied (condition level * risk parameter) and represented in Table 3.1. In method M II, condition levels were assigned one, two, three, and four but the $\mathrm{X} 1, \mathrm{X} 2$, and $\mathrm{X} 3$ were assigned with large difference as 1000,100, and 10, respectively and they were multiplied as before and represented in Table 3.2. In method M III, condition levels were assigned with larger difference such as 1, 10, 100, and 1000 for "good", "fair", "poor", and "critical" respectively. But X1, X2, X3, and X4 were assigned three, two, and one respectively as before with similar multiplication, as represented in Table 3.3 .

Limitations of these three methods are as follows:

1. In M I, a component with a "fair" condition in X1 and the same component with a "poor" condition in X2 are assigned the same score. Similarly, "good" in X1 is assigned the same score as "poor" in $\mathrm{X} 3$, etc.

2. If the formula for finding the overall condition of the component in a piece of equipment is by adding all the 6 risk parameters for all the three methods, in M I, the sum of better condition levels ("good" or "fair") are exceeding the sum of critical ones. For example, if a component were "Critical" in X1 (12), "fair" in X2 (4), and "good" in X3 (1) it would obtain a score of 17 for "physical plant". If another component were "fair" in X1 (6), "critical" in 
X2 (8), and "critical" in X3 (4) would obtain a score of 18. This sets a misleading priority, as a component leading to fatality for a worker should be corrected prior to the later condition.

Table 3.1. Physical Plant Condition Score

\begin{tabular}{|c|c|c|c|}
\hline M I & X1 & X2 & X3 \\
\hline $\mathbf{S}$ & $\mathbf{3}$ & $\mathbf{2}$ & $\mathbf{1}$ \\
\hline $\mathbf{1}$ & 3 & 2 & 1 \\
\hline $\mathbf{2}$ & 6 & 4 & 2 \\
\hline $\mathbf{3}$ & 9 & 6 & 3 \\
\hline $\mathbf{4}$ & 12 & 8 & 4 \\
\hline
\end{tabular}

Table 3.2. Physical Plant Condition Scores

\begin{tabular}{|c|c|c|c|}
\hline M II & $\mathbf{X 1}$ & $\mathbf{X} 2$ & $\mathbf{X 3}$ \\
\hline $\mathbf{S}$ & $\mathbf{1 0 0 0}$ & $\mathbf{1 0 0}$ & $\mathbf{1 0}$ \\
\hline $\mathbf{1}$ & 1000 & 100 & 10 \\
\hline $\mathbf{2}$ & 2000 & 200 & 20 \\
\hline $\mathbf{3}$ & 3000 & 300 & 30 \\
\hline $\mathbf{4}$ & 4000 & 400 & 40 \\
\hline
\end{tabular}

Table 3.3. Physical Plant Condition Scores

\begin{tabular}{|c|c|c|c|}
\hline $\begin{array}{c}\mathbf{M} \\
\text { III }\end{array}$ & $\mathbf{X 1}$ & $\mathbf{X 2}$ & $\mathbf{X 3}$ \\
\hline $\mathbf{S}$ & $\mathbf{3}$ & $\mathbf{2}$ & $\mathbf{1}$ \\
\hline $\mathbf{1}$ & 3 & 2 & 1 \\
\hline $\mathbf{1 0}$ & 30 & 20 & 10 \\
\hline $\mathbf{1 0 0}$ & 300 & 200 & 100 \\
\hline $\mathbf{1 0 0 0}$ & 3000 & 2000 & 1000 \\
\hline
\end{tabular}

3. To eliminate limitations, changes were made in M II, this method fails, because the condition "good" in X1 is assigned a number greater than the condition "critical" of X2 and X3.

4. To eliminate limitations one and three, M III changes were made, but this method also failed because of the same reason of limitation two, except for the larger number. 
Research was performed in prioritizing risk, but similar limitations were evidently seen. For example, [39] has limitation 1 and [40] has limitation 2. Five probability levels and five severity levels are explained in [40] with probability level two (remote) and severity level one (negligible) is assigned two. Similarly, probability level one (improbable) and severity level two (minor) is assigned two. In [39], public health and safety category has three levels of exposure with four levels of probability of occurrences. Public health and safety category level three (moderate to low level exposure) and probability of occurrence (one per year) level four is assigned 50. Similarly public health and safety category level two (excessive exposure) and probability of occurrence (1/10 years) level three is assigned 50. Limitation one is evidently not seen in [41] as one of the objectives of the paper includes solving the number of ties and equal values. Since [41] is comparatively not as complex a problem as this research, the limitation two problem need is not evidently seen. When compared with both the problems, the patient referral system can be assumed to be equivalent to the condition levels of the component, and the patient's medical condition can be compared with risk potential parameters. Patient medical condition can be classified further for priority setting into seven different conditions. In this FCA research, the risk parameters are classified into three different categories for physical plant and three different for university. Considering only physical plant, each risk parameter can be classified into four different condition levels and the patient referral system is classified into five levels. When compared, it was found that limitation two-problem reoccurs, though limitation one is solved. Hence, further research was required to eliminate these shortcomings, and it was found that any number of trials with the similar logic of weights and ties would generate the same limitations.

\subsection{Improved Priority and Scoring Model}

The model to be developed should prioritize the scheduling of resources and also indicate the most critical condition level in each risk potential parameter. Since there are chances for six critical condition levels for a component, classification is further needed to indicate the top one critical condition and subsequently rank them according to the importance of these parameters. To achieve the importance for the criticality, one of the methods is to assign priority according to the physical plant management's present and future decision-making criteria, service goals, work experiences, and mission. Physical plant's priority classification, considering all the 24 
consequences in the event of a component/equipment failure, is in Table 3.4 and Table 3.5 as a "most important factor is given the highest priority number."

Prioritization in Table 3.4 and Table 3.5 eliminates the limitation one, but limitation two is not yet solved for the cumulative score in achieving final priority. That is, summation of two or more low priority condition levels should not supersede any of the high priority condition levels. For example, during an assessment, it is found that an un-insulated electrical wire in a cooling tower can become fatal for a worker, but to replace this electrical wire would costs only 10 percent to 30 percent of the total wire value, and the time to replace this wire would take less than two hours. The abbreviation in Table 3.4 and Table 3.5 are worker job safety (WJS), component damage value (CDV), maintenance repair time (MRT), life safety (LS), property damage value (PDV), and maintenance down/hindrance time (MDT).

Table 3.4. Physical Plant Potential Risk Parameters

\begin{tabular}{|c|c|c|c|}
\hline \multicolumn{4}{|c|}{ Priority in scheduling work orders } \\
\hline Condition & X1 - & X2 - & X3 - \\
\hline Levels & W.J.S & C.D.V & M.R.T \\
\hline Good (G) & 1 & 3 & 2 \\
\hline Fair (F) & 7 & 6 & 4 \\
\hline Poor (P) & 11 & 8 & 5 \\
\hline Critical (C) & 12 & 10 & 9 \\
\hline
\end{tabular}

Table 3.5. University Potential Risk Parameters

\begin{tabular}{|c|c|c|c|}
\hline \multicolumn{4}{|c|}{ Priority in scheduling work orders } \\
\hline Condition & X4 - & X5 - & X6 - \\
\hline Levels & L.S & P.D.V & M.D.T \\
\hline Good (G) & 1 & 2 & 3 \\
\hline Fair (F) & 7 & 6 & 4 \\
\hline Poor (P) & 11 & 8 & 5 \\
\hline Critical (C) & 12 & 10 & 9 \\
\hline
\end{tabular}


Summation of the input results X1C (12), X2F (6), and X3G (2) would result in a score of 20. For example, in a cooling tower, replacing a completely worn out belt can cost more than 50 percent of the total belt cost, the time taken to replace this belt can consume three hours, and there can be a potential for minor injury due to the sharp edges in the belt guard. Summation of input results X4F (7), X5C (10), and X3F (4) would result in a score of 21. When the model prioritizes these scores for components in a equipment, the ranking would be 21 and then 20 . Thereby, it becomes misleading, and the score of a critical safety component cannot be superseded by any other lower prioritized components. This limitation should be eliminated to have an accurate automated priority scheduling and ranking system. There is a need for further research on scoring and revising the formula for overall priority.

Limitation two was studied further to identify and eliminate the root cause for the existing problem. The numbers used until now were continuous numbers such as $1,2,3,4,5,6,7,8,9$, 10,11 , and 12. The logic is that each number is increased to the next number by 1 unit. That is, 1 $+1=2,1+2=3,1+3=4$, etc. In this series, for example, to obtain 7 , there are 3 different ways such as $3+4=7,1+6=7$, and $5+2=7$. Hence, two or more low priorities exceed one high priority. To avoid this problem, one of the solutions is that any outcome number selected from the series when added should not be generated by any other way.

Let the first outcome of the series be one, since there is no other outcome, add ' 1 ' to this outcome, that is $1+' 1 '=2$. Since, when the outcomes from the series are added two could be obtained, two become an outcome. To this outcome, add the ' 1 ', that is, $2+$ ' 1 ' $=3$. Since, three can also be obtained by adding the previous outcomes two and one, three should not be retained. Hence, ' 1 ' should be added to all the previously retained outcomes, $2+1+$ ' 1 ' $=4$. Four become an outcome, as four could not be obtained by adding the previous outcomes. To this outcome, add ' 1 ', that is, $4+$ ' 1 ' $=5$, but five can be obtained by adding previous outcomes, four and one; hence, five should not be retained. Hence, add all the previous outcomes with ' 1 ' that is, $1+2+$ $4+' 1$ ' $=8$. Eight should be retained, as there is no other way of obtaining eight from the previous outcomes. This technique is shown in Table 3.6 as follows: 
Table 3.6. Scoring Outcomes

\begin{tabular}{|c|}
\hline 1.1 \\
\hline $2.1+{ }^{\prime} 1{ }^{\prime}=2$ \\
\hline $3.2+1+' 1 '=4$ \\
\hline 4. $4+2+1+{ }^{\prime} 1 '=8$ \\
\hline $5.8+4+2+1+{ }^{\prime} 1 '=16$ \\
\hline $6.16+8+4+2+1+' 1 '=32$ \\
\hline 7. $32+16+8+4+2+1+{ }^{\prime} 1 '=64$ \\
\hline $8.64+32+16+8+4+2+1+{ }^{\prime} 1 '=128$ \\
\hline 9. $128+64+32+16+8+4+2+1+' 1 '=256$ \\
\hline $10.256+128+64+32+16+8+4+2+1+{ }^{\prime} 1{ }^{\prime}=512$ \\
\hline $11.528+256+128+64+32+16+8+4+2+1+{ }^{\prime} 1 '=1024$ \\
\hline 12. $1024+528+256+128+64+32+16+8+4+2+1+{ }^{\prime} 1$ ' $=2048$ \\
\hline
\end{tabular}

Since there are only 12 priorities listed for this model, the series can be stopped.

By this technique, when any of the previous numbers are added, the next outcome number cannot be generated. Hence, two or more low priority numbers (outcomes) cannot supersede the high priority number. This method helps in solving limitation one and limitation two problems. These numbers can be assigned as scores to the priorities in Table 3.4 and Table 3.5 as Table 3.7 and Table 3.8, respectively.

Table 3.7. Physical Plant Priority and Score

\begin{tabular}{|c|c|c|c|c|c|c|c|c|c|}
\hline $\begin{array}{c}\text { Condition } \\
\text { Levels }\end{array}$ & $\begin{array}{c}\text { X1 - } \\
\text { W.J.S }\end{array}$ & Priority & Score & $\begin{array}{c}\text { X2 - } \\
\text { C.D.V }\end{array}$ & Priority & Score & $\begin{array}{c}\text { X3 - } \\
\text { M.D.T }\end{array}$ & Priority & Score \\
\hline $\begin{array}{c}\text { Good } \\
\text { (G) }\end{array}$ & Safe & 1 & 1 & $<10 \%$ & 3 & 4 & $\begin{array}{c}<2 \\
\text { hours }\end{array}$ & 2 & 2 \\
\hline $\begin{array}{c}\text { Fair } \\
\text { (F) }\end{array}$ & $\begin{array}{c}\text { Minor } \\
\text { Injury }\end{array}$ & 7 & 64 & $\begin{array}{c}10- \\
30 \%\end{array}$ & 6 & 32 & $\begin{array}{c}2 \text { hrs }- \\
1 \text { Day }\end{array}$ & 4 & 8 \\
\hline $\begin{array}{c}\text { Poor } \\
\text { (P) }\end{array}$ & $\begin{array}{c}\text { Major } \\
\text { Injury }\end{array}$ & 11 & 1024 & $\begin{array}{c}30- \\
50 \%\end{array}$ & 8 & 128 & $\begin{array}{c}1- \\
3 \text { Days }\end{array}$ & 5 & 16 \\
\hline $\begin{array}{c}\text { Critical } \\
\text { (P) }\end{array}$ & Fatality & 12 & 2048 & $>50 \%$ & 10 & 512 & $\begin{array}{c}>3 \\
\text { Days }\end{array}$ & 9 & 256 \\
\hline
\end{tabular}


Table 3.8. University Priority and Score

\begin{tabular}{|c|c|c|c|c|c|c|c|c|c|}
\hline $\begin{array}{c}\text { Condition } \\
\text { Levels }\end{array}$ & $\begin{array}{c}\text { X4 - } \\
\text { L.S }\end{array}$ & Priority & Score & $\begin{array}{c}\text { X5 - } \\
\text { P.D.V }\end{array}$ & Priority & Score & $\begin{array}{c}\text { X6 - } \\
\text { M.H.T }\end{array}$ & Priority & Score \\
\hline $\begin{array}{c}\text { Good } \\
\text { (G) }\end{array}$ & Safe & 1 & 1 & Nil & 3 & 4 & $\begin{array}{c}<2 \\
\text { hours }\end{array}$ & 2 & 2 \\
\hline $\begin{array}{c}\text { Fair } \\
\text { (F) }\end{array}$ & $\begin{array}{c}\text { Minor } \\
\text { Injury }\end{array}$ & 7 & 64 & $\begin{array}{c}< \\
10 \%\end{array}$ & 6 & 32 & $\begin{array}{c}2 \text { hrs }- \\
1 \text { Day }\end{array}$ & 4 & 8 \\
\hline $\begin{array}{c}\text { Poor } \\
\text { (P) }\end{array}$ & $\begin{array}{c}\text { Major } \\
\text { Injury }\end{array}$ & 11 & 1024 & $\begin{array}{c}10- \\
30 \%\end{array}$ & 8 & 128 & $\begin{array}{c}1- \\
3 \text { Days }\end{array}$ & 5 & 16 \\
\hline $\begin{array}{c}\text { Critical } \\
\text { (P) }\end{array}$ & Fatality & 12 & 2048 & $\begin{array}{c}> \\
30 \%\end{array}$ & 10 & 512 & $\begin{array}{c}>3 \\
\text { Days }\end{array}$ & 9 & 256 \\
\hline
\end{tabular}

\subsection{Improved Formula}

The formula for finding the overall score of a component should be improved, as during summation of the six parameters, the critical X1 parameter can be superseded by poor X1 and poor X4 with a good X2. For example, a component A with CX1, GX2, GX3, GX4, GX5, and GX6 obtains a score of 2058, and a component B with PX1, FX2, GX3, PX4, GX5, and GX6 obtains a score of 2087. But by priority, component A should be attended to as that component may lead to fatality. Hence, the formula should be improved.

The model priority should be arranged in such a way that, for any component, if the worker job safety and/or life safety is critical, invariably this component should be scheduled first than (except if all the Xi (s) is critical) any other condition combination. There can be totally 444,444 combinations possible in this model. It is not physically possible to test all the combinations. Hence, after various trials in finding a formula for this model, the formula that solved all the combinations tried was:

Step 1: $[(X 1+X 2+X 3) * \operatorname{Max}(X 1, X 2, X 3)]+[(X 4+X 5+X 6) * \operatorname{Max}(X 4, X 5, X 6)]$

Since the priority is to rank the CX1 and/or CX4 as first, multiplying the maximum number of $\mathrm{X} 1, \mathrm{X} 2$, or $\mathrm{X} 3$ with the summation of $\mathrm{X} 1, \mathrm{X} 2$, and $\mathrm{X} 3$ (whichever is greater) will always be a larger number. Similarly, multiplying the maximum number of X4, X5, or X6 (whichever is 
greater) with the summation of X4, X5, and X6 will always be a larger number. Adding these two large numbers would result in the largest number.

Though limitation two is being eliminated by this formula (step 1), there are chances of ties or equal numbers. Two components having the same conditions when assessed might end in the same scores. This becomes a tie. This situation can also happen for the two or more most critical components with the critical condition level in all the six risk parameters. Further, research is required to solve this tie or equal scores situation between components in equipment having the same conditions. The functional value of the component should be included with the formula as decision making in scheduling the work orders also involves this criterion. If in a situation when the condition with respect to all the six risk parameters are the same between two or more components, the first objective of a facility manager would be to schedule the repair or replacement for the component that enables the system to work. This decision would help in eliminating the impact from the potential risk parameters and also would make the system work. Hence, it is found that the functional value of the component is a key criterion in the decisionmaking process for scheduling work orders in ties and otherwise. This theory was explained to the physical plant management and compared with a few example situations to get their approval. The next step would be to include functional value ' $Z$ ' to the model and resolve the ties in scores. To include the ' $Z$ ' criteria in the model, two assumptions were considered:

- Workers job safety and/or life safety risk potential parameters occur irrespective of the functional value of the component; hence, "Z" should not affect X1 and X4 in the model.

- The "Z" criterion (functional value), when included to the model formula, should not result in limitation two problems.

The scoring for the functional value of the component should be assigned according to the priority established by physical plant earlier as Z1 - operational component, Z2 - primary support components, Z3 - secondary support components, and Z4 - accessories and fittings.

The priority is in the order as listed and the scores assigned should be the opposite. Z1 criterion should be assigned the highest number than the other three and subsequently the ranking decreases as Z2, Z3, and Z4. In order to eliminate limitation two, two low priority numbers added should not result in the next number. For example, from Table 3.6, when 512 and 256 are added, it results in 768 , but 768 is not a scoring outcome. The possibility of obtaining a scoring 
outcome is by multiplying with two to a score or by adding a single scoring outcome two times. The scoring outcome 1024 can be obtained by adding 512 two times or multiplying 512 by 2 . Hence, the highest " $Z$ " criterion should be less than two. These assumptions lead to assigning scores and are represented in Table 3.9.

Table 3.9. Functional Values - Score

\begin{tabular}{|c|c|c|}
\hline $\begin{array}{c}\text { Functional } \\
\text { Priority }\end{array}$ & $\begin{array}{c}\text { Functional Value for the } \\
\text { Equipment }\end{array}$ & Scores \\
\hline $\mathrm{Z} 1$ & Operational Component & 1.75 \\
\hline $\mathrm{Z} 2$ & Primary Support Component & 1.5 \\
\hline $\mathrm{Z3}$ & Secondary Support Component & 1.25 \\
\hline $\mathrm{Z} 4$ & $\begin{array}{c}\text { Accessories and or Fitting } \\
\text { Component }\end{array}$ & 1 \\
\hline
\end{tabular}

The functional value of the component should be added to the model formula in step 1 according to the assumptions made earlier as:

Step 2: $\left[\left(X 1+\left((X 2+X 3) Z_{i}\right) * \operatorname{Max}(X 1, X 2, X 3)\right]+\left[\left(X 4+\left((X 5+X 6) Z_{i}\right) * \operatorname{Max}(X 4, X 5, X 6)\right]\right.\right.$

Where $\mathrm{i}=1,2,3$, or 4 of the different functional values. This eliminates the ties and equal scores between components in the functional value. But, there are chances for ties between components in the same functional value. This would likely be the final step of the model, since the component cannot be broken further into any other classification for the designed assessment program. Finding a method to eliminate ties between components in the same functional values is the next research.

As explained in 1.8.8 (chapter one), OC.I should be included in the design as an X7 parameter. This parameter is added to the system for two reasons, one is to eliminate a tie between the 
components in the same functional value and the other is to obtain worker input to the model score.

This process can minimize error in the model. When an assessment is performed for five buildings' cooling towers, the OCI parameter can eliminate an overall score tie by giving a higher score for the building having special occasions such as graduation day, game day, exam week, etc. For components within the same functional value, an OCI rating directly depends on the number of components in the same functional value. For example, if there are five different components in the "operational component" (Z1) functional value category in a cooling tower, the OCI ratings would be written or designated as five numbers such as one, two, three, four, and five. Depending on the overall condition of the component after assessing in the various risks potential parameters, the inspector has the right and privilege to rank these components between one and five in which the lowest number, (one), would be the most important. Similarly, "accessories and fittings", Z4 has four different components. The OCI ratings would be one, two, three, and four and lowest number, (one), would be the most important and highest number, (four), would be the least important. Once the inspection is done, and if an inspector would assess according to X7 (OCI) in Excel, clicking the drop down menu in the corresponding cell and selecting the number should enter the data. The next step is to include this component in the model formula and also assign scores to OCI. The X7 parameter is included in the model (step two) formula as:

Step 3: $\left\{\left[\left(\mathrm{X} 1+\left((\mathrm{X} 2+\mathrm{X} 3) \mathrm{Z}_{\mathrm{i}}\right) * \operatorname{Max}(\mathrm{X} 1, \mathrm{X} 2, \mathrm{X} 3)\right]+\left[\left(\mathrm{X} 4+\left((\mathrm{X} 5+\mathrm{X} 6) \mathrm{Z}_{\mathrm{i}}\right) * \operatorname{Max}(\mathrm{X} 4, \mathrm{X} 5\right.\right.\right.\right.$, $\mathrm{X} 6)]\} * \mathrm{X} 7$

Since the ratings in $X 7$ depend on the number of components $Z_{i}$, the scores would be $1+(1 / 10)$ for the unit digit number of components (that is, if there are only 9 components), $1+(1 / 100)$ for the tenth digit number of components (that is, if the number of components are 99), $1+(1 / 1000)$ for the hundred digit number of components (that is, if the number of components are 999), and so on. For example, if Z1 has nine components and Z2 has 99 components the scores for X7 (OCI) would be as in Table 3.10. This scoring would eliminate the ties and also would not generate limitation 2 . 
As an example to explain the formula, consider the component "structure and/or columns" with checkpoints, "corrosion, cracks, stability, leaks, deterioration, and iron rot" with the component functional value as the primary support. The functional value $(Z)$ of the component is 1.5 . On inspection and assessment of its physical condition with respect to the risk potential parameters for "physical plant," "Worker Job Safety" (X1) was identified to be "fair" indicating a risk potential for minor injury (with a score of 64). "Component Damage Value" (X2) was identified to be "good" indicating a risk potential for the component to cost less than $10 \%$ of the component costs (with a score of three). "Maintenance Down Time" for the component (X3) is identified to be "good" indicating a risk potential that would take only two hours to complete the task (with a score of two).

On inspection and assessment of the physical condition with respect to the risk potential parameters for "University", Life Safety (includes human, plants, animals, and environment) (X4) was identified to be "good" indicating a safe environment (with a score of one). "Property Damage Value" (X5) was identified to be "good" indicating that damage is nil (with a score of one), and "Hindrance Maintenance Time" to repair or replace the Component (X6) is identified to be "good" indicating the time taken to complete the task is less than two hours (with a score of two).

After completing the assessment and inspection of the physical condition of the component with respect to the above-mentioned variables, the OCI (X7) is determined, based on the field situation and severity, to be in good condition (with a component score of 0.08 from Table 3.10). Substituting these scores in the step 3 formula:

Step 3: $\left\{\left[\left(\mathrm{X} 1+\left((\mathrm{X} 2+\mathrm{X} 3) \mathrm{Z}_{\mathrm{i}}\right)\right) * \operatorname{Max}(\mathrm{X} 1, \mathrm{X} 2, \mathrm{X} 3)\right]+\left[\left(\mathrm{X} 4+\left((\mathrm{X} 5+\mathrm{X} 6) \mathrm{Z}_{\mathrm{i}}\right)\right) * \operatorname{Max}(\mathrm{X} 4, \mathrm{X} 5\right.\right.$, $\mathrm{X} 6)]\} * X 7=\{[(64+((3+2) 1.5)) * 64]+[(1+((1+2) 1.5)) * 2]\} * 1.08=4953.96$

Normalizing the value to represent the number in more readable format becomes necessary, since when all the "Critical" scores are applied, the final numbers are huge. Hence, the logarithmic (log 10) value is equal to 3.69. This model formula (Step 3) would eliminate the ties between components in the same functional value category. This eliminates all the limitations and the model would result in an overall component and equipment score that would not have ties. 
Table 3.10. OCI Scores

\begin{tabular}{|c|c|c|c|}
\hline $\begin{array}{c}\text { I - Number of } \\
\text { Components in a } \\
\text { Functional Value } \\
\text { Category }\end{array}$ & $\begin{array}{c}\text { OCI } \\
\text { Scores } \\
(\mathbf{1} / \mathbf{1 0}) \text { of I }\end{array}$ & $\begin{array}{c}\text { II- Number of } \\
\text { Components in a } \\
\text { Functional Value } \\
\text { Category }\end{array}$ & $\begin{array}{c}\text { OCI } \\
\text { Scores } \\
\mathbf{( 1 / 1 0 ) ~ o f ~} \\
\text { II }\end{array}$ \\
\hline 1 & 0.1 & 1 & 0.01 \\
\hline 2 & 0.2 & 2 & 0.02 \\
\hline 3 & 0.3 & $\ldots$. & $\ldots$. \\
\hline 4 & 0.4 & 9 & 0.09 \\
\hline 5 & 0.5 & 10 & 0.1 \\
\hline 6 & 0.6 & $\ldots$. & $\ldots$. \\
\hline 7 & 0.7 & 15 & 0.15 \\
\hline 8 & 0.8 & $\ldots$. & $\ldots .99$ \\
\hline 9 & 0.9 & 99 & \\
\hline
\end{tabular}

Application of model formula in step 3 would result in an individual component score in any piece of HVAC equipment with priorities set automatically between components within a single piece HVAC equipment. Summation of these component scores would result in an overall equipment score that can be used for comparison.

Completing the six risk potential parameters and OCI assessments, the inspector should either recommend the need for repair or replacement or do nothing to that particular component. This decision and input made by the inspector is very important for the plant supervisor to take corrective action. Hence, this is added in the model as an input. In addition to all these, the inspector should also initiate actions and recommendations for the corresponding component. This statement would help the work order process in evaluating the situation and the amount of work from the assessment. This will also help in knowing the expected work performance level. This actions and recommendations stated enable the creation of a continuous flow of work orders to the shops on different trades. Hence, the methodology creates a proactive work order generation process. 


\subsection{Conclusions}

An HVAC condition assessment methodology eliminates the most evident limitations in the literature such as equal numbers or ties, summation of lower priority scores exceeding the higher priority score, and the need for a cost estimator. This model is a user-friendly inspection and assessment tool, where the components and their checkpoints are predefined according to the functional significance of the component in order to identify failure. This feature guides the worker through the process without the need for assessment training. It is an automated tool that considers safety, maintenance time, and maintenance costs unlike the FCI method. The assessment input from the workers is qualitative and is converted to quantitative in order to compare between components of the equipment and between equipment in a facility. The assessment results are in the form of a report, where the individual component's risk parameters are displayed with the condition. Also displayed is a scoring system that sets priorities to these components, thus enabling an effective work order scheduling system. This structured methodology when used by physical plant workers requires between 25 and 35 minutes per assessment and will generate an output instantly. This inspection time eliminates the limitation of inspection and report writing time of 1.6 hours per 1000 square feet reported in the literature [31]. HVAC condition assessment methodology is designed for physical plants to use as a routine program to reduce the DM backlogs. It also initiates the first two steps of the PM program. This in-house, automated tool would help in seeking funds from the university and/or state by indicating the consequences of equipment or component. Since this tool prioritizes and schedules repair and/or replacement work orders, the risk involved in investing in facilities is reduced and substantiated.

Since the corporate memory in maintenance management is part of this methodology, the existing condition of the equipment is stored at the component level with respect to their inspection details. FCA methodology, when applied in physical plant type of environment, minimizes inspection time and avoids the cost of hiring consultants and engineers for assessment and for identifying existing deficiencies in HVAC equipment. This is also a decision-making tool for utilizing the physical plant's resources in rectifying these deficiencies by priority scheduling. 


\section{Chapter 4 - Overall Implementation Plan for the Assessment Methodology}

The designed and developed HVAC assessment methodology must be tested for its robustness and ease of implementation. The assessment tool must be field tested for any equipment listed in chapter three to identify the robustness, and an implementation plan must be proposed to utilize the benefits of the tool. The following six recommendations can be used to check the robustness of the tool and the implementation plan for the assessment methodology:

- Benchmarking the assessment scores

- Recommendations for optimum assessment frequency

- Time-based sensitivity

- Implementing the assessment methodology in cooling towers

- Variation in assessment with multiple workers

- Effectiveness of the assessment tool

\subsection{Benchmarking the assessment scores}

Benchmarking is a method or technique to improve the performance of any process or business by measuring and improving products, services, and practices against the best industries identified. Benchmarking will help in answering questions such as "where are we," "what can we learn from others," and "how do we improve our system to reach the best standards." The assessment methodology results in a performance measurement or equipment condition score of HVAC equipment considering the risk potential factors. This performance (overall) score must be converted from a number to meaningful information. The overall equipment condition assessment score should be compared with the best available industrial standards to indicate the present level of maintenance effectiveness. Only when the present level is identified and known, the next desired level can be achieved by process improvement. Hence, benchmarking the scores is vital and meaningful. The HVAC equipment condition assessment is also a maintenance assessment strategy that provides the basis for prioritizing (due to limited resources) improvement efforts to meet the mission or goal. It also defines the potential to improve the maintenance operation. From this assessment overall score, maintenance effectiveness can be 
determined. Maintenance effectiveness can be determined by a two-phase process with phase one assessment being an initial study to define the plant's present position and phase two being evaluating the progress and continuing the improvement efforts [42]. Maintenance effectiveness is measured from the 21 essential elements required for any Plant operation, defined as "Maintenance Arch," [42] that are listed in Table 4.1.

Table 4.1 Elements of Maintenance Arch

\begin{tabular}{|l|l|l|l|}
\hline 1 & Status assessment & 12 & Maintenance engineering \\
\hline 2 & Objectives, goals and targets & 13 & Equipment history \\
\hline 3 & Master plan & 14 & Material, support and control \\
\hline 4 & Budgetary control & 15 & Work measurement \\
\hline 5 & Management reporting and control & 16 & Work planning \\
\hline 6 & Organization & 17 & Scheduling and coordination \\
\hline 7 & Supervision and control & 18 & Computer support \\
\hline 8 & Training & 19 & Cost distribution \\
\hline 9 & Facilities and equipment & 20 & Work order system \\
\hline 10 & Pride, quality and workmanship & 21 & Governing principles and concepts \\
\hline 11 & Preventive/ predictive maintenance & & \\
\hline
\end{tabular}

The general status of maintenance effectiveness is shown as a bar scale in Figure 4.1. The percentage of maintenance effectiveness was collected from various 170 assessments performed in maintenance organizations [42]. 


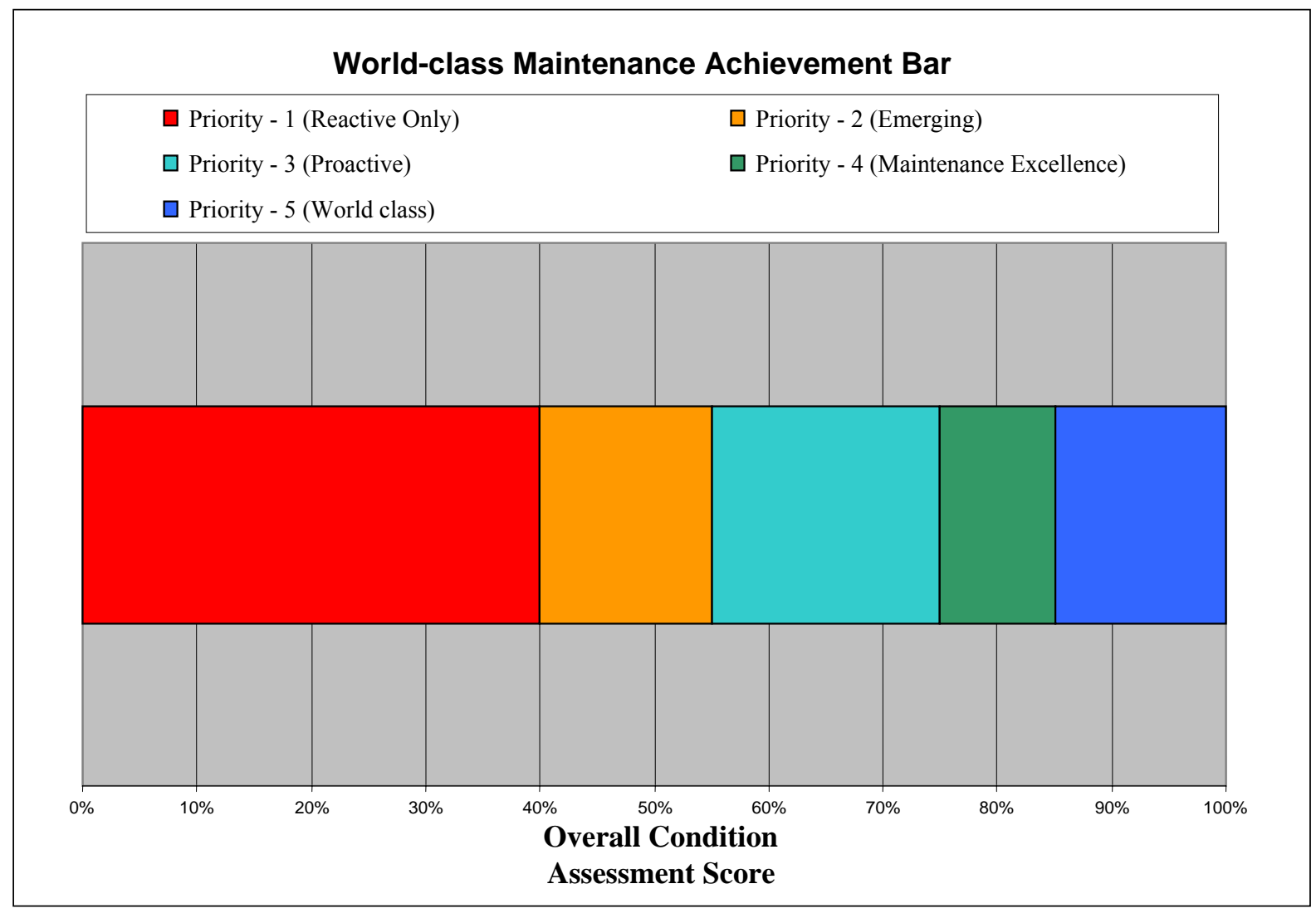

Figure 4.1.Overall Condition Assessment Score Benchmarking

Using this percentage scale as a basis, the HVAC condition assessment scores were converted from a number to a percentage and redefined as priorities for rectification and obtaining maintenance effectiveness. If the assessment scores are greater than zero percentage and less than or equal to 40 percent, then the maintenance effectiveness is reactive and the rectification of these deficiencies must be assigned as priority 1. Similarly, if the assessment scores are greater than 40 percent and less than or equal to 55 percent, then the maintenance effectiveness is emerging and rectification of these deficiencies must be assigned as priority two. If the assessment scores are greater than 55 percent and less than or equal to 75 percent, then the maintenance effectiveness is proactive and the rectification of these deficiencies must be assigned as priority three. If the assessment scores are greater than 75 percent and less than or equal to 85 percent, then the maintenance effectiveness is excellent and the rectification of these deficiencies must be assigned as priority four. If the assessment scores are greater than 85 percent and less than or equal to 100 percent, then the maintenance effectiveness is world class and the rectification of these deficiencies must be assigned as priority five (refer Figure 4.1 for these 
priorities). Within these five categories, the priorities can be ranked based on the scores. The purpose of scheduling these priorities is to optimize between the equipment deficiency criticality in relation to limited resources. This also indicates when the repair should be accomplished. Examples are presented to understand the time relation and do not mean the exact time.

- Priority one: These deficiencies should be corrected immediately as they involve life safety issue or catastrophe.

- Priority two: These deficiencies should be corrected within one month. If they are not corrected, then these would lead to adverse effects to the equipment or life safety hazard.

- Priority three - five: These deficiencies should be corrected within two to four months. If they are not corrected, then these would lead to serious impact to the equipment operation or further damage of the equipment that could lead to downtime, costs, etc.

\subsubsection{Score Conversion Method}

The condition of the equipment is evaluated qualitatively and assessed for the different components with respect to the risk potential parameters. This qualitative assessment of the existing condition of the equipment is converted to a quantitative output (numerical numbers) as the overall condition assessment score. This overall score can vary depending on the qualitative condition input. For example, in a cooling tower, if there are 26 components assessed in six different parameters, then the number of cells in the matrix is 156. Each cell has four possible condition levels and the matrix can change accordingly. If, for all the 26 components with respect to all the six parameters are assessed as "good", then the maximum score possible is 47.8 . Similarly, if for all the 26 components, with respect to all the six parameters, are assessed as "critical," then the maximum score possible is 186.2. This is the normalized score (logarithmic), and the overall condition assessment score varies between this maximum (186.2) and minimum (47.8). These scores are found based on the assumption that equipment could have all the 26 components, and the components are assessed for both the physical plant and the university. In a situation where only physical plant is assessed, the lowest possible score could be 44.796, and the highest possible score could be 61.032. The objective is to assign the lowest possible score's inverse as equivalent to 100 percent and any higher score would be a percentage less than 100 percent. The inverse for the overall condition score of 47.8 is 0.0209 . This 0.0209 is equivalent to 100 percent and the highest overall assessment score that is 61.032 would be 78 percent. The 
higher assessment score implies more deficiencies in the equipment, and the maintenance effectiveness is the percentage of the existing condition of the equipment score. This score as a percentage, can be compared to Figure 4.1, and the maintenance effectiveness and priorities can be known. The score of 78 percent means that the maintenance effectiveness is excellent, and tasks must be scheduled as priority four for rectifying deficiencies. Hence, this benchmarking scale would indicate the present scenario and would be helpful in understanding the importance of improving to the next desired level.

\subsection{Recommendations for Assessment Frequency}

The HVAC equipment assessment frequency is one of the important criteria that must be recommended to the management and workers of physical plant-type industries. Assessment frequency is the time between two assessments for all the HVAC equipment listed in Chapter three. It is important for the effective use of the automated tool. If equipment is assessed and deficiencies identified, work orders are generated to rectify the deficiencies. Once this repair or replacement work orders are completed, the equipment should perform without any failure for a period of time. It becomes imperative that the same equipment should be reassessed to know if its condition had changed after a period of time. But the question that could arise is "when is the reassessment to be performed', 'what is the time period' etc. Reassessments can neither be performed too often utilizing the resources nor too soon to reduce the risk of a potential catastrophe. An optimum assessment frequency should be determined and recommended. Assessment frequency certainly is not a single-driven factor. The factors that determine the assessment frequency are staffing levels, maintenance quality, equipment life expectancy, amount of equipment, failure rate of different components in the equipment, and risk exposure levels. Determining an exact time period for reassessment or the optimum assessment frequency is beyond the scope of this thesis as it is by itself a research topic. Considering all the factors, a fair time period is recommended in this research to cover over 12,000 pieces of equipment in the university. The most important caution in this tool or methodology is that it was not developed to substitute for or replace any method but resolves the issues mentioned in the research needs and objectives. 
Excessive assessment frequency adds costs in several ways, such as labor, material, and shop time. Insufficient assessment frequency would result in increased risk exposure levels, such as component and equipment failure or damage, repair or replacement down time, and health and safety hazards. Losses leading to costs may be incurred in both ways if not performed within an optimum time interval. An optimum range should be determined between costs and risks. The overall costs curve in Figure 4.2 shows the optimum time range between any two assessments, considering the risks and costs that could be incurred.

An assessment costs curve shows the total costs of performing an assessment. From Figure 4.2, it can be observed that this cost component tends to decrease when the time between two assessments is increased. This cost is the summation of resources, such as maintenance worker's time and salary, spare parts, transportation costs, etc.

The potential risks impact curve in Figure 4.2 is the curve that corresponds to the total costs that are incurred by postponing the assessment. The total cost is the summation of maintenance down time for repair and replacement of the equipment in the event of failure, component or equipment or property damage costs due to delay in identification or assessment, and safety hazards due to catastrophic failures. These cost components are not anticipated due to lack of proper assessment frequency. It is observed from the curve that the risk levels increase due to the increase in assessment time period, leading to losses as costs.

An overall costs curve indicates the optimum assessment frequency range where the assessment costs and the potential risk exposure levels are lowest. This can be observed in Figure 4.2. This is the assessment time period range or frequency where the equipment condition and the resources break even. But this is a representation of the problem, and the exact time period can be found only with data analysis on the costs to predict those points in the curve. This is one way of determining the time period. 


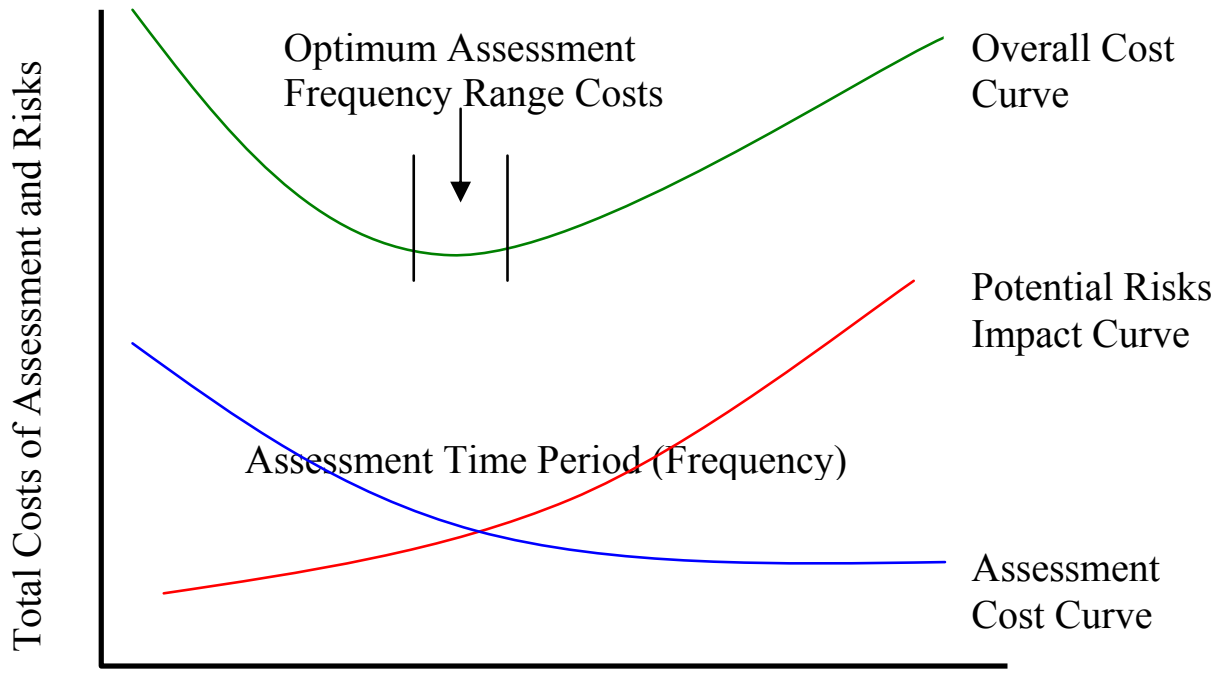

Figure 4.2. Assessment Frequency Optimization

The other method to approach the calculation of the assessment frequency problem is to determine the equipment life expectancy and failure rates of the different components in the equipment to calculate mean time to failure. This is a very tedious process but would result in an accurate assessment frequency and is beyond the scope of this thesis. The steps to reach that goal are explained below. There are three assumptions made to determine the assessment frequency schedule:

1. The time to fail is a Weibull distribution.

2. The cost of a defect increases linearly with time.

3. The assessments are 100 percent accurate at detecting a deficiency.

4. The assessment cost is $\mathrm{C}_{\mathrm{a}}$.

5. Cost of deficiency per unit time is $\mathrm{C}_{\mathrm{d}}$.

There are two defining parameters for the Weibull distribution and they are slope of the line -beta (shape factor) and characteristic life - eta (location factor in hours). The beta indicates the failure and the eta is the time to failure. The beta indicates the class of failures, such as infant mortality where beta is less than one, random failures (independent of age) where beta is equal to one and wear-out failures where beta is greater than one. If the failure rate increases (beta greater than one), then the time between successive assessments will decrease. If the failure rate is decreasing (beta lesser than one), then the time between successive assessments will increase. If the failure rate is constant, then the assessment frequency will be constant [43]. The most important reason to determine assessment frequency is to prevent failures and minimize catastrophes. The time to 
fail for any component is variable and they are generally represented by a probability density function (pdf) $\mathrm{f}(\mathrm{t})$. The pdf can be represented by a plot with time on the $\mathrm{x}$-axis or mathematically as follows: $\mathrm{pdf}=\mathrm{f}(\mathrm{t})=(\beta / 7 \mathrm{r}) *((\mathrm{t}-\gamma) / F)^{\beta-1} * \mathrm{e}^{-\left(\mathrm{t}-\gamma /{ }^{\prime} / 7\right) \wedge \beta}$

To obtain a statistical model on a data set, three parameters should be estimated. They are scale $(7$ (eta)), shape $(\beta$ (beta)) and location $(\gamma$ (gamma)). The method to estimate these parameters include probability plotting, rank regression on $\mathrm{x}$, rank regression on $\mathrm{y}$, and maximum likelihood estimation. Selecting an appropriate method depends on the data set. The mean time to failure (MTTF) can be calculated if beta, eta, and gamma functions are known for using the formula, $\mathrm{MTTF}=\pi * \gamma(1+1 / \beta)$.

Once the MTTF values are known for various components in the equipment, the assessment frequency is minimum, average, or summation of mean and standard deviation, etc. Values of eta and beta are listed in Table $\mathrm{E}$ of the appendix, but are only for educational purposes from [46]. The age of each failed and non-failed component in the equipment is required. The component age depends on the usage and the failure mode. For example, a burner or a bearing may fail as a function of time at high temperature or as the number of hot to cold to hot temperature cycles. When accurate data is not available on the failure mode, the date of shipment and date of return for service on a failure can be substituted. These data will increase the uncertainty and quality of identifying the failure, but the data fit will indicate the Weibull distribution. The average useful life of facility components in [44] shown in Table D, considers (1) development, production, and service, (2) mechanical, electrical, electronic materials and human failures, (3) natural causes such as lighting strikes, foreign object damage, climatic conditions, and (4) quality control, design deficiencies, and defective material for the lifetime calculations. Both these methods explained require data to proceed and determine accurate assessment frequency.

To recommend an assessment frequency time for physical plant-type of industries, few facts were considered. DM funds are allocated every fiscal year, and the DM lists identifying repair and replacement equipment are also compiled annually. To perform an extensive and comprehensive assessment for all the pieces of equipment in the university (approximately 12,000) during that time, using the limited resources and in-house personnel, the assessment frequency time should be at least once in a year. For example, in a cooling tower, the various factors that contribute to its failure, apart from maintenance and life expectancy of each component, are environment (air 
conditioning on an office building versus a chemical plant), water temperature, and chemistry (hot water strips galvanizing from steel, particulates plug fill, high or low $\mathrm{pH}$ can be corrosive), and usage (some air conditioning applications are seasonal versus process applications that run 24 hours a day), and construction types, such as corrosive and non-corrosive materials, etc. Considering the equipment manual listed in the assessment methodology, the constraints on the resources in a physical plant and brainstorming from physical plant management, the comprehensive assessment frequency should be at least once in a year.

\subsection{Time-Based Sensitivity - Real Time and Time Based Interactions in Updating System Reporting Aspects}

The real-time and time-based interaction in updating system reporting aspects of the FCA methodology are part of a continuous improvement system. The continuous improvement process in relevance with the FCA methodology is required for the following reasons:

- Integrating the proposed FCA methodology to the existing process,

- Setting achievable goals - to replace the reactive maintenance work orders with increased proactive work orders,

- Planning and scheduling the forecasted needs to meet the goal,

- Executing the assigned assessment with trained inspectors, and

- Reporting and updating the results to reset the goal.

To help in achieving these objectives, a process mapping of the existing work order flow is a good starting point. The process mapping with a feedback loop is shown in Figure 4.3. This process mapping creates a work flow defining the micro and macro level activities in the process. This process identifies the bottlenecks, missed steps, and redundancy from the beginning to the end. The developed HVAC equipment condition assessment process, when adopted in physical plant-types of industries should be part of the existing system. With the help of this newly developed process (specific problems are solved), overall system efficiency is increased and improved. The implication by not integrating this process with the existing main process would result in a situation where assessments would be carried out as a separate process, and work order complaint calls would be generated in physical plant as before. This would not lead to any process improvement and value addition, resulting in failure of the new process. Significant 
change in process would result only when this new process is a part of the existing process and provides a feedback system with reduced reactive work orders and increased proactive work orders.

The process mapping in Figure 4.3 has a 10 - step main process at the macro level that explains the general work order system from beginning to end. These macro level activities are broken into six micro-level activities as an individual process by itself. These six micro- level activities are $\mathrm{A}, \mathrm{B}, \mathrm{C}, \mathrm{D}, \mathrm{E}, \mathrm{F}$, and $\mathrm{G}$. The process flow of A, C, D, and $\mathrm{E}$ are only mapped for this feedback system in relation to this thesis work, as the other process flow is not relevant to this research. The main 10 step process flow with the four process flow as shown in Figure 4.4 is explained in the following sections.

\subsubsection{Modes of Work Requests and Classification of Work Orders}

The mode of work request is the first step in the work order process where physical plant's central office radio room receives two main work request types. The radio room is part of the resource management team explained in Chapter one. The two main work request types are reactive and proactive maintenance that are received by physical plant on a day-to-day basis. The different methods of receiving reactive maintenance work requests are through physical plant's electronic mail, through phone to the radio room personnel, through fax, and through workers initiating the work request during their routine maintenance (where they identify any deficiency) work. Proactive work requests are received by two different sources, such as night shift PM and HVAC equipment condition assessment. The night shift PM, as explained in Chapter one performs PM only on the AHUs and FCUs and generates work order requests. The proposed HVAC equipment assessment process generates continuous work order requests on completing an assessment. The assessment process is integrated to existing system at this stage.

Integration of the assessment process to generate automatic work orders can be done by the existing database software (TMA). The assessment process is performed using a laptop computer or a personal digital assistance (PDA). The existing database software can be installed on these electronic devices and on completing the assessments, the results can be updated through shared network access. This is a simple process that can be performed by the existing computer network

professionals in the physical plant department. Currently, using this TMA database, the work 
order requests and work orders are generated. Upon completion of the equipment assessment, either the data can be manually entered as work requests into the database or automatically transferred from the assessment fields to the database. In situations where both are not possible, the inspection worker can contact the radio room and issue these assessment forms as input for the proactive work order requests. The HVAC FCA process A, in Figure 4.3, is an exclusive tenstep process that explains the flow of proactive work request generation as shown in Figure 4.7. The reactive and proactive work requests are to be approved as work orders in order to execute the actual work. This is a verification process performed by the resource management where they accept or reject a work request depending on the management policies and procedures. All work requests need not be a work order. They can be cancelled as work requests either by the requestor or physical plant for various reasons. Work requests can be an estimation of a specific task, like a major alteration work that involves estimation of project costs, completion time, material requirement, and the methods of completing the task. Only when all these factors are acceptable and approved by physical plant and the requestor, can these work requests be executed as a work order. These work orders are called projects, shown as process B in Figure 4.3, but process B is not related to this research work. In other cases, the work requests are to be verified for duplication. A specific work request could be generated by one or more people. Hence, all the work requests cannot be performed as work orders.

Work requests should be verified for duplication by obtaining the inputs such as location, equipment, building identification, malfunction start date, work requestor name (inspector), etc. The details of the work requests are to be obtained as an input and built-in keywords should be generated to compare and identify the duplication. If duplication is identified, the requestor should be given feedback on the work order status and the work request should be cancelled. For example, on a particular equipment failure, if a prior work order exists, the requestor should be informed about the work order status as feedback and not generate a new one. Once the duplication is eliminated by verifying the input details and work order status, if the work request is identified as a first time complaint, a work order can be processed. 


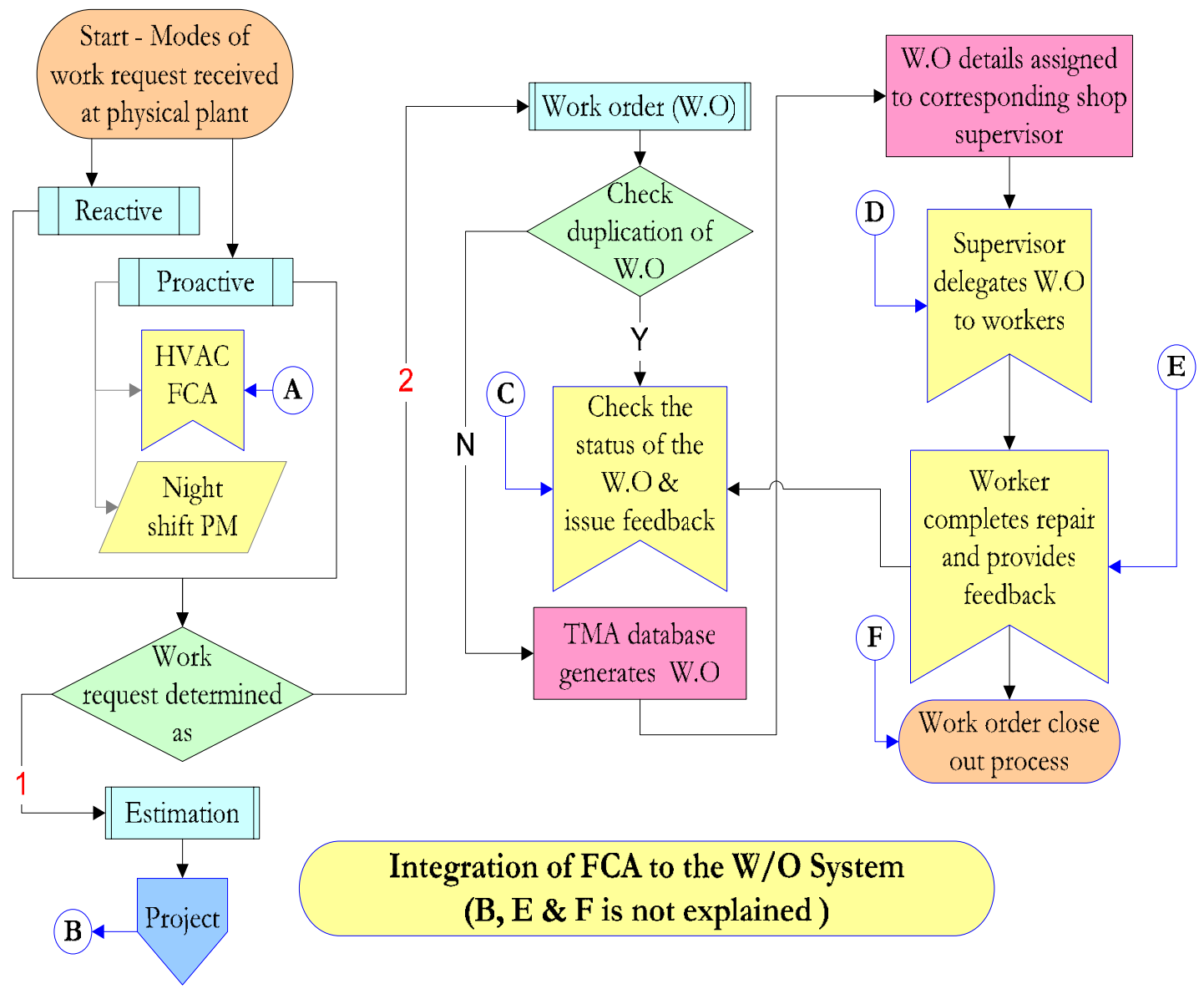

Figure 4.3. Work Order (W/O) Flow and Feedback Process

\subsubsection{Work Order Status Check}

The work order status is the exact stage of the work order in the system since the time it had been generated. Work order status should determine the current work in progress in the work order pipeline system. The status of any work order can be determined only by collecting inputs from the various personnel involved from the beginning to end of a work order process. At present, according to the specific requests, this status is verified by personnel communication and not electronically from the database. The work order status determination process $\mathrm{C}$ is shown in Figure 4.4, and the various stages required for recording the work order status are shown in Figure 4.5. Determination of work order status is a recording process of the exact date and time of receiving, sending, and the various activities performed in a work order. The process, shown in 
Figure 4.5, is a nine step process and they are represented as numbers from two to 10 . These numbers represents the different recording data.

Step one of this process, in Figure 4.4, is to record the work requests failure deficiency details, malfunction start date, location, and equipment identification code of the failure. To confirm these details and process the work requests, the database should ask "Confirm the Information" and "Return to the Information." By clicking the "Confirm the Information," the current date and time of the work requests should be recorded (2) and clicking "Return to the Information" would allow him/her to work on the work request details.

The next step, shown in Figure 4.4, is to record (3) the data and time of sending this work order to the corresponding shop supervisor. At present, this process is performed by printing three copies of the work order and sending them to the supervisor's mail box. Possibility of paper work missing, delay in sending paper work to the mail box, and the cost of paper work are current process inefficiencies. These inefficiencies can be eliminated and this activity time can be decreased (in fact no time) by performing the same task electronically. Printing the work order can be done whenever it is needed, depending on its purpose. The record (3) can be collected when the resource management personnel assigns this work order to a particular shop. Before he/she quits this process, the database should ask a question "Send," or "Return," By clicking "Send," the record (3) is collected and by clicking "Return," he/she can work on the same window. 


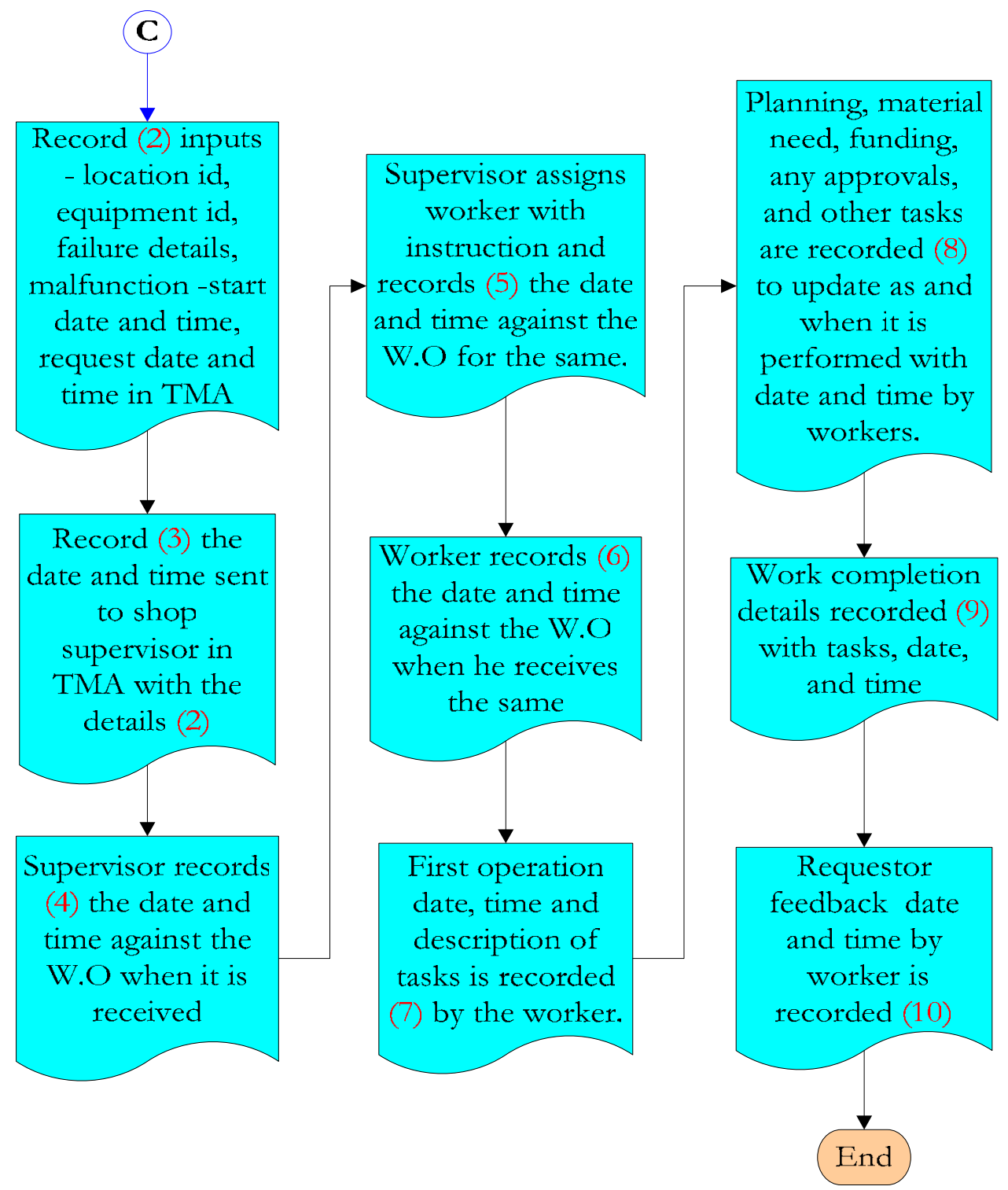

Figure 4.4. Work Order Status Recording Stages

The next step is to record (4) the date and time when the supervisor receives the work order. The supervisor should have access to the database via his "Username" and "Password." The database should indicate alerts such as "New Work Order" and "Pending Work Orders," etc. Once "New Work Order" is clicked, the window should indicate the work order details. This process is called receiving. Before quitting this window, the database should ask a question before closing the work order, such as "Confirm the Work Order Arrival." Once "Yes" is clicked, the current date and time should be recorded automatically to ease the process and to avoid tampering with the data. 
The next step is to record (5) the date and time of assigning workers to the work order by the supervisor. This decision is made by the supervisor considering various factors, such as work load, geographical distribution, skill requirement of the work order, etc. This is a process by itself, as shown in Figure 4.5 and is part of Figure 4.3 as D. A field can be created in the database called "Assign Workers." On clicking this field, a window indicating a drop-down list should be present. The drop down list should consist of fields such as "Worker Name," "Zone," "Skill Level," "Work Load," etc. On selecting a particular "Skill Level”, the lists of workers in that skill level should be listed. After selecting the "Zone" and the "Worker Name", the "Work Load" field should be clicked to find the current number of "Pending Work Orders" for that specific worker. Once the supervisor has made his decision on this particular worker, "Assign this Worker" or "Return," questions should be asked. When "Assign this Worker" is clicked, the date and time should be recorded, and by clicking "Return" should allow the supervisor to consider the other options in this window. At this stage the supervisor could print a copy of the work order and send it to the respective workers' mail box. To resolve the issues raised by the workers upon the assigned work orders, an option "Questions" should be available. These are the questions that the worker has with respect to the assigned work orders, and the supervisor sends his reply or correction as the "Feedback" field. The supervisor should have all privileges to access any workers' activity process or status.

The next step shown in Figure 4.4 is to record (6) the date and time of receiving the work order by the worker. To computerize the entire work order system, the computer use should be at the workers level too. The worker on a timely basis such as shift start time, etc., should login to the computer with their "Username" and "Password" to access the new work order arrival. The database should indicate the "Assigned New Work Orders" and "Pending Work Orders" etc. in the first window. On clicking the "Assigned New Work Orders," the work order details with the supervisor's suggestion or comment should appear. Before quitting this window, "Reviewed the Work Order" or "Questions" options should be available. "Reviewed the Work order" should record the date and time automatically and this implies that the worker is ready to start the first operation towards the work order. By clicking "Questions," the worker indicates the issues related to proceed with that work order, and this is sent to the supervisor for answers. The supervisor's reply or corrections are sent in the field "Feedback." Once this is acceptable to the worker, before quitting this window, "Reviewed the Work order" or "Questions" options should be available. Soft copies of the work orders should be available for copying in their PDA's. 
The next step, shown in Figure 4.4, is to record (7) the first operation or activity on the work order. This is the actual maintenance execution such as field inspection of the repair or ordering material for the repair, etc. Workers should possess a PDA to enter the activity description toward the work order. On completion of this data entry, this information should be saved. This would record the date and time of that activity toward the work order automatically. Consider a situation where a worker performs a field inspection on a specific date and time and identifies a leak in the plumbing fixture. The worker should login to his PDA and select the field "Building ID" and that would bring the lists of work orders in that building. The worker should select "Location ID" for the specific location of the deficiency such as the room number. The worker should select "MM/YY" to bring a lists of work orders generated in that location. By knowing the "Work Order Number", these steps can be avoided. On selecting the "Work Order Number," the activity details should be entered and "Save" key is to be clicked. A keyword drop-down lists should be generated with all the possible activity tasks listed. These keywords could be field inspection completed, initiate FCA, materials to order, lack of tools, field condition not suitable to work, work completed, consult supervisor, etc. These keywords should be updated and/or added as and when required.

The next step, in Figure 4.4, is to record (8) the intermediate activities and work-in-progress details to the work order. This process is similar to record (7) except for the changes in the keyword. This step would happen for every activity performed in the work order after every break in the process. The progressive activities could be listed such as planning of the job, material need, request for funding, any approvals, etc. The activity is entered in the same manner as explained in record (7) with respect to the "Work Order Number" and saved for an automatic record of data and time of that activity. This process is repeated until the actual repair or replacement work is completed.

The next step, shown in Figure 4.4, is to record (9) the technical work completion details. This process is also performed in a similar method, as explained in record (7), except that "Technical Completion" should be clicked at this stage. This field should be present in every work order window. The final maintenance activity is to be recorded from the keyword lists. On clicking "Save," the date and time are recorded. 
The final step is recording (10) the requestor feedback. This activity is an optional process, as this does not occur for all work orders. If feedback to the requestor is mandatory, the supervisor should recommend it in the suggestions or comments column in the work order. If this activity is not performed by the worker, the resource management would perform it in the work order closeout process, shown in Figure 9.

\subsubsection{Generating Work Orders}

The work order status process, explained in the previous section, is only for work orders generated before the work is done. This implies that for a completed work order or a work-inprogress work order, the status would be one of the nine steps. If a work order is generated currently, the process would follow the " $\mathrm{N}$ " loop, as shown in the Figure 4.3, indicating no duplication. The different types of work orders related to this thesis work are as follows:

- Quick Fix: Any work order that could be completed in one hour.

- Minor Repair: Any work order that could be completed within $\$ 25,000$.

- Preventive Maintenance: Any work order generated by the night shift maintenance.

- Routine Maintenance: Any work order that is a scheduled maintenance and the work order costs could be over or under $\$ 25,000$.

- HVAC FCA: Any work order generated from the assessment process.

- Emergency: Any catastrophic damage work order.

These different types of work orders type are selected from the built-in function of the TMA database. These are assigned to the work orders depending on their type. The immediate steps involved after generating a work order are explained in record (3) of work order status. At present, a four-copy work order document is generated as yellow, pink, golden red, and white copy. The white copy is to be retained by the resource management until they receive the pink copy. The golden red is retained in the supervisor's file and they send the pink and yellow copies are sent to the worker's mail box. The worker writes the work description on the pink and yellow and retains the yellow copy in his file. The pink copy is sent to the supervisor for his signature approval on completion and sent them on to the resource management. Storing, filing, and tracking the costs and time lost in this paper work-based work order system are the inefficiencies in the paper work process. The paper work has a start and end date for the work order and 
detailed information or activities are not recorded consistently, unlike the process explained in the earlier sections.

\subsubsection{Implementing the Continuous Improvement Goals}

Continuous improvement goals in maintenance management implies improving the work order flow, reducing the number of reactive maintenance work orders, increasing proactive work orders, monitoring work order flow, developing a work order feedback system, etc. The effective flow of work orders without stalling or blocking in the work order pipeline can be avoided by a constant monitoring process. Work order status is one of the monitoring processes, explained in the previous section. The next process in the work order system is assigning the work orders to the supervisors. This task is performed by the resource management, depending on the equipment failure type. For example, air compressor problems are assigned to millwrights, chiller problems are assigned to HVAC shop, and boiler problems are assigned to the plumbing shop supervisors (explained in chapter one). In case of quick-fix-type of work orders, the resource management also informs the worker through the wireless communication system. In these situations, the resource management assigns the worker, as it is a predefined function. Quick fix work orders are mostly assigned in this manner. For other work orders, the workers are assigned by the supervisors of the respective shops. Presently, a supervisor delegates work orders based on the geographic distribution and for any immediate completion of a work order, overtime is assigned. Since the work orders are not assigned based on current priority or need, replacement and repair maintenance work orders are performed as they are received. Due to the lack of centralized information on the deficiencies and conditions of the facilities, the work orders are carried out at the cost of the critical ones. To eliminate these problems, two processes such as A and D are shown in Figure 4.3. The process D, explained in this section, increases proactive work orders and decreases reactive work orders by work load measurement and a work order monitoring process, is shown in Figure 4.5.

The work order types and the modes of request should be assigned a code, and this information should be available on all work orders to identify "Total PM," "Total FCA," "Total Reactive," etc. The database should perform an automated count of these work-order types and modes. Access to these counts should be available for the supervisor during login. This would indicate to the supervisor the overall status of the work orders and would help for better decision making. 
The decision making should involve comparing these three fields with each other. It should be identified, if the FCA work order is greater or lesser than PM work orders. If the FCA is greater, the next comparison should be with reactive work orders. If the FCA is the greatest in total numbers, this indicates that the work orders are generated in a proactive manner. But, if the PM is greater than the FCA, PM should be compared with reactive work orders to identify the efficiency of the PM process. If it is observed that PM is the greatest, the PM process should to be improved by assigning FCA to AHU and FCU (existing PM process is explained in chapter one). This would enable the PM process to generate more FCA-related work orders apart from PM. The PM process should be expanded for other HVAC equipment for an efficient PM program and increasing proactive work orders. If it is observed that reactive work orders are the greatest, the percentage increase of reactive over FCA should be calculated. This would help in understanding the improvement required to achieve the higher maintenance level. The current work order should be checked, if it was assessed before using the FCA. 


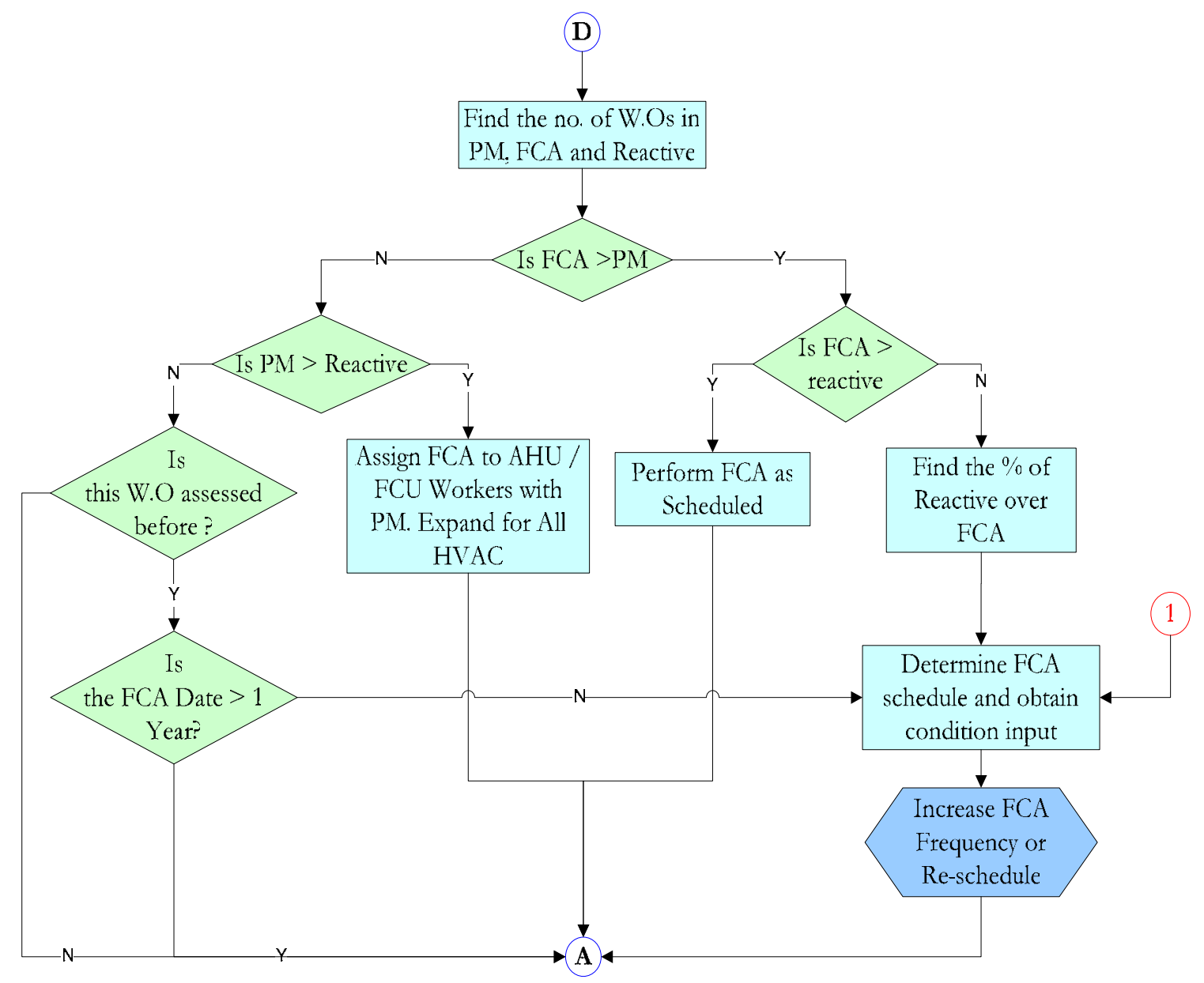

Figure 4.5. Continuous Improvement in Maintenance Management

If it is found to have been assessed before, the date of assessment should be verified. If the date of assessment is more than one year, the supervisor should verify the next assessment schedule on this equipment. In case the date is less than one year, the FCA document should be reviewed with the present equipment condition from worker input. Increasing FCA frequency or rescheduling should be considered from the workers input (1). This input (1) is part of process E, shown in Figure 4.7. This method of verifying the work order system is a continuous monitoring and improvement process. Process D, part of Figure 4.3, should be performed at the supervisor level with the help of the database. Hence the process, shown in Figure 4.5, would increase the proactive work orders (FCA) by reducing the reactive maintenance work orders through repeated utilization of the FCA assessments. Continuous improvement goals, like achieving better maintenance quality levels, are shown in Table 4.1, where, level one represents a showpiece 
facility, level two represents comprehensive stewardship, level three represents managed care, level four represents reactive management, and level five represents crisis. These levels were established by the Association of Physical plant Administrators (APPA).

Table 4.2. Maintenance Standards by APPA [43]

\begin{tabular}{|c|c|c|c|c|c|}
\hline Measures & Level 1 & Level 2 & Level 3 & Level 4 & Level 5 \\
\hline $\begin{array}{l}\text { Preventive } \\
\text { /corrective } \\
\text { maintenance }\end{array}$ & $\begin{array}{c}\text { Close } \\
\text { to } 100 \%\end{array}$ & $\begin{array}{l}75 \text { to } \\
100 \%\end{array}$ & $\begin{array}{l}50 \text { to } \\
75 \%\end{array}$ & $\begin{array}{l}25 \text { to } \\
50 \%\end{array}$ & $\begin{array}{c}\text { Less than } \\
25 \%\end{array}$ \\
\hline $\begin{array}{c}\text { Service } \\
\text { efficiency } \\
\text { and } \\
\text { reliability }\end{array}$ & $\begin{array}{c}\text { Fully } \\
\text { functional } \\
\text { and excellent } \\
\text { operating } \\
\text { condition }\end{array}$ & $\begin{array}{l}\text { Usually } \\
\text { functional } \\
\text { and in } \\
\text { operating } \\
\text { condition }\end{array}$ & $\begin{array}{c}\text { Mostly } \\
\text { functional } \\
\text { and } \\
\text { occasional } \\
\text { breakdowns. }\end{array}$ & $\begin{array}{l}\text { Frequently } \\
\text { broken and } \\
\text { inoperative }\end{array}$ & $\begin{array}{l}\text { Routinely } \\
\text { broken and } \\
\text { inoperative }\end{array}$ \\
\hline $\begin{array}{l}\text { Customer } \\
\text { service and } \\
\text { response } \\
\text { time }\end{array}$ & $\begin{array}{l}\text { High level of } \\
\text { trust and } \\
\text { immediate } \\
\text { response. }\end{array}$ & $\begin{array}{l}\text { Satisfied and } \\
\text { responses are } \\
\text { within a } \\
\text { week. }\end{array}$ & $\begin{array}{l}\text { Basic level } \\
\text { of trust and } \\
\text { responses are } \\
\text { within a } \\
\text { month. }\end{array}$ & $\begin{array}{l}\text { Losing trust } \\
\text { and } \\
\text { responses are } \\
\text { within a } \\
\text { year. }\end{array}$ & $\begin{array}{l}\text { Mistrust and } \\
\text { responses } \\
\text { only on } \\
\text { emergencies. }\end{array}$ \\
\hline $\begin{array}{c}\text { Facility } \\
\text { maintenance } \\
\text { operating } \\
\text { budget }\end{array}$ & $\begin{array}{l}\text { Greater than } \\
4 \% \text { of } \\
\text { component } \\
\text { replacement } \\
\text { value. }\end{array}$ & $\begin{array}{l}\text { Between } 3.5 \\
\text { and } 4 \% \text { of } \\
\text { component } \\
\text { replacement } \\
\text { value. }\end{array}$ & $\begin{array}{c}\text { Between } 3 \\
\text { and } 3.5 \% \text { of } \\
\text { component } \\
\text { replacement } \\
\text { value. }\end{array}$ & $\begin{array}{l}\text { Between } 2.5 \\
\text { and } 3 \% \text { of } \\
\text { component } \\
\text { replacement } \\
\text { value. }\end{array}$ & $\begin{array}{l}\text { Less than } \\
2.5 \% \text { of } \\
\text { component } \\
\text { replacement } \\
\text { value. }\end{array}$ \\
\hline
\end{tabular}




\subsubsection{Integrating Assessment Model and Preventive Maintenance Program}

As mentioned in the need for research in Chapter one, any planned maintenance activity that is designed to improve equipment life and avoid unplanned maintenance activity is PM. The primary goal of any PM program is to minimize and/or prevent failure or breakdown of equipment before it occurs. PM activities include equipment inspection, lubrication, overhauls at specified frequencies, recording equipment deterioration to identify repair or replacement need, etc. The PM interval is determined based on the prevailing condition of the equipment and/or the usage metrics prescribed by the manufacturer. In most cases, the age of the equipment is difficult to use in following the usage metrics, as the equipment might deteriorated due to various factors such as environment, priorities, funds, manpower, skill level, etc., as mentioned in Chapter one. Hence the identification of equipment that needs PM and the existing condition of the equipment are the two most important parts of a PM program. This assessment model is designed to meet these two criteria, and the explanation for these two steps is discussed in Chapter three. A PM program is effective only when performed on equipment or components with increasing failure rates (and not with a constant failure rate where PM has no impact) and when an overall cost of a PM action is less than the corrective action. To explain and verify the integration process of an assessment model (AM) and PM program, the tasks required for a PM program include [35]:

- PM: Identification of equipment breakdown consequences

AM: Job/human/environmental safety, component/property damage value, maintenance repair/hindrance time

- PM: Identifying where (equipment) to start

AM: HVAC equipment is identified and reason for selecting the same is explained in Chapter three

- PM: Identifying key components

AM: All the components in the selected HVAC equipment are identified and the functional value of each component is mentioned

- PM: Periodic inspection

AM: Frequency for performing the assessment is explained in this chapter in section two.

- PM: Non-destructive testing

AM: Physical and visual condition assessment is part of non-destructive testing.

- PM: Preplanned maintenance activities 
AM: Integration with the current maintenance activities and continuous improvement goals are part of preplanned maintenance activities

- PM: Maintenance to correct deficiencies found through inspections and testing AM: Work order generation from the assessment is to correct deficiencies

- PM: Guidelines to inspection

AM: Assessment model is a user friendly inspection program that guides the worker with components and checkpoints

- PM: Documentation of maintenance records, etc.

AM: Corporate memory and knowledge as part of this assessment model to document maintenance and assessment activities

Best maintenance practices in [44] mentions that 90 percent of work orders are generated by PM inspections and 30 percent of all work is PM. To achieve this goal, one of the best suited solutions is to utilize the assessment model effectively, as explained in this chapter.

\subsubsection{Executing Work and Assigning Assessments}

The actual work execution is performed by the maintenance workers of the respective shops, after they receive the work orders from the supervisor. This process $\mathrm{E}$ is shown in Figure 4.6 (also part of Figure 4.3). The first operation of the worker in the work orders is either inspection of the deficiency, or planning the work, if the deficiency is known. During field inspection, the worker should be checking on the job safety (x1), life or environmental safety issue (x4), equipment damage (x2), any University property damage to the (x5), and hindrance time (x6) for the occupants, etc. If any of these parameters are identified, worker contacts the radio room or supervisor or assistant directors (AD) for assistance. At this stage the supervisor should initiate FCA to evaluate the equipment. This process is shown in Figure 4.5 and Figure 4.6 as input (1). Prior to executing the work order, planning the work is required. Planning involves identifying material requirements for the work. Work orders such as tightening fasteners, changing belts, changing filters, etc are routine work orders that do not require extensive planning to complete.

Work orders that involve multiple tasks, such as planning of materials (ordering materials like motors etc.), scheduling workers (plumbers, welders, HVAC workers, etc.), time schedule of 
work execution, etc., requires extensive planning. To order materials, workers should identify part specification to check on the availability in the warehouse. The job can be completed, if the warehouse stocks the material that the work order requires. Otherwise the material ordering process $\mathrm{G}$ (shown in Figure 4.6) is an exclusive process that utilizes time for identifying the vendor, the bidding process, approvals from superiors, paper work, ordering the material, receiving process, and notifying to workers on arrival. This process is not explained in detail, as it is not relevant to this thesis work. Material ordering is a complex process with various policies and procedures. During this process, the various steps involved should be entered in the electronic device for monitoring and tracking the work order. The keyword database should include information such as stocked item in warehouse, non-stocked item, credit card purchase, competitive bidding, open-end contract, supervisor approval, assistant director approval, identifying vendor, material shipped, etc. The information-recording process would improve the efficiency of work order tracking and monitoring (shown in Figure 4.4). On material arrival the work order is completed by performing other physical tasks. This indicates the technical completion of the work order. Presently, the worker writes the repair and replacement deficiency on the yellow and pink copies of the work order. The yellow is retained in the shop for reference, and the pink copy of the work order is stamped complete and signed by the supervisor before being sent to resource management. The details for the delay in the process or the time involved in each activity for the work order are not recorded. The proposed feedback process would eliminate these process inefficiencies through continuous improvement. On completing the technical work, the work order close out process - E as shown in Figure 4.6, is the final step. This involves various steps and is not relevant to this thesis work, hence not explained. 


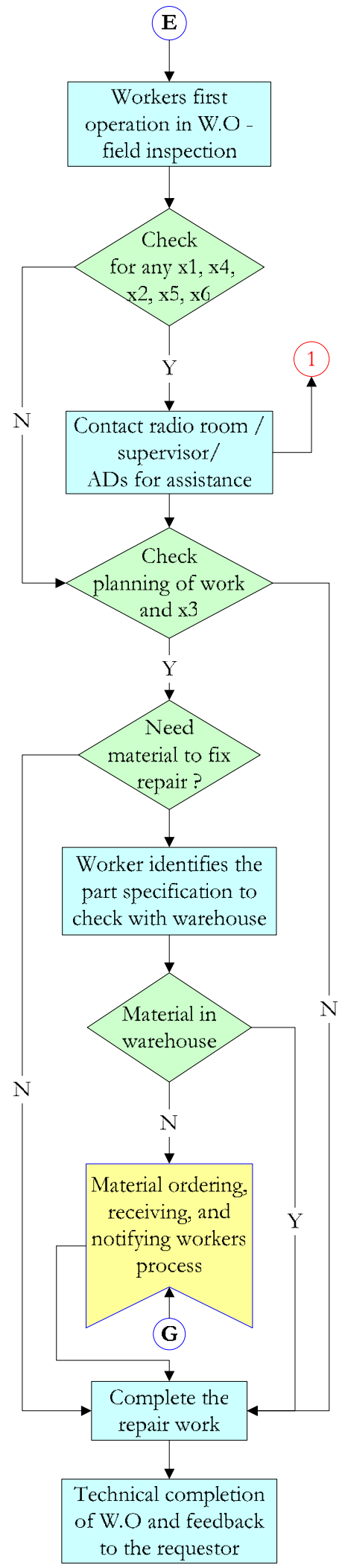

Figure 4.6. Technical Work Executions 


\subsection{Testing FCA Methodology with Cooling Towers}

The equipment condition assessment process flow chart, shown in Figure 4.7, is explained using two cooling towers. The cooling tower examples chosen are located in Allan Hall and the Creative Arts Center. The ten-step assessment process is explained in four different sections as input, model, output, and feedback (update, addition, or change) in the following sections:

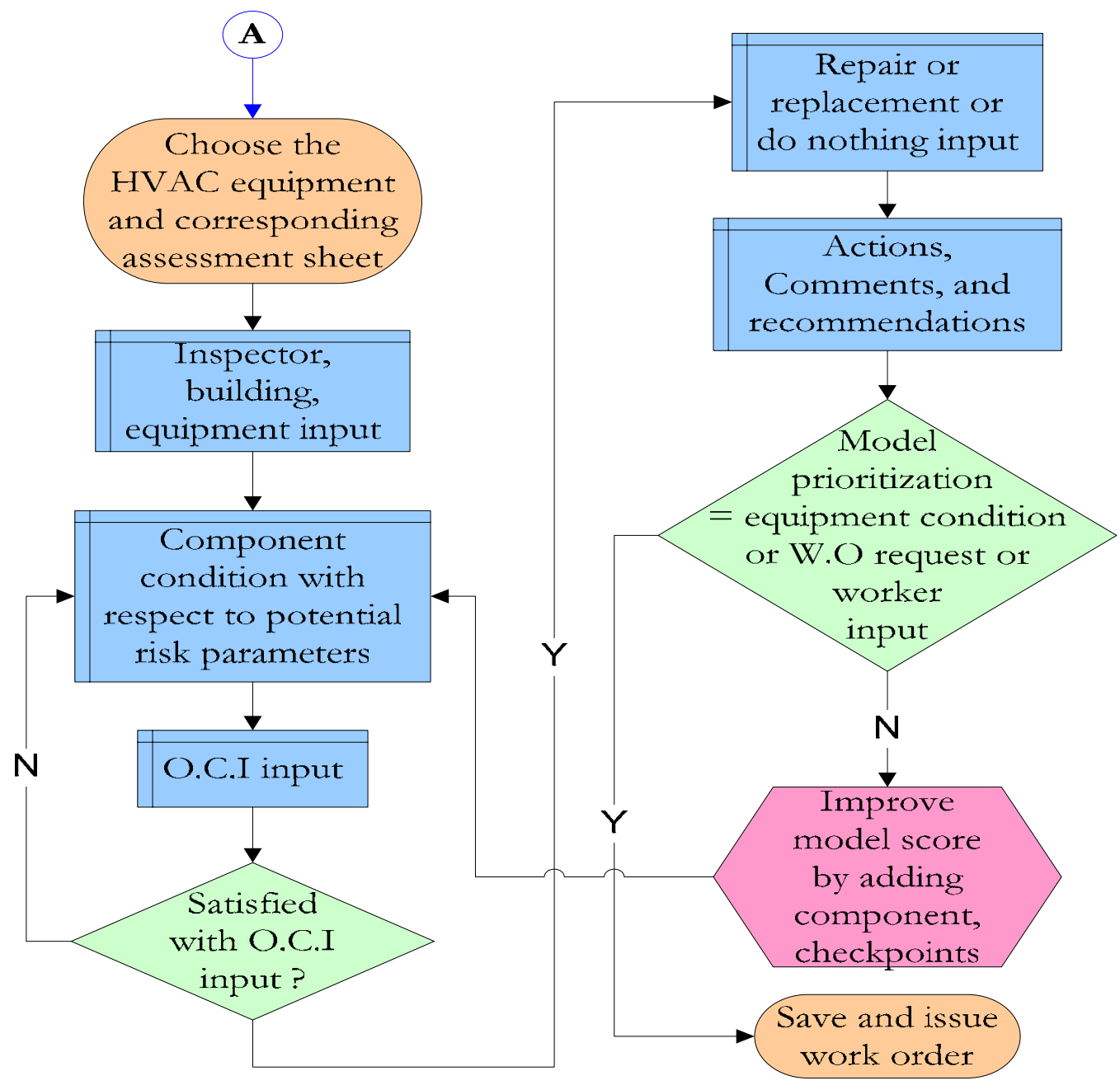

Figure 4.7. Facilities Condition Assessment Process 


\subsubsection{Assessment Input}

Once a scheduled assessment form is selected (for example, a cooling tower), the inspector, building and equipment are entered. The inspector name information would help in identifying the quality and consistency of assessment for any reassessments or rescheduling, and the inspection date (06/18/04) would help in the identification of the assessment schedule or frequency for future reference. While generating the work orders, the requestor name and request date would be recorded as the assessment worker name and date. This would also be helpful for future questions or clarifications on the work order and the assessment itself. The input information of equipment building name (Allan Hall), number (02010123), room number (roof top), and square feet are important for identifying the equipment with respect to the building it serves. This would help in associating the maintenance costs to the corresponding building. Creating a database for this information would indicate all the equipment in this particular room, building, and its condition. On issuing work orders for these pieces of equipment, it helps the worker assigned to the work order in locating the equipment, as the assessment worker and worker assigned for work orders would be different. The input information of equipment name (cooling tower), model (CL1478AR22) and serial number (58020-52862) of the equipment, manufacturer (Tower Tech), type (counter flow), capacity (gallons per minute), and installation year (1997) would help in identifying the components during replacement, material ordering, etc. Statistical analysis and study on the condition of the equipment with respect to age and type of equipment, etc., can be performed with this information.

This assessment tool helps in recording and documenting the above-mentioned basic information as and when they inspect the equipment. Monitoring and recording would help in identifying the behavior pattern and performance changes of the equipment over a period of time. As explained before, to cover the volume of equipment in university-type facilities (over 12,000), this method of data collection and related to the physical condition is imperative. This method of recording the equipment specification would eliminate the current hiring practices of temporary workers to collect similar data. The data collected using temporary workers is utilized for equipment tagging to the TMA database. The data collection process and conversion of data into useful information without any discrepancy is very complex. This limitation is eliminated by using the input phase of the assessment tool and helps in eliminating the existing limitations towards corporate memory, as shown in Table 4.3. 
Table 4.3. Assessment Input for Corporate Memory

\begin{tabular}{|c|c|c|c|}
\hline Inspector's Name & Gary Boyd & $\begin{array}{l}\text { Equipment } \\
\text { Name }\end{array}$ & Cooling Tower \\
\hline Inspection Date & $6 / 18 / 2004$ & Manufacturer & Tower Tech \\
\hline Building Name & Alan/ Percival Hall & Model Number & CL1478AR22 \\
\hline Building Number & 101123 & Serial Number & $58020-52862$ \\
\hline Room Number & Roof Top & Type & Counter flow \\
\hline Gross Square Footage & NA & Capacity & GPM \\
\hline Time To Assess & 32 Minutes & Year Installed & 1997 \\
\hline \multicolumn{2}{|c|}{ Repair or Replacement Suggestions } & \multicolumn{2}{|c|}{$\begin{array}{l}\text { Actions and Recommendations: } \\
\text { Example: Deteriorating wood, } \\
\text { clogging, debris, cleaning to be done. } \\
\text { These actions will be issued as a Work } \\
\text { Order as shown in Figure } 4-7 \text {. }\end{array}$} \\
\hline \multicolumn{4}{|c|}{$\begin{array}{l}\text { All Assessment information is recorded as and when each component / checkpoint is } \\
\text { inspected }\end{array}$} \\
\hline
\end{tabular}

\subsubsection{Assessment Model}

The assessment model is created based on risk potential parameters, as shown in Figure 3.5. The conversion of these risk potential parameters into four condition levels and measurements of each condition levels are shown in Table 3.7 and Table 3.8. All this information is designed and developed in such a manner that the worker assessing the equipment could visually refer to it during each component inspection. This guides the worker during the assessment process to remain focused, eliminates data entry error, fear towards technology, and creates a user-friendly tool. The assessment model inputs are listed in a drop-down format as good, fair, poor, and critical, as explained in Chapter three. The scoring, priority, and formula of the model can be held in the background of the assessments sheets for security reasons. The components of the equipment (cooling tower) with their corresponding check points are listed together in an individual row for each component. The first column corresponding to these rows list the respective functional values $(Z)$ of these components, as explained in Chapter three. A matrix of empty cells would be present for each component corresponding to their risk potential parameter. These are the assessment model inputs with the condition level drop-down menu. Each cell would result in the display of four options as good, fair, poor, and critical. The worker should select any one of these four options depending on the physical condition of the component with 
respect to the defined measures of the risk parameters. The component that is not applicable to that equipment, for example, fans or motors can be connected using belts or a gearbox, either the belt or gearbox would be "Not Applicable" (NA), and would result in a component score of zero.

The identification of components and checkpoints is shown in Figure 3.4. In the sections below, the components of a cooling tower and their respective check points are explained in an abstract manner with functional value (z) toward the tower. The worker assessment of the cooling tower's physical condition is also indicated with respect to all the risk potential parameter.

1. Electrical Wiring: Electrical wiring is considered a safety as well as an operational component on the functional value. The worker should check for insulation and loose connections in the cooling tower at all electrical terminals. Cleanliness and dust accumulations should also be checked as they might hide the insulation condition and lead to corrosion. Check for charring and short circuiting.

2. Motor: The motor drives the fan in the cooling tower. Workers should check the motor ventilation, overload heat, and the insulation. Check for alignment with drive system, lubrication, noise level, and the vibration of the motor. Check for motor accumulated dust and cleanliness. Since the motor is one of the operational components of the cooling tower, if it fails, then the fan will also fail to perform. Hence, its functional value is classified as operational.

3. Gear Box: The gear box is the alternative arrangement for the motor drive system. Check the oil level and drain the oil and check for any foreign material such as water, metal shavings, or sludge. Check for oil leaks and the seals condition. Check the noise, vibration, and alignment of the gear box inner parts. This is an operating component, and if they fail, the power transmission to the fans stops.

4. Fans: These can be induced or forced draft. They can be connected with a belt or gear box with the motor. These are considered to be the operational component with respect to their functional value as motors. Check for blade vibration or wobbling. Corrosion, bending, and scale formation on the fan and blades should be checked. Check for alignment, speed, lubrication and noise level of the fan. 
5. Water Distribution: Water distribution includes the spray nozzles and water distribution deck. Check for clogging and debris accumulation. Check the splash guards and the flow pressure. Check for corrosion and erosion. Check for leaks, deck wrapping, and water distribution holes. Since this action is responsible for the water flow to the fill, it is considered as an operational component with respect to the functional value.

6. Belts and Pulleys: Check the condition of the pulley by inspecting for corrosion, lubrication, and groove. Inspect the bushings holding the pulley. Check for proper alignment and tightness of the belts. Check for signs of wear and size. Check the shaft lubrication, seals, and other damage. This is an operating component. If belts and pulleys fail, then the power transmission to the fans is stopped.

7. Bearings, Couplings and Keys: These are the mechanical components in the motor, drive shaft, fan, and the gear box. Check for corrosion, wear and tear, and loss of metal. Check for vibration, alignment, noise level, and over heating. Check for brittleness and cracks. These are primary support components for the motor, fan drive system, etc., in the functional value.

8. Structure / Columns: The tower is built on these structures and columns. The material can be wood and or metal. Spot checks for corrosion should be conducted. Joint strength and bolt tightness should be inspected. Wood decay, including rot, cracks, and fractures should be checked. Check for general deterioration of the columns and structures due to age and water. If tapped with a hammer a dull soft noise indicates its weakness. Since, failure of this component will affect the operational components, this component of the cooling tower is classified as a primary support. As an example, a new cooling tower in Allan Hall with a "Fair" condition structure is shown in Figure 4.8. 


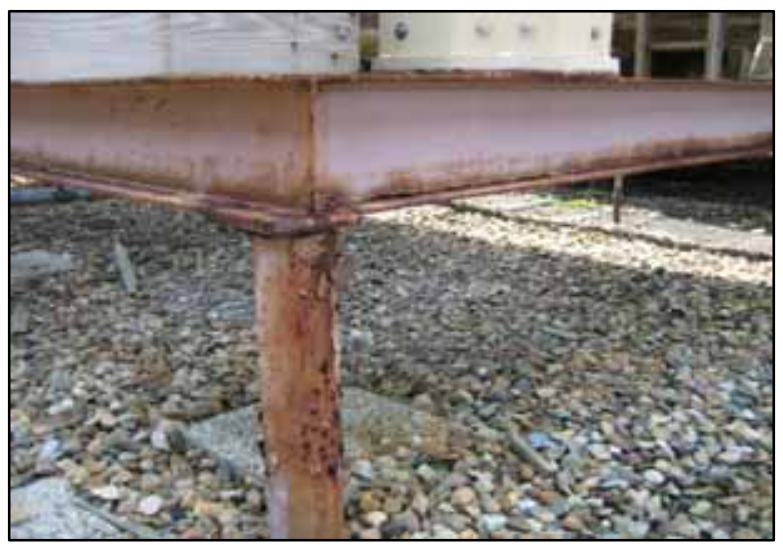

Figure 4.8. Example of a "Fair" Condition Structure in a New Cooling Tower (Allan Hall)

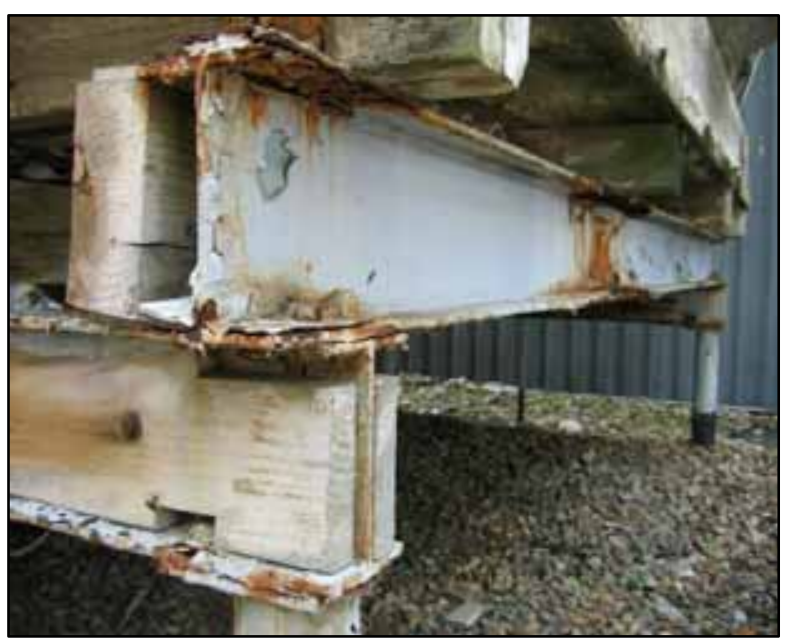

Figure 4.9. Example of a "Critical” Condition Structure in an Old Cooling Tower (Allan Hall)

Assessment Output: Explanation for Figure 4.9, structure and columns in critical condition. During work on the maintenance job, the critical condition of the structure and columns with respect to load bearing and strength due to corrosion, deterioration, etc., might lead to fatality. Hence "critical" was selected, and this assigns a score of 2,048 (safety is regardless of the functional value). To repair and replace the structural components, such as beams, wooden cross bars, etc, might cost more than 50 percent of the structure and column costs. Therefore, "critical" was selected and assigns a score of 768 as a result of multiplying score 512 with $Z$ value of 1.5 . This repair and replacement maintenance activity can be planned. Since there is another new tower to take care of the building load, no maintenance downtown 
would occur. 'Good' was selected, which assigns a score of three as a result of multiplying score two with $\mathrm{Z}$ value of 1.5. This is the condition evaluation with respect to physical plant risk potential parameters. The total score for physical plant is 5,773,312, and this is obtained from the formula $\left[\left\{\left(\mathrm{X} 1+(\mathrm{X} 2+\mathrm{X} 3)^{*} \mathrm{Z}\right)\right\}^{*}\{\operatorname{Max}(\mathrm{X} 1, \mathrm{X} 2, \mathrm{X} 3)\}\right]=[\{(2048+(512+2) *$ $\left.1.5)\}^{*}\{\operatorname{Max}(2048,512,2)\}\right]$. Since there is no restriction for university personnel entering the cooling tower area, the life safety is as critical as job safety. Hence, vulnerable to risk, the condition level selected is "critical." This assigns a score of 2048 (safety is regardless of the functional value). The present condition would not lead to any property damage, therefore, "good" was selected. This assigns a score of two, as a result of multiplying one and the Z value of 1.5 (rounded). There is no hindrance time, as the repair or replacement activity is planned, as "good" was selected. This assigns a score of three as a result of multiplying two with a $\mathrm{Z}$ value of 1.5 . This is the condition evaluation with respect to university risk potential parameters. The total score for university is 4,203,520, and this is obtained from the formula $[\{(\mathrm{X} 4+(\mathrm{X} 5+\mathrm{X} 6) * \mathrm{Z})\} *\{\operatorname{Max}(\mathrm{X} 4, \mathrm{X} 5, \mathrm{X} 6)\}]=[\{(2048+(1+2) * 1.5)\} *\{\operatorname{Max}(2048,1,2)\}]$

The OCI should be assessed based on reviewing all components in the same functional value category based on their condition. The OCI should be evaluated based on external factors that are not listed in the assessment form, like any event (game day, graduation, etc.) in the building and other field factors. The grouped functional values are ranked and the scoring is selected based on this ranking. In this assessment the worker considers the structure and columns as most important and ranks it nine by selecting 9. This decision was made after comparing the condition with other components in the same functional value group. The corresponding scoring for this ranking selected from table 10 was 1.09 (X7). This factor is multiplied with both the physical plant and university total as $(5,773,312+4,203,520) * 1.09$, and result in a score of $10,874,746.88$. This score is normalized by taking the logarithmic value of this number, resulting in 7.036. This is the penalty score and the priority number of this component in the equipment. The worker can suggest that the component be repaired or replaced or do nothing based on the assessment. Since this component is in critical condition, repair work would not solve the problem. Hence, replacement is suggested, considering the cost and condition of the tower. In the action and recommendation column, poor railing and generally weak structure is indicated. 
9. Strainers: Strainers are used for filtering the water dust and sediment particles in components having water flow. Check for the mesh condition and the mesh size. Corrosion and deterioration of mesh should be checked. Check for mesh cleanliness, filtering, leaks, and clogging. These are classified as a primary support component in their functional value.

10. Fin tubes: Fin tubes are used in dry cooling towers, unlike evaporative cooling towers where fill is present. They are called closed circuit or indirect cooling. The water from the condenser is passed through the coil, and no direct contact of the air and the fluid is involved. Usually water or a glycol mixture is being cooled. Check for scales and corrosion on the tubes. Check for leaks and clogging. Check the temperature of the glycol and the control valves at the entry and exit of the fin tube. These are classified as the primary support components in their functional value.

11. Basin: This cold water basin collects the cooling tower water after the heat is removed. Water is pumped from the basin to a sump or directly to the chiller. Depending on the material of the basin, check for wood warping or metal corrosion. Check for leaks, cracks, and deterioration. Check for algae and fungus buildup or accumulation. The debris and the sludge can lead to growth of bacteria, such as Legionella. The float valves and switches in the basin should also be checked for their operation and condition. Since failure of this component will affect the operational equipments, it is classified as a primary support component.

12. Casing: These are the enclosures for the cooling tower. The materials can be steel, fiber reinforced plastic, wood, etc. The worker should check for leaks, cracks, holes, or general deterioration. The leaks should include both water leaks and air leaks. The hardware attaching the casing to the structure should be sealed. The steel casing should be inspected for corrosion and or scales. Wood casing should be inspected for iron rot and decay, and cracks. Regardless of the condition, asbestos casing should be removed immediately, considering health factors. Since failure of this component will affect the operational components, it is classified as a primary support component.

Assessment Output: Explanation for Figure 4.10, casing in good condition. The condition indicates a safe working environment with respect to the worker job safety, hence, "good" was selected. This assigns a score of one (safety is regardless of the functional value). Since 
there is no component damage value, no investment is required therefore "good" was selected. This assigns a score of six as a result of multiplying score four with $\mathrm{Z}$ value of 1.5. No maintenance activity is required as the condition is good, and no maintenance downtown time is required. This assigns a score of three as a result of multiplying score two with $\mathrm{Z}$ value of 1.5. This is the condition evaluation with respect to physical plant risk potential parameters. The total score for physical plant is 60 , and this is obtained from the formula $[\{(\mathrm{X} 1+(\mathrm{X} 2+\mathrm{X} 3) * \mathrm{Z})\} *\{\operatorname{Max}(\mathrm{X} 1, \mathrm{X} 2, \mathrm{X} 3)\}]=[\{(1+(4+2) * 1.5)\} *\{\operatorname{Max}(1,4,2)\}]$. This assigns a score of one in the $14^{\text {th }}$ column (safety is regardless of the functional value). The present condition would not lead to any property damage; therefore "good" was selected.

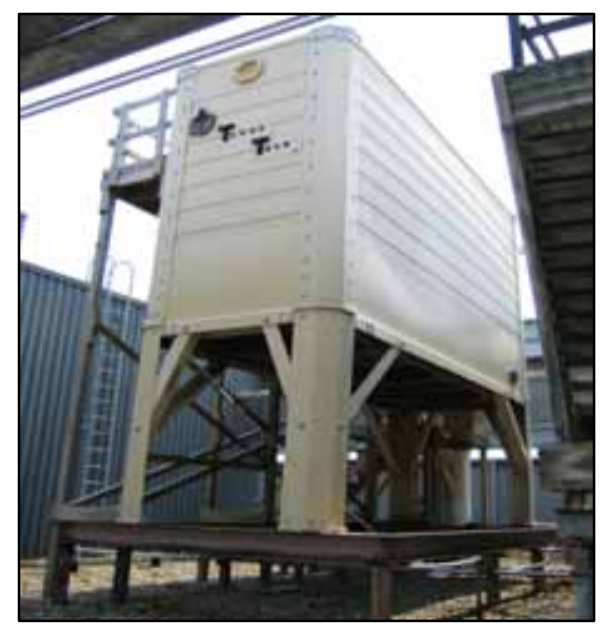

Figure 4.10. Example of a "Good" Condition Cooling Tower (Allan Hall)

This assigns a score of two as a result of multiplying one and $\mathrm{Z}$ value of 1.5 (rounded off). There is no hindrance time as there is no repair or replacement activity needed, hence, "good" was selected. This assigns a score of three as a result of multiplying two with $\mathrm{Z}$ value of 1.5. This is the condition evaluation with respect to University risk potential parameters. The total score for the university is 17 , and this is obtained from the formula: $[\{(\mathrm{X} 4+(\mathrm{X} 5+\mathrm{X} 6) * \mathrm{Z})\} *\{\operatorname{Max}(\mathrm{X} 4, \mathrm{X} 5, \mathrm{X} 6)\}]=[\{(1+(1+2) * 1.5)\} *\{\operatorname{Max}(1,1,2)\}]$.

The OCI should be assessed based on reviewing all components in the same functional value category based on their condition. The OCI should be evaluated based on external factors that are not listed on the assessment form like any event (game day, graduation, etc.) in the 
building and other field factors. The grouped functional values are ranked and the score is selected based on this ranking. In this assessment, the worker considers the electrical wiring component as most important and ranks it three. This decision was made after comparing the condition of other components in the same functional value group. The corresponding score for this ranking was selected from table 10 as 1.03 (X7). This factor is multiplied with both the physical plant and university total as $(60+17) * 1.03$, and results in a score of 78.8 (rounded off). This score is normalized by taking the logarithmic value of this number, resulting in 1.896. This is the penalty score and the priority number of this component in the equipment. The worker can suggest that the component be repaired or replaced or do nothing based on the assessment. Since this casing component is in good condition, neither repair nor replacement is required. Since assessment did not indicate any requirement for maintenance activity, the action and recommendation column is left blank, indicating good condition.

13. Drift Eliminators: Drift eliminators control the unnecessary loss of water and reduce the damp spray nuisance. Cleanliness and clogging should be checked to make sure that the air passages are clear from debris. Decay and deterioration should be checked. Asbestos should be replaced immediately regardless of their condition. Check for algae and scale formation. This is a primary support component.

14. Fill: Fill material can be wood, ceramic bricks, fiberglass grids, plastic bars, etc. Check for sagging, broken, or decaying fills. Missing splash bars should be identified. Check for algae, scale buildup, and clogging. Fill helps in reducing the water flow directly to the basin. In this process, the air contacts the water and transfers the heat. Fill is classified as a primary component for the efficiency of the system.

15. Controls: These are components that are electro-mechanical or pneumatic in working operation. These control the flow, pressure, temperature, water levels, etc., in the cooling tower. Their functional value is secondary support. Check for the makeup valve and the overflow switch operation. Check for the sump heaters, sensors, and the timer condition with respect to working and operation. Check the variable speed drives and their settings.

16. Valves: Includes the stop valve, drain valve, and the check valves. These may be butterfly or isolation or two-way or three-way valves, depending on the piping arrangement. Check for 
leaks, clogging, and the flow. Check for corrosion and working condition by moving the valve levers (handle). Check all the support and connection fittings and fasteners of these valves. Valves are considered to be the secondary support component in their functional value.

17. Water Treatment: Cooling tower circulation water should be treated with chemicals. Routine monitoring of the water condition should include $\mathrm{pH}$, conductivity measurement, total bacteria count, chemical concentration, and biocide concentration. The frequency of this monitoring process should be checked. Check for sediments, air borne impurities, fouling, and foaming of water. Check for biological and algae buildup. Water treatment is classified as a secondary support component.

18. Fan Enclosures: They are also called fan cylinders, enclosing the fan for safety reasons. The material can be wood or a steel shroud. Check the tightness, assembly, anchorage, and fasteners' condition. Check for any leaks, gaps and the clearance between the fan blade and the cylinder during wobbling, etc. Check for rusting and deterioration. These are classified as secondary support components.

19. Fan Deck: Check the general condition of the fan deck material for any corrosion or wood warping. The fan deck support should be checked for safety against strength and tripping. Check for gaps or holes for leaks. Inspect the fasteners' condition for corrosion and bolting. Since this is neither an operational nor primary support, it is classified as secondary support component.

20. Louvers: Check if all the louvers are in place and identify the missing and broken louvers. Check for deterioration, scale buildup, and algae growth on the louvers. Check the support members of the louvers for movement and fittings. Check for debris clogging in the louvers and replace the louvers regardless of their condition if they are of asbestos material. These are classified as secondary supports.

21. Piping: The piping includes the cooling tower supply and return pipes from the condenser and other internal water transfer pipes. The insulation on these pipes should be checked. They should also be checked for deterioration, leaks, loss of coating, etc. The support of the pipes 
should be checked for alignment, hangers, corrosion, bolts, etc. The pipes should be checked for flow and clogging. These are classified as secondary support components.

22. Temperature Gauges: These are classified as accessories and fittings with respect to their functional value. They are used for monitoring and recording the temperature at every entry and exit point of the system and subsystem in the cooling tower. Check for broken or missing parts and leaks in the gauges. Check the pointer operation and working and to make sure it is without damage. Check the cleanliness of the sight glass.

23. Pressure Gauges: These are classified as accessories and fittings with respect to their functional value. These are used for monitoring and recording the pressure at every entry and exit point of the system and subsystem in the cooling tower. Check for broken or missing parts and leaks in the gauges. Check the pointer operation. Check the cleanliness of the sight glass.

24. Ladder and walkways: This can be a stairway or a ladder with or without handrail and interior walkways. Check for wood decay and steel corrosion. Check for anchorage, fasteners, loose treads, and tightness. Check the joints for cracks and overall deterioration. Inspect the stability and slipperiness. Since the equipment will not stop running without this component, this component is classified as accessories and fittings.

25. Access Doors: For any maintenance task to be performed inside the cooling tower, the entry can be made only through access door. They are classified as accessories and fittings in their functional value. Check for hinge condition with respect to support tightness. Check the movement, lubrication, and locking. Check for rusting, corrosion, or any physical damage due to deterioration. 


\subsubsection{Assessment Output}

These individual component conditions would result in a priority number or penalty score as explained in assessment output of structures and casing in this section. Similarly, depending on the physical condition of each component, a score would be generated automatically. Summation of these individual scores would result in the equipment total score. In this example, the total normalized score is 49.264 . Average risk potential values are also calculated at the end of each risk parameter from the number of components assessed in each risk potential parameter. The normalized average risk potential for X1, X2, X3, X4, X5, and X6 are 2.04, 2.02, 1.58, 1.13, 1.28 , and 1.63 , respectively. These values can be compared with other cooling towers to observe and analyze the change in each parameter. Since the overall condition assessment score of 49.264 should be converted to a meaningful number, it is converted into a percentage, as explained in section one of this chapter. Since, a score of 47.8 is equivalent to 100 percent, as explained in section 4.1.1, 49.264 is equivalent to 96.65 percent. Measuring and comparing this score with the maintenance benchmark in Figure 8, indicates this cooling tower is maintained in world - class level. Hence, the priority for any repair or replacement decision is ranked five.

In the other example of the old cooling tower in Allan Hall, the total number of components assessed were 19 out of 25 , as the other six components were shut down due to failure of components in 19. Assessing these 19 components resulted in an overall assessment score of 78.702. This was converted to a percentage of 48.28 percent and compared with the maintenance benchmarking in Figure 4.1 to indicate the emerged level. Hence, the priority for any repair and/or replacement decision is ranked two.

\subsubsection{Feedback}

In the feedback loop, as shown in Figure 4.7, these scores are compared with the worker's input. The actions and recommendations suggested in these two towers are converted to work orders as explained and as shown in Figure 4.3. The new cooling tower with the score of 96.5 percent was issued four work orders, including as "cleaning and painting the base support of structure," "fittings and pumps showing chemical buildup and leakage due to improper water treatment," "cleaning and painting of the piping," and "slippery, skid-resistant coating for ladders and walkways." These repair work orders are sent to the shop for execution in the feedback process, 
as explained in earlier sections. The work orders are carried out based on the score. The highest number should be the first work order to be executed. In this example, the structure work order with a score 3.708 should be executed first and following this would be the next lower number and so on. The old cooling tower with the score of 48.28 percent was issued thirteen work orders. There are a total of four repair and nine replacement work orders. These work orders are also sent to the shop through the feedback process. The work orders should be executed based on the highest number first principle explained. Decision making by the supervisor and higher management is required before actual work order execution, as the cooling tower is in priority two category in spite of six components not assessed. Physical plant should proceed with work orders or replace the tower with a new one depending on the decision made to complete the process. Similar assessments are performed on the other cooling towers to identify the existing physical condition. The work orders generated from assessments are executed based on the priority of the component and equipment.

Apart from cooling towers, this assessment methodology is also developed for HVAC equipment, shown in the appendix, such as air compressors (Table F 4.4), air handling units (Table F 4.5), boilers (Table F 4.6), chillers (Table F 4.7), heat exchangers and water heaters (Table F 4.8) pumps (Table F 4.9), steam distribution systems (Table F 4.10), and unitary heating and cooling systems (Table F 4.11). The corporate memory data input, condition levels, potential risk parameters, condition measurements on each risk parameter, priorities, and scoring methodology are similar to the cooling tower. The components and their checkpoints would change depending on the equipment and their application. Overall functional index is a parameter depending on the functional value. The total number of components and the number of components in each functional value depends on the equipment. For example, a boiler is defined with 43 components and each functional value such as operational, primary, secondary, and accessories had 17, 10,11, and 5 components respectively. The components and check points were defined as explained in section 3.2,3.3, and the equipment/component condition inspection process flow chart in Figure 3.4. Hence, this methodology is applied to all nine pieces of equipment with the development of components and checkpoints. 


\subsection{Operating Characteristic Checklists to the Cooling Tower Assessment}

The condition assessment (physical) on the components, such as the water distribution system, fill, drift eliminator, temperature gauges, pressure gauges, water treatment, motor, fan, and gearbox, directly affects the operating characteristics of the cooling tower. The operating characteristics of the cooling tower are the parameters that determine the cooling tower capability. Cooling tower capability is the percentage ratio of "capacity units available" and "capacity units required." Water flow rate, water temperatures, air temperatures, brake horsepower, and tower pumping head are the key performance indicators for determining the cooling tower capability. Their limits are established by the American Society of Mechanical Engineers and Cooling Tower Institute.

"Capacity units required" are determined by the gallons per minute of water (design conditions) circulated in the process multiplied with the rating factor. Rating factor is the degree of thermal capability relative to a given wet bulb temperature for the range and approach. Range is the difference between the hot water temperature entering the tower and cold water temperature leaving the tower. Approach is the difference between the cold water temperature and the entering air wet bulb temperature.

"Capacity units available" are determined by the adjusted gallons per minute of water multiplied with the rating factor. The adjusted gallon per minute of water is the actual gallons per minute of water multiplied with the cube root of the ratio of design fan brake horsepower and actual fan brake horsepower.

To determine fan horsepower, cubic feet per minute of airflow (Q), static pressure drop through the system in inches of water (Hs), velocity pressure at point of measurement in inches of water $(\mathrm{H} \mathrm{v})$, and density of water at gauge fluid temperature in pound per cubic feet (D) is required. The formula for determining the fan horsepower is $(\mathrm{Q} *(\mathrm{Hs}+\mathrm{Hv}) * \mathrm{D}) /(33,000 * 12)$. To determine the velocity pressure (Hv), average velocity through fan in feet per second, acceleration due to gravity in feet per square second, D, air density at point of flow in pounds per cubic feet must be known. The velocity through the fan can be known from the ratio of $\mathrm{Q}$ and the product of net flow area in square feet and 60 . Hv is determined by the formula 
$\left(\mathrm{V}^{2} * 12 * \mathrm{~d}\right) /(2 * \mathrm{~g} * \mathrm{D})$. Checklists for the operating characteristics to determine the cooling tower capability are as follows, in [49]:

- Water flow rate in gallons per minute.

- Hot water temperature in ${ }^{\circ} \mathrm{F}$.

- Cold water temperature in ${ }^{\circ} \mathrm{F}$.

- Wet-bulb temperature in ${ }^{\circ} \mathrm{F}$.

- Airflow in cubic feet per minute.

- Net flow area in square feet.

- Static pressure drop in inches of water.

\subsection{Variation in Assessment with Multiple Workers}

As explained before, the assessment input is qualitative, that is, the condition assessment input is either of four choices such as "good", "fair", "poor" and "critical". The assessment should be performed based on the existing condition of the equipment. In a qualitative assessment, the change in inspector (worker) could change the overall score. In this assessment, three different reasons are anticipated for the change in overall score, namely conservative assessment, holistic approach of the assessment and meeting basic requirements. To understand these two reasons, four different inspectors were chosen to assess the cooling tower at the law school. The four inspectors are referred as A, G, R, and W, as shown in Table 4.12. This variation analysis would indicate the consistency of the assessment and the tool. The consistency of the assessment refers to the inspector's knowledge, approach, and technical considerations. The consistency of the tool refers to the sensitivity of the scores and priorities due to the assessment changes. In this section, only the components and the risk parameters that were assessed differently by the four different inspectors would be discussed. The components that were assessed in the same condition level are not discussed. These components were electrical wiring, motor, gear box, fans, water distribution, bearings, couplings and keys, structure/columns, fill, controls, stop, check and drain valves, fan enclosures (inspector W initiated a work order to cover the fan for safety), fan deck, and temperature gauges. All these components were assessed in "good" condition on their respective potential risk parameter columns. But these components had minor work, such as lubrication, greasing, gear oil check, and routine inspection, during startup. These 14 components, though assessed by four different workers on four different days, resulted in a 
common condition evaluation. The existing condition of the component is captured by the inspector and the tool, as it appears and operates. This is one example of the consistency of the assessment and the tool. The total number of components is 26 in the cooling tower assessment tool. But, the components, such as fin tube and drive system (belt/gear box), would vary depending on the type of the tower. Hence, from 24 components, 14 components were assessed to be in "good" condition by the four inspectors. The reasons for the variation of the assessments are described in the section below to understand the consistency of the component's assessment. The major nine components that contribute to this score variation are discussed below after the assessment results.

- Inspector A utilized 30 minutes for assessment and resulted in an overall condition score of 54.06. Converting this score to a benchmark percentage, as explained in section 4.1.1, resulted in 77.90 percent. This percentage classifies the cooling tower as priority four (excellent).

- Inspector R utilized 25 minutes for assessment and resulted in an overall condition score of 50.826. Converting this score to a benchmark percentage, as explained in section 4.1.1, resulted in 82.87 percent. This percentage classifies the cooling tower as priority four (excellent).

- Inspector W utilized 26 minutes for assessment and resulted in an overall condition score of 50.52. Converting this score to a benchmark percentage, as explained in section 4.1.1, resulted in 83.36 percent. This percentage classifies the cooling tower as priority four (excellent).

- Inspector $\mathrm{G}$ utilized 25 minutes for assessment and resulted in an overall condition score of 50.54. Converting this score to a benchmark percentage, as explained in section 4.1.1, resulted in 83.33 percent. This percentage classifies the cooling tower as priority four (excellent).

The summary of the four assessment results classifies the overall percentage score as priority four. It is evident that the inspector's assessment results are consistent with respect to their knowledge, approach, and technical considerations. The methodology and the tool's consistency are indicated by converting the inspector's evaluation to an overall score with respect to the equipment condition. As mentioned earlier, those nine components for which the inspectors have assessed differently, other than "good," are discussed in this section as they lead to variation. 
Table 4.12. Results of Variation in Assessments

\begin{tabular}{|c|c|c|c|c|}
\hline \multicolumn{5}{|c|}{$\begin{array}{l}\text { Variation in Assessments by Multiple Inspectors at Law School } \\
\text { in WVU for Cooling Tower }\end{array}$} \\
\hline Inspector & $\mathrm{A}$ & $\mathrm{G}$ & $\mathrm{R}$ & $\mathrm{W}$ \\
\hline Score & 54.06 & 50.54 & 50.82 & 50.52 \\
\hline Benchmark & 77.9 & 83.33 & 82.8 & 83.36 \\
\hline Priority & 4 & 4 & 4 & 4 \\
\hline Condition & Excellent & Excellent & Excellent & Excellent \\
\hline Time (minutes) & 30 & 25 & 25 & 26 \\
\hline \multicolumn{5}{|c|}{ Variation Assessment Sheets on Cooling Towers } \\
\hline $\mathrm{A}$ & \multicolumn{4}{|c|}{ Conservative Approach } \\
\hline$G$ & \multicolumn{4}{|c|}{ Holistic Approach } \\
\hline $\mathrm{R} \& \mathrm{~W}$ & \multicolumn{4}{|c|}{ Meeting Basic Requirements } \\
\hline
\end{tabular}

1. Basin: Cracks were seen on the exterior sides of the structure. All four inspectors have initiated repair work order to plaster the cracks. They assessed as "fair" the potential maintenance down time to repair the cracks, as the job requires two hours per day of work.

2. Casing: Inspector $G$ initiated a repair work order to seal cracks and prevent algae growth in the casing. The cost and time involved to work on this repair work order were assessed as "fair" and "poor." Inspector A and R evaluated the casing to be in "good" condition with no work order. Inspector W initiated a work order to seal the cracks with epoxy and evaluated the time involved to perform this work as "fair." The possible reason for this difference is that inspector $\mathrm{G}$ evaluated the cooling tower during its operation, and hence, algae were present. But during the assessment of inspector A, W, and R, the tower was not operating. Inspector $\mathrm{A}$ and $\mathrm{R}$ did not observe any cracks that would result in any further damage.

3. Drift eliminator: Two years ago the drift eliminator had broken and was removed. Hence, all four inspectors assessed and initiated a work order for a missing component. Since the component was not available to assess, they selected "NA." 
4. Bolts, brackets, and fittings: Inspector $G$ initiated a work order to remove the mineral deposits on the fasteners and assessed the maintenance time as "fair." Inspector A, W, and R assessed this component as "good" in all six risk potential parameters. The possible reason for the difference in assessment between inspector $\mathrm{G}$ and others could be due to conservative assessment. That is, if this bolt continues to corrode and rust, the bolted joints would weaken the structure and vibrate the rotating component.

5. Water treatment: The algae formation in the tower is due to improper water treatment frequency and chemical treatment. Hence, all four inspectors initiated work orders to contact Nalco Water Treatment Company. Physical plant would not incur any damage value or time to perform this task, as the job is outsourced. Hence, it was assessed "good."

6. Louvers: This cooling tower has screens to suck air instead of a louver. Inspector A assessed these screens as "fair" in worker job safety and maintenance time to repair. The work order initiated was to repair the metal grating and the screens. Inspector A assessed these screens as "good" in all risk potential parameters but issued a work order to staple the loose screens. Inspector W assessed as "fair" in the maintenance repair time for these screens and initiated a repair work order for the same. Inspector G assessed these screens to be "good" as during the assessment was performed (July) the screens were in good condition. During this time the screens were not the same as they were in December. The other reason for the difference between inspector $\mathrm{A}, \mathrm{W}$ and $\mathrm{R}$ is the holistic approach. Considering the over all condition of the tower and the construction type of the screen led to initiating a work order to repair the grating and the screen. Possibility of an on-job minor injury due to corrosion and rusting on the screen and metal grating is also another reason. But, inspector R assumed wearing gloves and stapling the screen would not result in minor injury and the time taken to staple can be performed within two hours.

7. Pressure Gauges: The condensing water loop pressure gauges are the gauges for reading the cooling tower water pressure. A pointer was observed to be not moving, the glass was unclean, and reading the pressure was difficult during the assessment of inspector $\mathrm{A}, \mathrm{W}$, and R. Inspector A, W, and R initiated a replacement work order and assessed as "critical" in the component damage value. But, during the time when inspector $G$ assessed, the pressure gauge was in "good" condition. 
8. Ladders and Walkways: During the winter (five-month period), the ladder had deteriorated badly due to rain. This component is one example for weather effects and corrosion effects in metals. Inspector G assessed the ladder as "fair" in worker job safety and maintenance repair time for cleaning and painting. Inspector A assessed the ladder as "fair" in worker job safety, component damage value, and maintenance repair time. Inspector A issued a work order for removing rust and painting with consideration for the handrail around the fan deck. Inspector $\mathrm{R}$ assessed it as "fair" in worker job safety and component damage value. Inspector $\mathrm{R}$ initiated a work order for fixing the bolts and painting and was comfortable with the strength. Inspector W assessed it as "poor" in worker job safety and maintenance repair time, and "critical" in component damage value. Inspector W initiated a work order to replace the ladder with an access door as an integral part. Since a ladder is a safety component and the existing condition is not safe, recommendations were dependent on different improvement levels. The differences in the inspectors' assessments were due to both conservative assessment and holistic approach.

9. Access doors: In this cooling tower, the access door and the ladder are an integral part. The condition of the access door is rusted. Since inspector W considered ladder and access door to be a single unit, their assessment of ladder included the access doors, hence, he selected "NA" for the access door. Inspector R assessed as "fair" in worker job safety and initiated a painting work order for access door. Inspector A assessed the access doors as "fair" in component damage value and observed the screens to be locked as they might allow access to the tower. He also issued a work order for corrosion removal and painting the access door. Inspector G assessed it as "fair" in worker job safety and initiated a work order for cleaning and painting. Assessment differences between inspectors $A, G$, and $W$ were due to conservative assessment followed by others and holistic approach followed by inspector A.

The differences in the assessment for some components were as follows. Inspector G assessed considering a holistic approach; inspector A and W performed conservative assessments; and inspector $\mathrm{R}$ performed as assessment that would result in fulfilling basic repair requirements to fix the current problems. Though the inspectors followed three different considerations during the assessment, the overall final percentage score resulted in a variation less than five percent between them. Hence, the four inspectors' assessments were classified in the same priority level 
four (excellent). The variation analysis of the multiple inspectors assessing a cooling tower on the law school proved consistency in assessment and the tool.

\subsection{Effectiveness of the Assessment Tool}

Benchmarking the assessment scores and variation testing in the assessment process validates the tool as part of the robustness study. To measure the impact and performance of the tool itself, determining the tool's effectiveness is important. Effectiveness of the tool could be measured from the continuous improvement goals explained in this chapter. One of the continuous improvement goals that could be measured for the effectiveness of this tool is the decrease in reactive work orders. On implementing this system, TMA would be able to quantify the work orders based on reactive and proactive mode. If the assessment generated work order increases based on historical data on that particular piece of equipment, the effectiveness of this tool would be the percentage decrease in the work orders from the historical number. This percentage increase in proactive work orders must decrease the reactive work orders from that equipment during the same time period. For example, five work orders were received for equipment in a three month time period based on the existing process. The assessment generated work orders for that particular piece of equipment should increase the number of proactive work orders. This increase in proactive work orders on completion should reduce the reactive work orders until the next assessment is performed. The decrease in the percentage of work orders for that equipment shows the effectiveness of this tool. The increase in proactive work orders on reducing the reactive work orders could also be considered for determining the effectiveness of the tool as an overall percentage increase in the proactive work order.

\subsection{Conclusions}

The following six recommendations such as benchmarking the assessment scores, recommendations for optimum assessment frequency, time based sensitivity, implementing the assessment methodology in cooling towers, variation in assessment with multiple workers, and effectiveness of the assessment tool were studied, tested, validated, and implemented to prove the robustness of the methodology. The results of these six recommendations are stated below. 
- The benchmarking scale indicated the present scenario and helps to explain the importance of improving to the next desired level.

- Based on the amounts of equipment, the constraints on the resources in a physical plant type of industry, and brainstorming from physical plant management, a comprehensive assessment frequency was determined to be at least once in a year.

- As part of time-based sensitivity, the real-time and time-based interactions in updating system reporting aspects were explained through six sections. These were, modes of work requests and classification of work orders, work order status checks, work order generation, implementation of continuous improvement goals, integrating an assessment model and PM program, and work execution and assessments. All these would help in eliminating redundancy, duplication, and reduction in reactive maintenance work orders.

- The implementation and testing of the methodology were conducted using cooling towers by successfully validating the input, model, output, and feedback of the assessment. Also cooling tower operating characteristic checklists were considered as future inclusion in the model.

- The variation in assessment with multiple workers also proved the robustness of the assessment methodology by indicating consistent scores and results.

- By utilizing this tool the increase in proactive work orders must decrease the reactive work and was discussed as part of the effectiveness study of the assessment tool.

Hence, the designed and developed HVAC assessment methodology was tested for its robustness with an overall implementation and continuous improvement plan. 


\section{Chapter 5: Conclusions}

\subsection{Summary}

The research objective was to develop an in-house assessment tool that saves time and helps in reducing costs that would otherwise be incurred with the current practices. This tool identifies equipment that needs condition assessment, evaluates equipment at the component level, guides workers through the inspection process with checkpoints in components, and identifies the functional value of each component of the equipment. This methodology helped in reducing inspection time. This tool also identifies the impact (safety, down time, and equipment damage) on physical plant and the university in the event of component failure or poor condition and assists in repair or replacement decisions. This methodology determined factors and levels to measure and scores the equipment. A formula was determined to prioritize jobs within the equipment inventory for components. It can be used and tested by workers without extensive training, without hiring consultants, and with minimum assessment time. Hence, zero costs for assessments at any physical plant of any size. An FCA tool captures all the above equipment details for corporate memory in maintenance management.

The contributions of this methodology to the literature include the use of a common and comprehensive automated tool for HVAC physical condition assessments, failure (risk) impact based facilities assessment, impact-based scoring and formula methodology as a priority scheduling system, and quantitative evidence for maintenance funding proposals. Hence, the development of an FCA methodology is one of the better-suited solutions to determine the existing condition of HVAC equipment for physical plant industries.

\subsection{Results}

The existing conditions of the six cooling towers were assessed at the component level and an overall condition score was generated by the tool. This tool was user-friendly, helped assess checkpoints on the components and helped identify the potential risk impact on the physical plant and university. The average time spent in capturing the corporate memory data of the inspector, building, equipment, and assessment details was 31 minutes per cooling tower. The assessment 
results of the six selected cooling towers are shown in Table 5.1 with the priority ranking of the assessment score.

Table 5.1. Cooling Tower Prioritized Ranking

\begin{tabular}{|c|c|c|c|c|}
\hline \multicolumn{5}{|c|}{ Results of 6 Cooling Tower Prioritized Ranking. } \\
\hline Priority & $\begin{array}{c}\text { Location of the } \\
\text { Cooling Tower }\end{array}$ & $\begin{array}{c}\text { Condition } \\
\text { Assessment } \\
\text { Score }\end{array}$ & $\begin{array}{c}\text { Benchmarked } \\
\text { Percentage } \\
\text { Conversion }\end{array}$ & $\begin{array}{c}\text { Benchmarked } \\
\text { Priority Level }\end{array}$ \\
\hline 1 & Creative Arts Center & 126.58 & 31.87 & 1 \\
\hline 2 & Allan Hall - Old & 78.7 & 48.28 & 2 \\
\hline 3 & Law School & 50.54 & 83.33 & 4 \\
\hline 4 & Allan Hall - New & 49.26 & 85.49 & 5 \\
\hline 5 & Evansdale Chiller Plant & 48.4 & 87.01 & 5 \\
\hline 6 & Engineering Sciences & 46.41 & 90.75 & 5 \\
\hline
\end{tabular}

The condition assessment scores are converted to benchmarked percentages and the priority level is determined from Figure 4.1. If the priority levels are the same as in the 3 cooling towers, the priority ranking should be based on the benchmarked percentage conversion ascending scores. The prioritized ranking of equipment and work orders would reduce DM backlogs in the long run. This methodology initiates repair, replacement, and proactive work orders from actions and recommendations suggested by the inspectors. The time-based sensitivity and the continuous improvement goals ensure the reduction of reactive maintenance work orders.

\subsection{Change Management}

A change in the work practice and/or process improvement can be different for employees to adapt to. Systematic education and training to overcome the resistance and barriers is an important task in implementing any new system. To continue using the FCA automated tool successfully, policy guidelines should be implemented from the top management level. These 3 important questions such as who, how, and when should be answered by the top management in the form of policy guidelines. Who should assess should be based on inspection personnel (workers), considering factors such as technical knowledge of the equipment, understanding the 
objective of the assessment, and basic repair time and costs knowledge. When the assessment should be performed, is answered with regard to time, sequence, and schedule. How the assessment should be performed should be answered with respect to equipment rooms, age of the equipment, as a work order generated every day or a special team visiting each building, etc. The objective of the assessment should be to evaluate all the equipment in a year for the annual DM and other budget proposals. This assessment methodology, if performed by hand in the field and re-entering it into the computer may create duplication of work, data entry error, paper work and delay in issuing the proactive work orders. It becomes imperative for top management to follow the real-time and time based update of the reporting aspect's flow charts and use of PDA or notebook computer in the field. Training the inspectors on adapting this tool should be provided prior to introducing this process as a work order system. Monitoring inspectors and assessment results should be performed until both the management and inspectors are confident and comfortable. Hence, systematic education for the inspectors and other staff involved in this process should be provided until the resistance and barriers are removed. This can be achieved only when both the top management and the work force participate and take ownership of the process.

\subsection{Advantages of FCA Methodology over Existing Practices}

- Extension of the availability and life of facilities to their maximum

- Periodic visual inspections of equipment, components, and their subcomponents

- Assessment of the facilities physical conditions enabling better understanding of the equipment for a structured PM program

- Early identification of facility failure, thereby avoiding breakdown or damage to equipment

- Enhanced personnel safety by identifying potential hazards

- Provision for constant flow of proactive work orders to the workforce

- Reduction of the frequency of complaint calls

- Valid measure of total DM backlog requirements

- Recommendation of priorities for maintenance, repairs, and replacements

- Reduction of maintenance downtime to physical plant and hindrance time to occupants

- Reduction of overall costs of maintenance by reducing secondary failures through corrective actions. 
An FCA would identify equipment failure, and therefore avoid breakdown, damage to equipment, and other properties that were not detected prior to this system. Hence, an FCA would extend the availability and life of facilities to their maximum. Assessment of facility physical condition enables better understanding of the equipment for the PM program. Thereby an FCA process would identify the equipment and the corresponding PM requirement based on the equipments' condition. Through this system, constant flow of proactive work orders are generated, which was not done with the current practices (systems). Proactive work orders would eventually reduce the frequency of service calls. The mathematical and scientific methodology developed would support the funding proposals from university. FCA is also a valid measure for total DM backlog requirements that was not in existence prior to this automated tool. FCA would eliminate the inconsistent DM lists. The inspection time published in [31] for 1000 square footage of a mechanical facility is 1.6 hours, and the report generation time on these inspections is equal to the field inspection time [34]. But this FCA methodology has taken 31 minutes on average to complete the cooling tower assessments. Maintenance, repairs, and replacement work orders were not prioritized with the existing method. Hence these prioritized work orders would help in resource management and scheduling, thereby, reducing overall costs of maintenance by reducing secondary failures through corrective actions.

\subsection{Applications and Future Work}

This methodology when implemented for all HVAC equipment would generate a large volume of data. Statistical data analysis could be performed to identify the trend and correlation between components, potential risk parameters, age, construction type, etc. Developing a database for these assessments and data points would build a history and knowledge base for future analysis. This methodology should be developed for other mechanical, electrical, and structural systems. Developing mechanical, electrical, and structural systems assessments with the developed HVAC assessment, results in an extensive building assessment for any type of facility. This methodology can be adapted to any physical plant type of industry to generate proactive work orders and prioritize the DM projects. 


\section{References}

1. Tim Mearig, et.al, 1999, "Developing a PM Program", Alaska School Facilities Preventive Maintenance Handbook, State of Alaska - Department of Education \& Early Development.

2. Barry C. Abramson, et.al, 1999, "Quantifying the Energy Benefits of HVAC Maintenance Training and Preventive Maintenance,” Energy Engineering, Volume 96, Number 2.

3. Jerry C. Black, October 13, 2003, "Strategies for a Preventive Maintenance Program," Duke University, SRAPPA Seminar, p 1-19.

4. John L. Lingefelt, "Preventive Maintenance: Developing and Managing Your Program," Advanced Manufacturing Institute, p 1-36.

5. Chapter 5, Planning Guide for Maintaining School Facilities, "Maintaining School Facilities and Grounds," p 73, 74, 94, February 2003.

6. Peter Thompson, 1994, "The Maintenance Factor in Facilities Management," Facilities Journal, Volume 12, Number 6, p 13-16.

7. Steve Kraal, November 2003, "Budget Planning Tips From the Front Line of Facility Management," Special Edition, ACUHO-1 Talking Stick, p 1-2.

8. ECEFast-698AJ "The basics of predictive/preventive maintenance," http://www.ferret.com.au/articles/ad/0c0259ad.asp [Last access November 19, 2005].

9. William L. Reeves, September 2001, “Avoiding Boiler Problems,” ASHRAE Journal, p 3642.

10. Peter F. Hoey, December 1997, "Dual, Dissimilar Boiler Flame Safety Control," ASHRAE Journal, p 45-48.

11. Tomothy B. DeMoss, February 1996, "Boiler life extension requires accurate condition assessment," Power Engineering, p 37-39.

12. G.J. Nakoneczny, "Boiler Fitness Survey for Condition Assessment of Industrial Boilers," Babcock \& Wilcox, Barberton, Ohio, U.S.A, http://www.babcock.com/pgg/tt/pdf/BR1635.pdf, [Last access November 19, 2005].

13. David Houghton, December 1997, "Operating and Maintaining Rooftop Air Conditioners," ASHRAE Journal, p 50-54.

14. Kevin McBurney, June 1990, "Maintenance Suggestions for Cooling towers and accessories," ASHRAE Journal, p 16-26. 
15. Joseph L. Foszcz, September 2003, "Synthetic oil in air compressors," Plant Engineering, p $38-40$.

16. Mike Batchelor, April 1998, "Benefits of remotely monitoring rotary screw air compressors," Plant Engineering, p 77-80.

17. Wayne Perry, July 2001, "Maximizing compressor maintenance intervals and energy savings," Plant Engineering, p 56-58.

18. Steam Utilization, “Design of Fluid Systems,” Spirax Sarco, Inc., Course Manual.

19. Chapter 6 and 7, Operation and Maintenance "Maintenance," and "Trouble Shooting Guide", p 6.1-6.20, 7.1-7.3, Section 16HA-1Z.

20. Timothy J. Barnish, et.al, 1997, "Motor Maintenance: A Survey of Techniques and Results," Proceedings ACEEE Summer Study on Energy Efficiency in Industry, p 287-297.

21. Robert Haydu, November 2001, "Protecting and Maintaining Coils," ASHRAE Journal, p 2527.

22. Victor Wowk, November 2001, "Management Guide to Alignment," ASHRAE Journal, p 3335.

23. Will K. Brown, July 2000, “Operation and Maintenance of Evaporative Coolers," ASHRAE Journal, p 27-32.

24. Tim Lippert, June 2002, “Assessment report of CAC and Mountainlair cooling tower," P.F Sherman Company, Inc.

25. RFP Number: 90000870 P, December 2003, "Campus -Wide Chilled Water and Utilities Infrastructure Improvements," RMF Engineering, Inc.

26. Kunu Harmony, March 1998, "Facility Risk Assessment and Risk Management in Offshore Oil \& Gas Industry," Chevron Nigeria Limited, Society of Petroleum Engineers, p 111-123.

27. Maratha J. Whitaker, June 1995, "Conducting a facility management audit," Facilities, Volume. 13, Number 6, p 6-12.

28. Subodh A. Kumar, 1997, "Prioritizing Condition Assessment: A Systems Approach," Proceedings of the Specialty Conference on Infrastructure Condition Assessment Art, Science, Practice, p 171-179.

29. G. C. Kao, et.al, 1993, "Priority Ranking Of Safety-Related Systems for Structural Assessment at Savannah River Site," Plant Systems/ Components Aging Management, ASME, Volume. 252, p 15-20.

30. NAVFAC MO-322, March 1993, "Inspection of Shore Facilities," Department of the Navel Facilities Engineering Command, Navel Publications and Forms Center, Volume 1. 
31. NAVFAC MO-322, January 1993, "Inspection of Shore Facilities," Department of the Navel Facilities Engineering Command, Navel Publications and Forms Center, Volume 2

32. National Association of College and University Business Officers, 1991, "Managing the Facilities Portfolio - A Practical Approach to Institutional Facility Renewal and Deferred Maintenance".

33. Los Angles harbor College, "Facility Condition Assessment Report," 3D/I, http://www.smc.edu/facilities_resources/pdfs/facility_assessment_report/02_september_2003 /september_2003.pdf, [Last access November 20, 2005].

34. Harvey H. Kaiser, "Facilities Audit Workbook," Sponsored by The Association of Governing Boards Of Universities And Colleges (AGB), Association Of Physical plant Administrators Of Universities And Colleges (APPA), National Association Of College And University Business Officers (NACUBO).

35. M. L. Casada, et.al, October 1990, "Facility Risk Review as an Approach to Prioritizing Loss Prevention Efforts," Plant/Operations Progress, Volume. 9, Number. 4, p 213-219.

36. Howard McKew, December 2001, "Facility condition index or facility business plan," Engineered Systems, Volume 18, Number 12, p. 78.

37. Sheldon J. Fuchs, 1982, “Complete Building Equipment Maintenance Desk Book,” PrenticeHall, Inc.

38. Faisal I. Khan, et.al, 2003, "Risk-based maintenance (RBM): a quantitative approach for maintenance/inspection scheduling and planning," Journal of Loss Prevention in the process industries, Volume 16, p 561-573.

39. Carl B. Smith, 1995, "Simplified Decision Making Using Risk Prioritization Method," Risk and Safety Assessments: Building Viable Solutions, ASME, PVP-Volume.320/SERAVolume. 5, p 321-332.

40. Bergmann, August 1993, "Approximate risk assessment priorities remedial decisions," Hydrocarbon Processing, p 111-116.

41. Robert C. Creese, et.al, 1983, “A Patient Priority Scheduling System For Radiation Therapy Treatments,” IIE, Annual Industrial Engineering Conference Proceedings, p 297-299.

42. Ricky Smith et.al, December 2003, "Benchmarking maintenance organization effectiveness" Plant Engineering, p 61-63.

43. Matt Adams, et.al, 2002, "Maintenance Staffing Guidelines for Educational Facilities", APPA, p 48-49.

44. Best Maintenance Practices, Life Cycle Engineering, Inc., http://www.reliabilityweb.com/excerpts/excerpts/Best $\% 20$ Maint $\% 20$ Pract $\% 20 \mathrm{Fac} \% 20$ White \%20Paper.pdf . 
45. John Housley, March/April 1997, "Managing the estate in higher education establishments", Facilities, Volume. 15, p 72-83.

46. Barringer \& Associates, Inc., "Weibull Reliability for Failure Data for Various Components", http://www.barringer1.com/wdbase.htm [Last access November 20, 2005].

47. Online Chemical Engineering Information, Cooling Tower Design and Operation Considerations, http://www.cheresources.com/ctowerszz.shtml [Last access November 20, 2005]. 


\section{APPENDIX \\ Table A. HVAC and MM Deferred Maintenance Lists}

For example, during a two hour meeting with HVAC, MM shop employees and their supervisors, Assistant Director Mechanical Operations prepared a deferred maintenance lists (September 2004) with priority number, building name, equipment deficiency and scoring are as follows,

1. Mountainlair - replace chiller, cooling tower and pumps 54

2. Stewart Hall - replace chiller 39

3. CAC - replace chillers 30

4. Stansbury Hall - replace chillers 29

5. Woodburn Hall - replace chillers 25

6. Martin Hall - replace chillers 25

7. Chitwood Hall - replace chillers 25

8. Law School - replace chiller and cooling tower 23

9. Evansdale Pump House - replace pumps 23

10. Percival Hall - replace chiller and cooling tower 20

11. Clark Hall - replace dampers and fume hoods 20

12. Stadium - replace air handling units (AHU) and pumps 16

13. CRL - condensate return system 14

14. CRL - replace AHUs 14

15. Clark Hall - replace chiller 13

16. Colson Hall - replace chiller, pumps and air handling unit 12

17. ESB - replace air compressors 11

18. ARC and Eisland Hall - replace AHU 10

19. ERB - replace air compressor $\quad 10$

20. CRL - replace chiller and air compressor $\quad 10$

21. Natatorium Shell - replace domestic hot water system 9

22. Coliseum - replace air compressor 8

23. CRL - replace attic fans 6

24. Communications - replace chiller and ventilation system 6 
25. Colson - replace chilled water pumps 6

26. NRCCE - replace exhaust fans 5

27. ESB Chiller Plant - repair cooling tower 3

28. Mountainlair - replace AHUs 2

29. Hodges Hall - replace classroom chiller 1

30. Natatorium Shell - replace AHUs 0

31. Agricultural Sciences - replace AHUs 0

32. Hodges Hall - replace air compressor 0

Similar approach is also followed for Plumbing shop to obtain the deferred maintenance lists, shown in Table B.

Table B. Plumbing Shop Deferred Maintenance Lists (October 2004)

1. Down town - back flow prevention 35

2. Physical plant - piping 29

3. Steam tunnel supports 28

4. Steam tunnel assessment 26

5. Steam tunnel valves and expansion joints 25

6. Coliseum - replace boilers 21

7. CAC - replace condensate pumps 20

8. Natatorium - replace domestic hot water 19

9. All Campus - install isolation valves 19

10. All Campus - labeling piping and repair insulation 18

11. Mountainlair - domestic hot water 17

12. Mountainlair - plumbing 17

13. Evansdale - pump house replace pumps 14

14. Steam tunnel insulation $\quad 12$

15. CRL - replace condensate pumps 11

16. Hodges - replace constant temperature 11

$\begin{array}{ll}\text { 17. Stansbury - sewage system } & 10\end{array}$

18. Agricultural sciences - replace chilled water lines 9

19. Water tower - demo and connect to main 9 
20. Law - move boilers $\quad 8$

21. Armstrong - flush valve isolation 8

22. Greenhouse - replace steam heating system 7

23. Agricultural sciences - replace sewage lines 7

24. Percival - isolation valves 6

25. Steam systems - replace pop valves 4

26. Steam tunnel replace traps 5

27. Agricultural science - replace still 3

28. NRCCE - domestic hot water and heat for sullair room 2

29. ESB - replace steam line 1

30. ESB - replace air drier 0

31. Coliseum - repair hose bibs and fountains 0

32. CAC - clean or replace FCU piping 0

33. McCoy - extend hot water 0

34. Law - water recovery 0

35. White Hall - install still 0

36. Surgery barn - replace heating system 0

37. Woodburn circle - install air vents in cooling water 0 
Table C: Cooling Towers in WVU

\begin{tabular}{|l|l|l|l|}
\hline \multicolumn{2}{|l|}{ List of Cooling Towers in WVU } & \multicolumn{2}{l|}{} \\
\hline No. & Building & Manufacturer & Year \\
\hline 1 & Percival Hall & Marley & 1964 \\
\hline 2 & Chem. Annex & Marley & 1966 \\
\hline 3 & Mountainlair & Marley & 1967 \\
\hline 4 & Creative Arts Center & Marley & 1968 \\
\hline 5 & Allen Hall & Old Tower Tech & 1969 \\
\hline 6 & Allen Hall & Old Tower Tech & 1970 \\
\hline 7 & Law School & Ceramic & 1972 \\
\hline 8 & Chiller Plant & Ceramic & 1991 \\
\hline 9 & Chiller Plant & Ceramic & 1991 \\
\hline 10 & Chiller Plant & Ceramic & 1991 \\
\hline 11 & CERC & Evapco & 1993 \\
\hline 12 & Natatorium & Evapco & 1995 \\
\hline 13 & Coliseum & BAC & 1995 \\
\hline 14 & White Hall & Evapco & 1999 \\
\hline 15 & Physical plant & Evapco & 1999 \\
\hline 16 & Waterfront & BAC & 2001 \\
\hline 17 & REC Center & Evapco & 2001 \\
\hline 18 & Engineering Sciences Building & BAC & 2001 \\
\hline 19 & Clark Hall & BAC & 2001 \\
\hline 20 & Life Sciences & BAC & 2002 \\
\hline 21 & Life Sciences & BAC & 2002 \\
\hline
\end{tabular}

Recommended CTI Certified Manufacturers (by WVU):

1. Tower Tech Oklahoma City, OK.

2. Baltimore Air coil Company, Baltimore, MD.

3. Marley Cooling Tower Overland Park, KS.

4. EVACO Inc., Taneytown, MD. 
Table D. HVAC Systems Average Lifetime in Years

\begin{tabular}{|c|c|c|}
\hline No. & HVAC Systems & Lifetime \\
\hline 1 & Air Conditioning Systems & \\
\hline A & Central, including ducts and piping & 15 \\
\hline B & Window type & 10 \\
\hline $\mathrm{C}$ & Cooling towers & 15 \\
\hline $\mathrm{D}$ & Air conditioning compressors & 15 \\
\hline $\mathrm{E}$ & Rooftop air conditioners & 15 \\
\hline 2 & Heating Systems & \\
\hline A & Furnaces and boilers & $20-30$ \\
\hline $\mathrm{B}$ & Radiators, convectors, piping & 25 \\
\hline $\mathrm{C}$ & Heat pumps & 15 \\
\hline $\mathrm{D}$ & Unit heaters & $15-20$ \\
\hline 3 & Humidifiers & $8-10$ \\
\hline 4 & Water heaters & \\
\hline A & Electric & 14 \\
\hline $\mathrm{B}$ & Gas & $10-15$ \\
\hline 5 & Induction fan coil units & 20 \\
\hline 6 & Dampers & 20 \\
\hline 7 & Condensate pans & $20-25$ \\
\hline 8 & Coils & \\
\hline A & DX, water, or steam & 20 \\
\hline B & Electric & 15 \\
\hline 9 & Heat Exchangers & $20-25$ \\
\hline 10 & Burners & 20 \\
\hline 11 & Ventilating systems - fans, exhaust & 15 \\
\hline 12 & Piping & \\
\hline A & Cast iron waste & Lifetime \\
\hline $\mathrm{B}$ & Concrete & $20-30$ \\
\hline $\mathrm{C}$ & Copper & Lifetime \\
\hline $\mathrm{D}$ & Plastic & $30-40$ \\
\hline $\mathrm{E}$ & Steel & 20 \\
\hline 13 & Sump pumps & $10-15$ \\
\hline
\end{tabular}


Table E. Weibull Data Lists for Beta and Eta Values [46]

\begin{tabular}{|l|l|l|l|l|l|l|}
\hline Item & \multicolumn{4}{|l|}{ Beta Values } & \multicolumn{4}{l|}{ Eta Values } \\
\hline \multirow{2}{*}{ Components } & \multicolumn{2}{l}{ (Weibull Shape } \\
Factor) & hours) & \multicolumn{2}{l|}{} \\
\cline { 2 - 8 } & Low & Typical & High & Low & Typical & High \\
\hline Ball bearing & 0.7 & 1.3 & 3.5 & 14,000 & 40,000 & 250,000 \\
\hline Roller bearings & 0.7 & 1.3 & 3.5 & 9,000 & 50,000 & 125,000 \\
\hline Sleeve bearing & 0.7 & 1 & 3 & 10,000 & 50,000 & 143,000 \\
\hline Belts, drive & 0.5 & 1.2 & 2.8 & 9,000 & 30,000 & 91,000 \\
\hline Bolts & 0.5 & 3 & 10 & 125,000 & 300,000 & $100,000,000$ \\
\hline Clutches, magnetic & 0.8 & 1 & 1.6 & 100,000 & 150,000 & 333,000 \\
\hline Couplings & 0.8 & 2 & 6 & 25,000 & 75,000 & 333,000 \\
\hline Couplings, gear & 0.8 & 2.5 & 4 & 25,000 & 75,000 & $1,250,000$ \\
\hline Diaphragm, metal & 0.5 & 3 & 6 & 50,000 & 65,000 & 500,000 \\
\hline Diaphragm, rubber & 0.5 & 1.1 & 1.4 & 50,000 & 60,000 & 300,000 \\
\hline Gaskets, hydraulics & 0.5 & 1.1 & 1.4 & 700,000 & 75,000 & $3,300,000$ \\
\hline Filter, oil & 0.5 & 1.1 & 1.4 & 20,000 & 25,000 & 125,000 \\
\hline Gears & 0.5 & 2 & 6 & 33,000 & 75,000 & 500,000 \\
\hline Impellers, pumps & 0.5 & 2.5 & 6 & 125,000 & 150,000 & $1,400,000$ \\
\hline Joints, mechanical & 0.5 & 1.2 & 6 & $1,400,000$ & 150,000 & $10,000,000$ \\
\hline $\begin{array}{l}\text { Linear, reciprocating, compression } \\
\text { cylinder }\end{array}$ & 0.5 & 1.8 & 3 & 20,000 & 50,000 & 300,000 \\
\hline Nuts & 0.5 & 1.1 & 1.4 & 14,000 & 50,000 & 500,000 \\
\hline "O"-rings, electrometric & 0.5 & 1.1 & 1.4 & 5,000 & 20,000 & 33,000 \\
\hline $\begin{array}{l}\text { Packings, reciprocating, compression } \\
\text { rod }\end{array}$ & 0.5 & 1.1 & 1.4 & 5,000 & 20,000 & 33,000 \\
\hline Pins & 0.5 & 1.4 & 5 & 17,000 & 50,000 & 170,000 \\
\hline Pivots & 0.5 & 1.4 & 5 & 300,000 & 400,000 & $1,400,000$ \\
\hline Pistons, engines & 0.5 & 1.4 & 3 & 20,000 & 75,000 & 170,000 \\
\hline Pumps, lubricators & 0.5 & 1.1 & 1.4 & 13,000 & 50,000 & 125,000 \\
\hline Seals, mechanical & 0.8 & 1.4 & 4 & 3,000 & 25,000 & 50,000 \\
\hline Shafts, Pumps & 0.8 & 1.2 & 3 & 50,000 & 50,000 & 300,000 \\
\hline Springs & 0.5 & 1.1 & 3 & 14,000 & 25,000 & $5,000,000$ \\
\hline Vibration mounts & 0.5 & 1.1 & 2.2 & 17,000 & 50,000 & 200,000 \\
\hline Wear rings, cent. Pumps & 0.5 & 1.1 & 4 & 10,000 & 50,000 & 90,000 \\
\hline Valves, compressor & 0.5 & 1.4 & 4 & 3,000 & 40,000 & 80,000 \\
\hline Circuit breakers & 0.5 & 1.5 & 3 & 67,000 & 100,000 & $1,400,000$ \\
\hline
\end{tabular}


Table E. Weibull Data Lists for Beta and Eta Values [46], (Continued).

\begin{tabular}{|c|c|c|c|c|c|c|}
\hline Item & Beta & Values & & Eta Values & & \\
\hline Components & $\begin{array}{l}\text { (Weil } \\
\text { Facto }\end{array}$ & $\begin{array}{l}\text { ull Shape } \\
\text { r) }\end{array}$ & & $\begin{array}{l}\text { (Weibull C } \\
\text { hours) }\end{array}$ & haracterist & c Life-- \\
\hline & Low & Typical & High & Low & Typical & High \\
\hline Compressor blades & 0.5 & 2.5 & 3 & 400,000 & 800,000 & $1,500,000$ \\
\hline Compressor vanes & 0.5 & 3 & 4 & 500,000 & $1,000,000$ & $2,000,000$ \\
\hline Diaphragm couplings & 0.5 & 2 & 4 & 125,000 & 300,000 & 600,000 \\
\hline Motors, AC & 0.5 & 1.2 & 3 & 1,000 & 100,000 & 200,000 \\
\hline Motors, DC & 0.5 & 1.2 & 3 & 100 & 50,000 & 100,000 \\
\hline Pumps, centrifugal & 0.5 & 1.2 & 3 & 1,000 & 35,000 & 125,000 \\
\hline Transformers & 0.5 & 1.1 & 3 & 14,000 & 200,000 & $14,200,000$ \\
\hline Controllers, pneumatic & 0.5 & 1.1 & 2 & 1,000 & 25,000 & $1,000,000$ \\
\hline Controllers, solid state & 0.5 & 0.7 & 1.1 & 20,000 & 100,000 & 200,000 \\
\hline Control valves & 0.5 & 1 & 2 & 14,000 & 100,000 & 333,000 \\
\hline Solenoid valves & 0.5 & 1.1 & 3 & 50,000 & 75,000 & $1,000,000$ \\
\hline Transducers & 0.5 & 1 & 3 & 11,000 & 20,000 & 90,000 \\
\hline Transmitters & 0.5 & 1 & 2 & 100,000 & 150,000 & $1,100,000$ \\
\hline Temperature indicators & 0.5 & 1 & 2 & 140,000 & 150,000 & $3,300,000$ \\
\hline Pressure indicators & 0.5 & 1.2 & 3 & 110,000 & 125,000 & $3,300,000$ \\
\hline Flow instrumentation & 0.5 & 1 & 3 & 100,000 & 125,000 & $10,000,000$ \\
\hline Level instrumentation & 0.5 & 1 & 3 & 14,000 & 25,000 & 500,000 \\
\hline $\begin{array}{l}\text { Electro-mechanical } \\
\text { parts }\end{array}$ & 0.5 & 1 & 3 & 13,000 & 25,000 & $1,000,000$ \\
\hline Boilers, condensers & 0.5 & 1.2 & 3 & 11,000 & 50,000 & $3,300,000$ \\
\hline Filters, strainers & 0.5 & 1 & 3 & $5,000,000$ & $5,000,000$ & $200,000,000$ \\
\hline Check valves & 0.5 & 1 & 3 & 100,000 & 100,000 & $1,250,000$ \\
\hline Relief valves & 0.5 & 1 & 3 & 100,000 & 100,000 & $1,000,000$ \\
\hline Coolants & 0.5 & 1.1 & 2 & 11,000 & 15,000 & 33,000 \\
\hline $\begin{array}{l}\text { Lubricants, screw } \\
\text { compressor }\end{array}$ & 0.5 & 1.1 & 3 & 11,000 & 15,000 & 40,000 \\
\hline Lube oils, mineral & 0.5 & 1.1 & 3 & 3,000 & 10,000 & 25,000 \\
\hline Lube oils, synthetic & 0.5 & 1.1 & 3 & 33,000 & 50,000 & 250,000 \\
\hline Greases & 0.5 & 1.1 & 3 & 7,000 & 10,000 & 33,000 \\
\hline
\end{tabular}


Table F 4.4. Air Compressor

\begin{tabular}{|c|c|}
\hline \multicolumn{2}{|c|}{ Components and Checkpoints } \\
\hline 1 & Electrical wiring \& panel - insulation, loose connections, charring, size, corrosion \\
\hline 2 & Motor - heat, load, insulation, dust, wiring, vibration, noise, lubrication, brushes \\
\hline 3 & Pulley \& drive shaft - coupling, alignment, bearings, fasteners, grease, burrs and noise \\
\hline 4 & Belts - guards, lubrication, wear and tear tension, size, vibration, noise, alignment \\
\hline 5 & Pressure relief valve-calibration $(<10 \%$, ) leaks, operation, throttling range, pr. Setting \\
\hline 6 & Piston, rings, rod, cylinder bore \& head, water jackets-maintenance report \\
\hline 7 & Compressor - noise, corrosion, leak knocking, cleanliness, vibration, friction \\
\hline 8 & Automatic start-stop/constant speed control- working, switches, condition. \\
\hline 9 & Check valves-discs, leak, lubrication, moisture, original lift, springs, gaskets \\
\hline 10 & Intake filter - clogging, cleanliness, dirt, usability and humid conditions \\
\hline 11 & Oil filter - cleanliness, dirt, size, fluid flow, replacement hours/cycles \\
\hline 12 & Drain valve - rusting, leaks, operation, lubrication, packing, disc, connections \\
\hline 13 & Air receiver - low pr. Cut-in, moisture and interior scales while draining \\
\hline 14 & Pipe line - leaks, frost free from condensation, corrosion, clean airflow \\
\hline 15 & Intercooler-fin tube cleanliness, oil deposit, dirt, plugged, leak, separator \\
\hline 16 & After cooler- fin tube cleanliness, oil deposit, dirt, plugged, leak, temperature \\
\hline 17 & Moisture trap/dryers- chemical, leak, draining, valves, pre-filters, gauges \\
\hline 18 & Air/oil separator unit, differential pressure switch, regulator - working \\
\hline 19 & Air cooled - fan and fins cleanliness, valves, temp. gauges and working \\
\hline 20 & Water cooled - heat exchangers tube bundle cleanliness temperature gauge, valves \\
\hline 21 & Pressure switch-moisture/oiled/ ruptured diaphragm, burnt, air block \\
\hline 22 & Thermostats/valve-calibration, throttling range, temperature, leaks, corrosion \\
\hline 23 & Pilot valve - hot line indicates leak, defective O-ring, settings, calibration \\
\hline 24 & Unloader - gasket leak, air leak thru filter opening, lubrication, operation \\
\hline 25 & High air temperature switch - leaks, working, temperature setting and calibration \\
\hline 26 & Temperature gauges - accuracy, broken, leaks, unclean glass, and pointer damage \\
\hline 27 & Pressure gauges - accuracy, broken, leaks, unclean glass, pointer damage \\
\hline 28 & Compressor location- ventilated, dry, clean, free from excessive heat \\
\hline 29 & Foundation and mounting - support and bolts, clearance for air circulation \\
\hline
\end{tabular}


Table F 4.5. Air Handling Unit

\begin{tabular}{|c|c|}
\hline \multicolumn{2}{|c|}{ Components and Checkpoints } \\
\hline 1 & Electrical wiring- insulation, loose connections, charring, corrosion \\
\hline 2 & Motor - heat, load, insulation, dust, wiring, vibration, noise, lubrication \\
\hline 3 & Belts, Pulleys- guards, lubrication, wear, tension, size, vibration, noise, alignment \\
\hline 4 & Fans-blades, vibration, noise, corrosion, wobble, lubrication, alignment, speed \\
\hline 5 & Heating coils - leakage, clogging, drain tap, corrosion, freezing and dirt \\
\hline 6 & Cooling coils - leakage, clogging, drain tap, freezing, corrosion and dirt \\
\hline 7 & Bearings, couplings, keys - noise, heat, vibration, alignment, corrosion, wear \\
\hline 8 & Evaporator - coil scales, rusting and damage, float system, leaks, clogging \\
\hline 9 & Humidifier -tube leaks, fittings, screws strainer, cleanliness, and control valves \\
\hline 10 & Air filter - dust and filter frames gasketing for unfiltered air entry, changing frequency \\
\hline 11 & Controls, limit switches, fuses, relays, thermostat, sensors, contactors \\
\hline 12 & Return air damper-blade damage, leak, dirt, link movement, controls response \\
\hline 13 & Exhaust air damper - blade damage, leak, dirt, link movement, controls response \\
\hline 14 & Outside air damper-blade damage, leak, dirt, link movement, controls response \\
\hline 15 & Ducts - corrosion, leaks, joints, seal, screws, vibration, pressure, insulation \\
\hline 16 & Stop, check \& drain valves - leaks, corrosion, clogging, operation, fittings \\
\hline 17 & Thermostat - setting, calibration, leaks, corrosion, operation, sensors \\
\hline 18 & Mixing box - corrosion, sensors, leaks damper movement, temperature, controls \\
\hline 19 & Steam line - steam traps, leaks, clogging, condensate line, insulation, corrosion \\
\hline 20 & Casing - corrosion, gasketing and seal, leaks, fasteners, deterioration \\
\hline 21 & Piping - leaks, hangers, bolts, flow, expansion, corrosion, clogging, alignment \\
\hline 22 & Access door/panel- insulation, hinges, gasketing, screws, corrosion, deterioration \\
\hline 23 & Temperature gauges - broken, missing, leaks, unclean glass, and pointer damage. \\
\hline 24 & Pressure gauges - broken, missing, leaks, unclean glass, and pointer damage \\
\hline
\end{tabular}




\section{Table F 4.6. Boilers}

\begin{tabular}{|c|c|}
\hline \multicolumn{2}{|c|}{ Components and Checkpoints } \\
\hline 1 & Burners - floating, lifting, flashback, blockage, corrosion, cleanliness, missing \\
\hline 2 & Low water/fuel cut-off valve - rust, wear, defective, corrosion, broken, missing \\
\hline 3 & Safety and pressure relief valves - rust, scales, blockage, operation, limit settings \\
\hline 4 & Water/Fire tubes - wear, thickness reduction, cracks, bulges, scales, corrosion, leaks \\
\hline 5 & Pressure reducing vales - broken, missing, rust, scale, leak, operation, fasteners \\
\hline 6 & Pilot igniter - blockage, corrosion, broken, scales, electrical supply, leaks, missing \\
\hline 7 & Gas valve pressure regulator - leakage, operation, settings, calibration \\
\hline 8 & Fusible plugs - condition, metal, usage temperature exposure, replace cycle \\
\hline 9 & Electrical steam generator - loose connection, burnt, corrosion, voltage \\
\hline 10 & Low gas pressure valve/switch - rust, defective, corrosion, improper function \\
\hline 11 & High gas pressure valve/switch- rust, defective, corrosion, improper function \\
\hline 12 & Manual gas shut-off/cock valve -leakage, operation, corrosion, deterioration \\
\hline 13 & Manual and auto reset hi-limit switch - operation, rust, wiring connections \\
\hline 14 & Main power switch - operation and electrical wiring, insulation, broken \\
\hline 15 & Firing rating control - operation, sensors, wiring, settings, connections \\
\hline 16 & Air pressure switch- working, alignment, switch sensitivity, settings, deterioration \\
\hline 17 & Electrical wiring- insulation, loose connections, charring, corrosion \\
\hline 18 & Water column - sight glass cleanliness, leakage, gaskets, strainers, sensors \\
\hline 19 & Fireside metal surfaces - corrosion bulges, blistering, fly ash, leaks, and scales \\
\hline 20 & Waterside metal surfaces - evidence of oil, scale, corrosion, cracks, leaks, scales \\
\hline 21 & Feed water quality- solids, scale build up, foaming, corrosion, strainers \\
\hline 22 & Dampers, grates, feeders -operating condition, wear, corrosion, broken \\
\hline 23 & Stop, check, \& drain valve - leakage, corrosion, operation, clogging, vibration \\
\hline 24 & Improper $\mathrm{pH}$, sulfite concentration inadequate supply of desiccant \\
\hline 25 & Furnaces - improper baffles, spalling, fly ash, fitting, cracks, seam, expansion joints \\
\hline 26 & Expansion tank - corrosion, scales, support, water level, fittings, pressure \\
\hline 27 & Blow-off tanks and valves - frequency, scale, rust, leaks, cracks, worn, distortion \\
\hline 28 & Vent stack - duct freezing, cleanliness, leaks, blockage, support, location \\
\hline 29 & Purge blower and motor - lubrication operation, vibration, noise, and cleanliness \\
\hline 30 & Steam gauges - pointer movement, operation, leaks, sight glass cleanliness \\
\hline 31 & Fuel handling - leaks, consumption, operation, storage, unnecessary heating \\
\hline 32 & Air intake - corrosion, leak, crack, joint seal, tightness, blockage, location \\
\hline
\end{tabular}




\section{Components and Checkpoints (continued).}

33 Plates - cracks, defective joints, corrosion, erosion, deposition

34 Controls - circuit breaker, insulation, relay wiring, overload protector functions

35 Stays \& braces - broken, bends, cracks, corrosion, loosened, uneven tension

36 Pipe - corrosion, scales, blockage, leaks, expansion, blockage, alignment, hangers

37 Casing - cracks, distortion, corrosion, rusting, leaks, fittings tightness

38 Soot blowers - worn, misalignment of nozzles, incorrect blowing, traps

39 Ladders, runways - broken, missing or loosened bolts, welds, anchorage

40 Pressure gauges - broken, missing, leaks, unclean glass, and pointer damage

41 Temperature gauges - broken, missing, leaks, unclean glass, and pointer damage

42 Foundation - improper level, settings, cracks, load bearing, structure

43 Doors and hinges -sagging, warping, cracking, defective locks, movement 
Table F 4.7. Chillers

\begin{tabular}{|c|c|}
\hline \multicolumn{2}{|c|}{ Components and Checkpoints } \\
\hline 1 & Insulation- condition, anti-corrosion, expansion, air/water leak, ends seals \\
\hline 2 & Vacuum breaker -spring, ball, retainer tube, corrosion, o-ring, leaks, blockage \\
\hline 3 & Safety \& pressure relief valves - rust, scales, blockage, operation, limit settings \\
\hline 4 & Water/Fire tubes - wear, reduction in thickness, cracks, bulges, scales, corrosion, and leaks \\
\hline 5 & Pr. reducing vales-diaphragm, broken, leaks, missing, corrosion, scale, operation, fasteners \\
\hline 6 & Temp. regulators-thermo-element tubing, bulbs, settings, corrosion, leaks, sensors \\
\hline 7 & Actuators-leaks, corrosion, settings, stem, gasket, cage, spring, seat ring, operation \\
\hline 8 & Steam pit -crack foundation, manhole cover, trash, work space, ladder damage \\
\hline 9 & Steam separators - drain outlet, leaks contaminants, corrosion, and flow rate \\
\hline 10 & Steam accumulator-nozzle spray, leaks clogging, corrosion, valves, and scales \\
\hline 11 & Steam traps- working, blockage, freezing internal parts, leaks, baffles, corrosion \\
\hline 12 & Steam meter-leaks, transducers, signal processor, transmitter, flow computer \\
\hline 13 & Expansion joints - support noise vibration, pipe movements, and off-set \\
\hline 14 & Expansion joints - seal, bolts, cracks, leaks, corrosion, gaskets, sliding \\
\hline 15 & Main valve- working, seats, discs, stems, diaphragms, gasket, springs, leaks, rust \\
\hline 16 & Drip leg- corrosion, leaks, flange bolts, scales, valves, gaskets, plates \\
\hline 17 & Isolation valves-blockage, corrosion, leaks, bolts, open/close, gaskets \\
\hline 18 & Check valve-lubrication, blockage, open /close, bolts, corrosion, leaks, and gaskets \\
\hline 19 & Humidifiers-dirt, drainage, steam supply, corrosion, leak, noise, silencing chamber \\
\hline 20 & Heat exchangers-bonnet, shell, baffles, tube sheet, tubes, bolts, leaks, corrosion \\
\hline 21 & Heating coils-coil thickness, scales, corrosion, leaks, fittings, coatings, fins \\
\hline 22 & Water heaters-sensors, tube bundle, corrosion, scales, leaks, baffles, and wrapper \\
\hline 23 & Condensate tank-corrosion, leaks, drain \& float valves, scales, fittings, insulation \\
\hline 24 & Flash tank - corrosion, leaks, drain \& float valves scales, fittings, and insulation \\
\hline 25 & Desuperheaters- leaks, corrosion, noise, vibration, baffles, gaskets \\
\hline 26 & Noise suppressor-regulator, leaks, muffler orifice plate, bolts, corrosion \\
\hline 27 & Pipe - corrosion, scales, blockage, leaks, vibration alignment, hangers, anchorage \\
\hline 28 & Air vents- blockage, leaks, corrosion, gasket, o-ring, strainers, valves working \\
\hline 29 & Strainers - leaks, mesh condition, dirt, corrosion, gasket condition, clogging \\
\hline 30 & Pressure gauges - broken, missing, leaks, unclean glass, and pointer damage \\
\hline 31 & Steam gauges - pointer movement, operation, leaks, sight glass cleanliness \\
\hline 32 & Temperature gauges - broken, missing, leaks, unclean glass, and pointer damage \\
\hline
\end{tabular}




\section{Table F 4.8. Heat Exchangers and Water Heaters}

\begin{tabular}{|l|l|}
\hline \multicolumn{2}{|l|}{ Components and Checkpoints } \\
\hline 1 & Electrical wiring- insulation, loose connections, charring, corrosion \\
\hline 2 & Motor - heat, load, insulation, dust, wiring, vibration, noise, lubrication \\
\hline 3 & Vacuum breaker -spring, ball, retainer tube, corrosion, o-ring, leaks, blockage \\
\hline 4 & Heating unit - connection, element contacts, amperage, voltage, and transformer \\
\hline 5 & Safety relief valves - pressure settings, leaks, corrosion, working, gaskets \\
\hline 6 & Pressure reducing valve-settings, leaks, corrosion, gaskets, seat ring, working \\
\hline 7 & Tubes - expansion, cleanliness, flow, leaks, sludge/scale, fouling, corrosion \\
\hline 8 & Shell - corrosion, leakage, distortion, cracks, cracked welds and rivets, caulking \\
\hline 9 & Strainers - mesh condition, clogging, corrosion, leaks, cleanliness, filtering \\
\hline 10 & Heating coils-coil thickness, scales, corrosion, leaks, fittings, coatings, fins \\
\hline 11 & Plates - deterioration, corrosion, hanger, rigidity, cracks, vibration, bolts \\
\hline 12 & Tank - linings peeling, rust, corrosion, scale, coatings, granulation, sloughing \\
\hline 13 & Water treatment-period, fouling, scales soluble/insoluble deposits, chemicals \\
\hline 14 & Insulation- condition, anti-corrosion, expansion, air/water leak, ends seals \\
\hline 15 & Isolation valves-blockage, corrosion, leaks, bolts, open/close, gaskets \\
\hline 16 & Stop, drain, check valves-lubrication, leaks, corrosion, blockage, seals, open/close \\
\hline 17 & Main valve- working, seats, discs, stems, diaphragms, gasket, springs, leaks, rust \\
\hline 18 & Temperature regulators -thermo-element tubing and bulbs, settings \\
\hline 19 & Controls-overflow switch, fuses, VFD, sensors, timers, relays, starters - operation \\
\hline 20 & Steam traps - working, blockage, freezing internal parts, leaks, corrosion, scales \\
\hline 21 & Baffles - corrosion, distortion cracks, cleanliness, joints, bolts, position \\
\hline 22 & Piping - leaks, hangers, bolts, flow, vibration, corrosion, clogging, alignment \\
\hline 23 & Gaskets - cleanliness, scratches, positioning, leaks, damage, worn out \\
\hline 24 & Strainers - leaks, mesh condition, dirt, corrosion, gasket condition, clogging \\
\hline 25 & Temperature gauges - broken, missing, leaks, unclean glass, and pointer damage \\
\hline 26 & Pressure gauges - broken, missing, leaks, unclean glass, and pointer damage \\
\hline
\end{tabular}




\section{Table F 4.9. Pumps}

\begin{tabular}{|c|c|}
\hline \multicolumn{2}{|c|}{ Components and Checkpoints } \\
\hline 1 & Motor - leaks, noise, alignment, vibration, over load, heat, cleanliness, lubrication \\
\hline 2 & Shaft - corrosion, alignment, packing, leaks, vibration, seals, sleeve nut, bent \\
\hline 3 & Pump- oil level, rpm, tachometer comparison with name plate, rotation \\
\hline 4 & Couplings-misalignment, wear, pin, deterioration, torque, shock, over heat \\
\hline 5 & Bearings -lubrication, fitting, lock nut, washer, noise, friction, over load \& heat \\
\hline 6 & Wiring-switches, wet insulation, fuse switch blown, short circuit, frequent tripping \\
\hline 7 & Belt/pulleys - guard, alignment, wear \& tear, tension, sagging, size, groove \\
\hline 8 & Check valve-lubrication, blockage, open /close, bolts, corrosion, leaks, and gaskets \\
\hline 9 & Packing glands, gaskets, O-ring- leaks, alignment, fitting, wear deformation \\
\hline 10 & Seals- fitting, carbon rating, leaks, temperature deformation, corrosion \\
\hline 11 & Impeller - shaft, wearing ring, spacer, key, hub gaskets, corrosion, cleanliness \\
\hline 12 & Case \& head -tightness, overheating, stress cracks, cracked, corrosion, leaks, gaskets \\
\hline 13 & Inner-cavitation, lubrication, seal faces, noise, heat, wear, vibration, friction \\
\hline 14 & Flange joints - leaks, bolts, rust and corrosion, alignment, tightness \\
\hline 15 & Inlet Strainer - obstruction, cleanliness, mesh condition, dirt, filtering, corrosion \\
\hline 16 & Discharge Strainer - obstruction, corrosion, cleanliness, mesh condition, dirt, filtering \\
\hline 17 & Float assembly-linkages, ball float, rod, float switch, corrosion, clogged, slipping \\
\hline 18 & Gate valve and isolation valve - leaks, corrosion, working, clogging, open/close \\
\hline 19 & Controls - circuit breaker, sensors, relays, timers, overload protector, VFD, starters \\
\hline 20 & Pipe - corrosion, scales, blockage, leaks, expansion, blockage, alignment, hangers \\
\hline 21 & Water quality- solids, scale build up, foaming, corrosion, color, fouling \\
\hline 22 & Suction and discharge pressure - compare with name plate, pr settings, leaks \\
\hline 23 & Pressure gauges - broken, missing, leaks, unclean glass, and pointer damage \\
\hline 24 & Sump pit - water level, cleanliness, debris, drain, enclosure, clogging \\
\hline 25 & Bolts, nuts, screws, fittings - loose, missing, damaged, size, threading \\
\hline 26 & Pump foundation - level, cracks, grouting, support, bolts, cleanliness, load bearing \\
\hline
\end{tabular}


Table F 4.10. Steam Distribution Systems

\begin{tabular}{|c|c|}
\hline \multicolumn{2}{|c|}{ Components and Checkpoints } \\
\hline 1 & Insulation- condition, anti-corrosion, expansion, air/water leak, ends seals \\
\hline 2 & Vacuum breaker -spring, ball, retainer tube, corrosion, o-ring, leaks, blockage \\
\hline 3 & Safety \& pressure relief valves - rust, scales, blockage, operation, limit settings \\
\hline 4 & Water/Fire tubes - wear, reduction in thickness, cracks, bulges, scales, corrosion, leaks \\
\hline 5 & Pr. reducing vales-diaphragm, broken, leaks, missing,corrosion,scale,operation,fasteners \\
\hline 6 & Temp. regulators- thermo-element tubing, bulbs, settings, corrosion, leaks, sensors \\
\hline 7 & Actuators-leaks, corrosion, settings, stem, gasket, cage, spring, seat ring, operation \\
\hline 8 & Steam pit -crack foundation, manhole cover, trash, work space, ladder damage \\
\hline 9 & Steam separators - drain outlet, leaks contaminants, corrosion, flow rate \\
\hline 10 & Steam accumulator-nozzle spray, leaks clogging, corrosion, valves, scales \\
\hline 11 & Steam traps- working, blockage, freezing internal parts, leaks, baffles, corrosion \\
\hline 12 & Steam meter-leaks, transducers, signal processor, transmitter, flow computer \\
\hline 13 & Expansion joints - support noise vibration, pipe movements, off-set \\
\hline 14 & Expansion joints - seal, bolts, cracks, leaks, corrosion, gaskets, sliding \\
\hline 15 & Main valve- working, seats, discs, stems, diaphragms, gasket, springs, leaks, rust \\
\hline 16 & Drip leg- corrosion, leaks, flange bolts, scales, valves, gaskets, plates \\
\hline 17 & Isolation valves-blockage, corrosion, leaks, bolts, open/close, gaskets \\
\hline 18 & Check valve-lubrication, blockage, open /close, bolts, corrosion, leaks, and gaskets \\
\hline 19 & Humidifiers-dirt, drainage, steam supply, corrosion, leak, noise, silencing chamber \\
\hline 20 & Heat exchangers-bonnet, shell, baffles, tube sheet, tubes, bolts, leaks, corrosion \\
\hline 21 & Heating coils-coil thickness, scales, corrosion, leaks, fittings, coatings, fins \\
\hline 22 & Water heaters-sensors, tube bundle, corrosion, scales, leaks, baffles, and wrapper \\
\hline 23 & Condensate tank-corrosion, leaks, drain \& float valves, scales, fittings, insulation \\
\hline 24 & Flash tank - corrosion, leaks, drain \& float valves scales, fittings, and insulation \\
\hline 25 & Desuperheaters- leaks, corrosion, noise, vibration, baffles, gaskets \\
\hline 26 & Noise suppressor-regulator, leaks, muffler orifice plate, bolts, corrosion \\
\hline 27 & Pipe - corrosion, scales, blockage, leaks, vibration alignment, hangers, anchorage \\
\hline 28 & Air vents- blockage, leaks, corrosion, gasket, o-ring, strainers, valves working \\
\hline 29 & Strainers - leaks, mesh condition, dirt, corrosion, gasket condition, clogging \\
\hline 30 & Pressure gauges - broken, missing, leaks, unclean glass, and pointer damage \\
\hline 31 & Steam gauges - pointer movement, operation, leaks, sight glass cleanliness \\
\hline 32 & Temperature gauges - broken, missing, leaks, unclean glass, and pointer damage \\
\hline
\end{tabular}


Table F 4.11. Unit Heaters and Coolers

\begin{tabular}{|c|c|}
\hline \multicolumn{2}{|c|}{ Components and Checkpoints } \\
\hline 1 & Electrical wiring- insulation, loose connections, charring, corrosion \\
\hline 2 & Motor - rotation, heat, load, insulation, dust, wiring, vibration, noise, lubrication \\
\hline 3 & Compressor-heat, noise, vibration, dust refrigerant leak, oil level, pr \& temp \\
\hline 4 & Fans-blades, vibration, noise, corrosion, wobble, lubrication, alignment, speed \\
\hline 5 & Fan switch- regulator working, speed change, insulation, heat, On/Off \\
\hline 6 & Belts, Pulleys- guards, lubrication, wear, tension, size, vibration, noise, alignment \\
\hline 7 & Temp. sensor - wiring, connections, bulb, working, sensitivity, settings, location \\
\hline 8 & Thermostat - settings, calibration, working, cleanliness, accuracy, corrosion \\
\hline 9 & Control valve - leaks, operation, rust, clogging, pressure, corrosion, fittings \\
\hline 10 & Fins- spacing, bending, corrosion, dirt, leaks, cleanliness, heat transfer rate \\
\hline 11 & Coil - corrosion, rust, clogging, scales, bending, leaks, coil thickness, header \\
\hline 12 & Transformer, circuit breakers, fuses, contactors, thermal over loads - operation \\
\hline 13 & Electric heat coils-leak, coil element, power consumption, heating, wiring \\
\hline 14 & Microprocessor controls, VFD, timer, relays, logic module, overflow switch \\
\hline 15 & Expansion valves-leaks, clogging, size, direction, corrosion, pr, temp, superheat \\
\hline 16 & Filter-installation, dust accumulation, replacing frequency, dirt, size, damage \\
\hline 17 & Strainers - fittings, leaks, dirt, mesh condition, clogging, corrosion, rust \\
\hline 18 & Balancing, ball \& drain valves - leaks, corrosion, clogging, operation, fittings \\
\hline 19 & Gaskets, ferrule, washers, bearings, lock nut, couplings, screws, fittings \\
\hline 20 & Insulation-noise, vibration protection, anti-heating/cooling transfer, rust \\
\hline 21 & Outside air dampers - movement, corrosion, cleanliness, airflow, motor \\
\hline 22 & Chassis - corrosion, coating removed, vibration, bolting, support, rust \\
\hline 23 & Inner cabinet - support, corrosion, vibration, bolts, fittings, clearances \\
\hline 24 & Piping - scales, leaks, hangers, bolts, flow, bending, corrosion, clogging, alignment \\
\hline 25 & Temperature gauges - broken, missing, leaks, unclean glass, and pointer damage \\
\hline 26 & Pressure gauges - broken, missing, leaks, unclean glass, and pointer damage \\
\hline 27 & Drain pan - leaks, drain valves, slope, clogging, size, connections, and corrosion \\
\hline 28 & Grille - corrosion, dirt, vibration, air distribution, flow, support \\
\hline
\end{tabular}

